\title{
Zwei Heiligenleben des Jonas von Susa.
}

\author{
Von \\ Bruno Krusch.
}

\section{Die Vita Johannis Reomaensis.}

Es sind von der V. Johannis drei verschiedene Texte gedruckt. Die erste Ausgabe von Surius, De probatis sanctorum historiis, Coloniae 1581, tom. VII, p. 708. 709, füllt nur etwa 11/2 Seiten. Der Herausgeber fand die Vita in einer sehr alten Handschrift, hat aber seiner Gewohnheit gemïss den Text umgearbeitet und sehr gekürzt. Er deutet dies selbst in der Ueberschrift an: „Verum stylum opportunis locis mutavimus". Einen blossen Nachdruck dieser Ausgabe lieferte Vincentius Barralis, Chronologia sanctorum sacrae insulae Lerinensis, Iugduni 1613, p. 367-369, aber ohne Quellenangabe und unter Verschweigung der Bemerkung ïber die Aenderung des Stils ${ }^{1}$ ) Einen viel ausführlicheren, in 2 Bücher eingetheilten Text publicirten Roverius (d. j. Royer), Reomaus, Paris 1637, p. 1-23, 70. 73, ans einer Handschrift des Klosters Reomans und Bolland-Hensehen, AA. SS., Antwerpen 1643, Jan. II , p. 856-863, unter Benutzung von Hss. und der vorhergehenden Ausgabe. Diese Recension gibt sich in einer kurzen Vorbemerkung als eine Schrift des Abtes Jonas zu erkennen, des bekannten Hagiographen des 7. Jahrh. Roverius nahm diese Angabe in gntem Glauben hin, aber schon die Bollandisten bemerkten den Widerspruch der darin liegt, dass sich der Verf. für einen Schüler des Johannes und Insassen seines Klosters ausgibt, während Jonas über

1) Dagegen behielt er den Zusatz des Surius: ,ut habetur in pervetusto Ms. codice ${ }^{\circ}$ bei, um den Glauben zu erwecken, er habe Hss. benutzt. BollandHenschen bemerken mit Recht hierzu: , verum eum ipse codicem non viderat". Mittheilnngen, XIV. 
100 Jahre nach dem Tode des Heiligen lebte und sich nach der Vorbemerkung nur einmal gelegentlich wenige Tage in Reomaus aufhielt. Deshalb möchten sie in Jonas eher den Bearbeiter und Interpretator einer älteren gleichzeitigen Vita sehen.

Diese ältere Vita glanbte Mabillon, AA. SS. ord. S. Benedicti, Paris 1668, Jan. I., p. 633-636, in einer Hs. von St. Germain des Prés gefunden zu haben. Er hielt seinen Text, der übrigens die Quelle der Surius'schen Ueberarbeitung ist, für die Urform, verfasst von einem Mönche von Reomaus bald nach dem Tode des Johannes, und glaubte, dass Jonas diese interpolirt und um ein zweites Buch bereichert habe. Daher hielt er es für unnöthig, die vorhergehende Recension ganz abzudrucken, sondern theilte nur das 2 . Buch mit.

Auf diesem Standpunkte stand die Forschung noch vor wenigen Jahren. Da unternahm Stöber, Zur Kritik der Vita S. Johannis Reomaensis ${ }^{1}$ ), eine neue Untersuchung der Frage. Mabillon hatte die Vorbemerkung über die Abfassung des Jonas in einigen seiner späteren Werke aus einem alten Codex Fossatensis abgedruckt. Diesen erkannte Stöber wieder in der Handschrift der Nationalbibliothek in Paris lat. 11748, saec. X. und er fand bei genauerer Prüfung derselben, dass sie die Arbeit des Jonas in ihrer ursprünglichen Gestalt enthalte und die Quelle der beiden bisher bekannten Recensionen sei. Stöber hat mit grossem Scharfsiun ganz überzeugend nachgewiesen, dass nur dieser neue Text die stilistischen Eigenthümlichkeiten des Jonas trägt, dass er später in die von Mabillon publicirte, in Bezug auf Sprache und Darstellung bessere Form gebracht worden ist, und endlich durch Compilation mit der Ueberarbeitung die Gestalt erhalten hat, welche in der aus 2 Büchern bestehenden Recension vorliegt. Leider ist aber der Fossatensis nicht bloss aus einer lückenhaften Vorlage abgeschrieben, da er aus den Text' der V. Johannis plötzlich in den der V. Eugenjae übergeht, sondern auch selbst verstümmelt, indem nach Fol. 151 ein Blatt ausgeschnitten, und die Schrift auf den erhaltenen Blättern theilweise mit Bimsstein abgerieben ist. Erhalten ist die Vorrede, das Capitelverzeichniss, das aber am Ende fast ganz unleserlich ist, der eigentliche T'ext etwa von der Mitte von Cap. 4 an bis in die Mitte von Cap. 18, doch sind die zweite Hälfte von Cap. 14 und die erste von Cap. 15 fast ganz unleserlich. Im Allgemeinen kann man sagen, dass gerade die historisch wichtigsten Partieen im Fossatensis ausgefallen sind. Aus diesem Grunde hat sich Stöber da-

1) In den S. B. der phil.-hist. Classe der kais. Akademie der Wissenschaften CLX., 1. Heft, S. 319, Wien 1885. 
mit bescheiden müssen, das Verhältnis der neuen Form zu den beiden andern Recensionen festzustellen, was ihm auch vollständig gelungen ist. Die Verwerthung des in diesem Texte gebotenen historischen Materials, wie die Herstellung einer den wissenschaftlichen Anforderungen genügenden Ausgabe stellte er zurück, bis eine vollständigere Handschrift der neuen Recension gefunden sein würde.

Diese habe ich gefunden. Die Hs. der Nationalbibliothek in Paris lat. 5306, saee. XIV. enthält den vollständigen Text des Jonas, und nur die Vorrede und das Capitelverzeichniss sind fortgelassen. Diese beiden Stücke sind aber in der andern Hs. leidlich erhalten, bis auf den letzten Theil des Capitelverzeichnisses, an dem jetzt weniger liegt, da wir den vollständigen 'Text haben. Nachdem somit die ältesten Aufzeichnungen über den $\mathrm{H}$. Johannes aufgefunden sind, erhebt sich zunächst die Frage, welchen Grad von Glaubwärdigkeit ihnen beizumessen ist. Hierzu ist es aber nöthig, sich zuvờ die Umstände zu vergegenwärtigen, unter welchen die Vita geschrieben wurde.

Es war im November 659, als sich der Abt Jonas auf Befehl des jungen Königs Chlothar und der Königinmutter Balthilde, die für ihren unmündigen Sohn die Regierung führte, nach Chalon begab und auf der Reise dorthin wenige Tage im Kloster des H. Johannes in Reomaus rastete. Die Mönche baten damals den berühmten Hagiographen, ihnen niederzuschreiben, was sich über das äussere Leben des Heiligen sowie über seine geistige Entwicklung durch seine Schüler bis auf ihre Tage in der Erinnerung erhalten hatte. Seine Schrift richtete Jonas an Abt Hunna von Reomaus, von dem sonst nichts bekannt ist.

Jonas stand damals bereits in reiferem Alter. Er war in Susa geboren und nach dem Tode Columbans (615) in das Kloster Bobbio eingetreten, dem er bei dem Tode des Abtes Attala 9 Jahre angehörte. Den dritten Abt Bertulf begleitete er 628 nach Rom, als das Kloster sich bei Papst Honorius um die Exemption vom Diöcesanbischof bewarb ${ }^{1}$ ). Noch vor Bertulfs Tode verliess er aber Bobbio und begab sich nach Gallien, nachdem er vorher seinen Klosterbrüdern das Versprechen gegeben hatte, die Thaten Columbans zu beschreiben. Hier widmete er sich unter des Amandus Leitung der Mission der heidnischen Franken. Es war ein unstätes IJeben und ein aufreibender Beruf, der ihm wohl nicht viel Musse zu literarischer Arbeit liess. Im dritten Jahre überreichte er endlich seinen Freunden die V. Columbani, die

1) V. Bertulf c. 6 . 
in dem Fredegar von 642 bereits benutzt, also spätestens 641 geschrieben ist.

In dem an die Aebte Waldebert von Luxeuil (629-669) und Bobolenus von Bobbio gerichteten Widmungsbriefe vor der V. Columbani bezeichnet sich Jonas schlechtweg als "peccator", dagegen in der Vorbemerkung zur V. Johannis als Abt, und dies Prädicat gibt ihm auch die V. Walarici c. 9. Man hat sich nun vergeblich bemüht, das Kloster zu finden, dem Jonas rorgestanden habe. Zuletzt hat Stöber vermuthet, dass es eines der Vogesen-Klöster Columbanischer Gründung gewesen sei.

Die Thätigkeit aber, in welcher wir 659 den Abt Jonas finden, bietet nicht den geringsten Auhaltspunkt für die Annahme eines klösterlichen Berufs. Seine Reise nach Chalon exfolgte im Auftrage der fränkischen Regierung. Zunächst wäre also meines Erachtens zu prüfen gewesen, ob er nicht in königlichen Diensten gestanden habe.

In der That finden sich im 7. Jahrh. in der Umgebung der fränkischen Könige and Königinnen Aebte, deren Beruf allein im herrschaftlichen Dienste bestand ${ }^{1}$ ) Sie sind natürlich zunächst als Beichtväter anzusehen, werden aber sicher wie diese auch in weltlichen Geschäften verwendet worden sein. Der Königin Balthilde gab ihr Gemahl Chlodoveus den Abt Genesius ${ }^{2}$ ) als Beistand bei ihren Liebeswerken. Er besorgte im Namen der Königin die Vertheilung der Almosen an die Armen und die Unterstützung der Klöster durch kostbare Geschenke. Da anzunehmen ist, dass sich bei Lebzeiten ihres Gemahls die äussere Thätigkeit der Königin auf diese Gebiete beschränkt haben wird, so kann man den Abt im Allgemeinen als ihren Geschäftsträger bezeichnen. Nach dem Tode des Chlodoveus, Ende 657, übernahm Balthilde für ihren unmündigen Sohn Chlothar die Regierung. In diese Zeit fällt die Sendung des Abtes Jonas nach Chalon: "ex iusso ipsius principes vel genetrice suae praecelse domne Balthilde regine". Ich meine nun, dass Jonas Abt entweder beim jungen Könige oder bei dessen Mutter war.

$\mathrm{Zu}$ dem Kloster des H. Johannes hatte Jonas keine anderen Beziehungen, als dass er sich, wie bemerkt, einmal auf der Durchreise wenige Tage dort aufgehalten hatte. Als Fremder unternahm er es damals, über 200 Jahre nach der Geburt des Heiligen, auf Grund von Klostertraditionen ein Lebensbild desselben zu entwerfen. Man wird deshalb an die V. Johannis nicht den Massstab legen dürfen,

') Waitz, V.-G. II, 2, ${ }^{3}$ p. 102.

2) V. Balthildis c. 4 . 
wie an die anderen Lebensbeschreibungen desselben Schriftstellers, für die er das Material in langjährigem persönlichen Verkehr mit den Heiligen selbst oder doch wenigstens mit ihren Schülern sammeln konnte. Man wird die Mangelhaftigkeit der Composition durch die Art der Entstehung der Vita entschuldigen und bei der Dürftigkeit des Inhalts berücksichtigen, dass wenn sich 659 kein Jonas zufällig bei den Klosterbrüdern eingefunden hätte, wir vermuthlich heute über die Entstehung und erste Geschichte jenes alten gallischen Klosters gar nichts wüssten.

In kurzen Umrissen erzähit Jonas von den Eltern und der Heimath des Johannes, von der Gründung des Klosters Reomaus und einem zeitweiligen Aufenthalte des Heiligen in Lerinum. Er fügt dann eine Anzahl Wundergeschichten hinzu, von denen die letzten einen Anhalt für das Todesjahr des Heiligen geben. Die Schilderung von dessen Ableben und kurze Nachrichten über die drei nächsten Aebte zusammen mit einer Translationsgeschichte machen den letzten Theil der Vita aus.

Geboren war Johannes nach Jonas von frommen Christen Namens Hilarius und Quieta, die den Sohn in der christlichen Religion erzogen. Nun handelt Gregor, Gl. Conf. c. 41. über einen Senator Helarius in Dijon, der verheirathet war und Söhne gehabt haben soll. Er rühmt die Sittenreinheit dieses Ehepaares und erzählt zum Belege dafür ein Wunder an ihrem Grabe. Schon der Verf. der Chronilk von SaintBénigne identificirte diese Familie von Dijon mit derjenigen, der Johannes angehörte, ja er behauptete sogar, das Grab des Hilarius und der Quieta befände sich in seinem Kloster 1). Seitdem hat man die Nachrichten Gregors über jenen Helarius von Dijon unbedenklich für die Lebensgeschichte des Johannes verwerthet und zunächst aus ihnen gefolgert, dass der Heilige in Dijon geboren sei ${ }^{2}$ ). Die späteren Bearbeitungen der V. Johannis bezeichnen nämlich den Geburtsort nur sehr unbestimmt: "sub territorio Lingonicae urbis". Die genaue Ortsbezeichnung erfahren wir erst jetzt aus der ursprünglichen Arbeit des Jonas: „infra terminos Ternoderensis castri, qui locus in suburbano Lingonice urbis situs est, villa que vocatur Quartamiacum super fluvium Bridenam ". Johannes war also in demselben Gau von Tonnerre geboren, in welchem er auch sein Kloster gegründet hat, in einem Flecken an der Brenne, - denn dies ist zweifellos die Bridena, -

1) „Chronique de l'abbaye de Saint-Bénigne de Dijon* in Analecta Divionensia 1875 , S. 11 .

2) Roverius, Reomaus p. 473 ! 
einem Nebenflusse des Armençon. Hiermit wird die Identität des Vaters des Johannes mit dem Helarius von Dijon ausgeschlossen. Wenn Jonas den Gau von Tonnerre als „suburbanum " von Langres bezeichnet, legt er diesem Ausdruck eine weit ausgedehntere Bedeutung bei, als er gewöhnlich hat.

Mit 20 Jahren fasste Johannes den Entschluss, seine Heimath zu verlassen, um seinen religiösen Neigungen mehr nachgehen zu können. Zuvor erbaute er jedoch ein kleines Oratorium in seinem Geburtsorte für seine geistlichen Uebungen. Den Entschluss des Heiligen, sich in die Einsamkeit zurückzuziehen, setzt Jonas in die Zeit, als der Consul Johannes unter kaiserlicher Hoheit Gallien regierte.

Consuln dieses Namens gab es 456, 467, 498, 499. Die beiden letzteren stehen in den abendländischen Fasten nicht, sind auch viel zu spät für die Geschichte unseres Heiligen. Der Johannes der beiden früheren Jahre steht in den occidentalischen Listen 456 an erster, 467 an zweiter Stelle:

456. "Johanne et Varana"

467. "Pusaeo et Johanne".

In beiden Fällen scheint es sich um einen orientalischen Consul dieses Namens zu handeln ${ }^{1}$ ).

Jonas hat aber offenbar gar nicht an einen Jahresconsul, sondern an einen hohen römischen Verwaltungsbeamten in Gallien gedacht, wie seine Worte "Gallias sub imperii iure regebat" zeigen. Die oberste Instanz für die gallische Provinzialverwaltung war der „Praefectus praetorio Galliarum " 2), unter dem auch Spanien und Britannien standen. Jedes dieser drei Länder hatte ausserdem seinen Specialbeamten und zwar Gallien in dem "Vicarius septem provinciarum" 3 ). Unter diesem fungirten die Leiter der 17 Provinzen, denen theils "Consulares", theils "Praesides" vorstanden. In der That hatte nun die "Lugdunensis prima", zu der die Diöcese Langres gehörte, zur Zeit der Notitia Dignitatum einen "Consularis“ an der Spitze, während sie zur Zeit Constantins von einem "Praeses" verwaltet.wurde. Es ist nicht unwahrscheinlich, dass mit dem "Consul Johannes" der "Consularis" der "Lugdunensis prima" gemeint ist ${ }^{4}$ ). Das Eine geht aber aus den Angaben des Jonas mit Sicherheit hervor, dass die Be-

1) Vergl. Arndt, Marius S. 46; Mommsen im N. Archiv XIV, 239.

2) Vergl. Notitia Dignitatum ed. Seeck p. 110.

3) Not. Dign. p. 104.

4) Roverius, Reomaus p. 475, der diese Frage mit voller Sachkenntniss behandelt, hat dies bereits vermuthet. 
gebenheit vor die Zeit fallen muss, in welcher die Burgunder bis in diese Gegend vorgerückt waren (457) ${ }^{1}$ ).

Johannes zog sich damals in die gebirgige Gegend zwischen Armançon und Serain, zwei Nebenflüssen der Yonne, zurück. Er gründete hier, 7 Milien von der Burg Semur-en-Auxois entfernt, das Kloster, welches heute nach seinem Stifter Moutiers St. Jean genannt wird. Von einem Brunuen daselbst gieng die Sage, dass vor der Aukunft des Heiligen ein Drachen darin hauste, dessen Tod er durch Gebet und energische Durchstöberung des Brunnens veranlasst haben soll. Bei dieser Gelegenheit ersehen wir aus der Darstellung des Jonas, dass Johannes nicht allein gekommen war, denn er tritt „cum sodalibus" an den Brunnen heran.

Nachdem Johannes die Leitung des neugegründeten Klosters übernommen hatte, hielt er bei seinen Untergebenen streng auf die Beobachtunng der Regel. Der Ruf des frommen Mannes veranlasste ein gewaltiges Zuströmmen des Volkes, welches ihn durch seine Dienste zu ehren suchte. In demselben Masse, wie die Schaar seiner Mönche wuchs, nahm sein Selbstvertrauen ab, und es schien ihm jetzt zuträglicher für sein Seelenheil zu sein, anderen zu dienen als "zu befehlen. Dazu war er selbst noch nicht ausgebildet in der Strenge klösterlicher Disciplin, denn alles was er davon wusste, hatte er sich als Autodidact durch Lectüre oder mündliche Berichte angeeignet.

Aus Demuth und auch in dem Bestreben nach weiterer Vervollkommnung begab sich Johannes in Begleitung zweier Genossen in die damalige Musteranstalt für das Mönchsleben, das Kloster Lerinum, dem Honoratus vorstand. Unerkannt weilte er hier in strengem Gehorsam gegen seine Oberen 11/2 Jahre. Da erst führte ein Zufall seine Entdeckung herbei. Ein Fremder, der das Kloster besuchte, erkannte ihn unter den arbeitenden Mönєhen und erzählte den staunenden Lerinern, wer der schlichte Mönch sei, der die niedrigsten Dienste that. Das Gerücht von dieser Begebenheit kam dem Bischof Gregor von Langres zu Ohren, zu dessen Diöcese das Kloster des Johannes gehörte. Er sandte Mönche aus diesem Kloster mit zwei Briefen nach Lerinum: Honorat und dessen Mönche ersuchte er, der Rückkehr des Johannes nichts in den Weg zu legen, und diesen selbst forderte er auf, sogleich in sein verlassenes Kloster heimzukehren. Der ernsten Mahnung seines Bischofs musste der Heilige Folge leisten.

Diese Episode macht auf den ersten Blick den Eindruck grosser

1) Vergl. Binding, Geschichte des burgundisch - romanischen Königreichs S. 58 . 
historischer Glaubwürdigkeit. Von den beiden Briefen könnte wenigstens der eine an Johannes im 7. Jahrh. noch im Kloster gewesen sein und dem Jonas vorgelegen haben. Bei näherer Prüfung aber erweist sich die Darstellung als unhaltbar.

Zunächst sind der Abt Honoratus von Lerinum und Bischof Gregor von Langres keine Zeitgenossen gewesen. Denn ersterer erhielt 426 den Bischofsstuhl von Arles, den er nur kurze Zeit innehatte, - 439 unterzeichnete nämlich das Concil von Riez schon Hilarius von Arles, Gregor aber verwaltete das Bisthum Langres von 506|7-539. Die beiden Männer sind also etwa durch ein Jahrhundert von einander getrennt. Keiner von beiden passt ausserdem für die Zeit des Johannes. Denn, wenn dieser, wie wir unten sehen werden, nach 543 starb im Alter von circa 120 Jahren, so stand er bei Lebzeiten des Honoratus noch in den Knabenjahren und war am Beginn von Gregors Episcopat-bereits ein Achtziger. Der Abt Johannes aber, der um zu lernen nach Lerinum gieng, könnte füglich nur im Mannesalter gestanden haben.

Da der grösste Theil der Lebenszeit des Heiligen in das 5. Jahrh. fällt, so ist es allerdings sehr wahrscheinlich, dass er die Schule von Lerinum durchgemacht hat, wo so viele andere bedeutende Männer dieser Zeit ihre Ausbildung genossen haben. In so weit wird man dem Jonas Glauben schenken dürfen. Dass aber sein Aufenthalt auf der Insel in die Zeit des Gründers von Lerinum fiel, ist ebenso unhaltbar, wie die Rückberufung durch Gregor von Langres.

Nach seiner Rückkehr liess sich Johannes wiederum die Leitung und Ausbildung seiner Mönche nach der Regel angelegen sein, unterstütat durch einen Mönch Namens Filomeris. Die Regel, welche der Heilige vor der Lerinenser Periode befolgte, hatte Jonas nicht näher bezeichnet; jetzt nennt er den Verf. Macarius. Die unter diesem Namen bekannte Regel ist nach ihrem Latein gallischen Ursprungs und kaum vor dem 6. Jahrhundert geschrieben. Angeführt wird sie noch in der V. Filiberti Gemetic. c. 5 .

Diese Regel 1) macht den Mönchen harte Arbeit zur Pflicht; vgl. $\S 8$ : ,Non oderis laboriosa opera, otium quoque ne secteris'. Erschöpft vou der Arbeit sollen sie am Abend ihr Lager aufsuchen. Nach der Frühmesse dürfen die Brüder eine Stunde meditiren; wenn aber dringende Geschäfte ihre gemeinsame Thätigkeit erfordern, fällt die Meditation weg. Um 7 Uhr geht jeder an seine Arbeit bis Nachmittags

1) Gedr. bei Roverius, Reomaus p. 24 ff. und Holstenius, Codex regularum, Paris 1663, S. $25 \mathrm{ff}$. 
um 3 Uhr. Auf den Glockenschlag lassen dann die Mönche die Arbeit liegen und begeben sich zur Gebetstunde. Wer bei den Messen und Vigilien einschläft, muss sogleich zu seiner Arbeit zurückkehren. Mittwochs und Freitags wird gefastet. Die Mönche sollen sich selbst erniedrigen, keiner sich für gerechter halten als die anderen. Wer etwas Nützliches vollbracht hat, darf sich dessen nicht rühmen. Keinem dürfen seire Verwandten näher stehen als die Brüder in den Zellen. Dem Gebot ihres Abtes ("senioris") sollen sie ohne Widerrede und willig gehorchen. Auswärtige Geschäfte durfte niemals ein einzelner Mönch besorgen, sondern je zwei oder drei sollten dazu verordnet werden und nur solche, die Vertrauen einflössten, keine Schwätzer oder Schlemmer.

Diese Regel entspricht durchaus den Schilderungen, welche Jonas von dem Leben der Mönche im Kloster des Johannes entwirft. Die erste Sorge der Brüder war, den mit dichtem Gebüsch bewachsenen Boden urbar zu machen, damit er ihrem Unterhalte diene. Mit Aexten bewaffnet begaben sie sich in die Wälder, hieben sie nieder und rodeten das Land, das so der Cultur erschlossen wurde. Als sie einmal auf den Ruf des Abtes ("senior") gehorsam ins Kloster zurückkehrten und aus Bequemlichkeit die Beile draussen liegen liessen, stahl diese ein Dieb, so dass sie hernach die unterbrochene Arbeit nicht fortzusetzen vermochten. Johannes unwillig über die Nachlässigkeit eilte selbst ins Freie, um nachzusehen. Er fand auch den Dieb und nahm ihm die Beute ab.

Die harte Arbeit trug ihre Früchte. Wohlgefüllte Speicher schützten nicht allein die Mönche vor Noth, sondern gestatteten auch die Unterstützung der Nachbarn bei Missernte. Die Besorgung der Feldwirthschaft blieb aber nach wie vor Sache der Mönche.

Auch ein Bild aus dieser späteren Zeit führt uns Jonas vor. Es ist die Zeit der Ernte; die Saaten sind reif und harren der Schnitter. Die Mönche begeben sich truppweise auf die Felder, um die Frucht zu schneiden. Erst der Eintritt der Nacht setzt ihren Mühen ein Ziel. Die fleissigen Brüder kehren jetzt in das Kloster zurück, nur einer, Claudius, bleibt auf Befehl der Vorsteher die Nacht über als Wächter bei der Frucht. Auch er versinkt in Schlaf, aber mitten in der Nacht erwacht er und macht sich Sorgen, dass die ermatteten Genossen die Gebetsstunde verschlafen würden. Da sieht er plötzlich eine strahlende Kugel den Himmel erleuchten. Während er noch betäubt ist von dem Wunder, hört er, wie der Hahnenschrei den kommenden Tag verkündet, und zugleich auch das Läuten der Glocken, welches die Brüder zum Gebet ruft. Am Morgen erzählt er dem Abte 
sein nächtliches Erlebuiss. Aber dieser warnt ihn vor Ueberhebung; keiu sündiger Mensch sei werth, die himmlischen Vorgänge zu schanen.

Die freie Natur zogen diese Mönche der engen Klosterzelle vor. Nach Art der alten Streiter (,more adletarum antiquorum') pflegte Johannes dem Gebet und Fasten im Walde obzuliegen, wo er dann mit den arnen Leuten zusammentraf, die sich Waldfrüchte für ihren Unterhalt suchten.

Als seine Mutter zum Kloster kam, um ihn nach langer Trennung wieder zu sehen, schlug er ihr diesen Wunsch ab. Dieselbe Geschichte erzählt man sich auch von Symeon dem Styliten. Johannes war aber nicht ganz so hartherzig wie dieser. Um die Mutter nicht gar zu schwer zu verletzen, zeigte er sich ihr wenigstens von Ferne. Er liess ihr aber ankündigen, sie würde ihn in diesem Leben nicht mehr sehen.

Wie ganz anders wurde Sequanus ${ }^{1}$ ) empfangen, ein benachbarter Heiliger, der Gründer von Segestrum, heute S. Seine. Dem Sonderling hatte es beliebt, in stockfinsterer Nacht seinen Besuch abżustatten. Heimlich betrat er die Kirche, um zu beten. Aber Johannes erhielt durch göttliche Offenbarung Kenntniss von seiner Ankunft. Er weckte einen Diener und liess durch den Glockenschlag die Mönche zusammenrufen, die nun dem Ankömmling die Pflichten der Gastfreundschaft erwiesen.

Jonas setzt voraus, dass Sequanus damals schon ein bekannter Heiliger war. Dagegen verlegt die V. Sequani ${ }^{2}$ ) diese Episode in die Jugend des Heiligen, der sich von Johannes in der klösterlichen Lebensweise habe unterrichten lassen wollen, um später selbst ein Kloster zu gründen. Der Widerspruch ist ohne Belang, denn die V. Sequani ist aus sprachlichen Gründen späteren Ursprungs, findet sich auch nur in jungen Hss. des 13. und 14. Jahrh. ${ }^{3}$ ) und weiss Positives von dem Heiligen fast nichts zu berichten.

Zur Messe war das Kloster des Johannes mit Andächtigen überfüllt, die alle seine Predigt zu hören wünschten. Der Heilige pflegte aber für die Fremden besonders Messe zu lesen, denn er mochte nicht leiden, dass seine Mönche durch den Lärm der Menge gestört würden.

1) Die richtige Schreibung hat Greg., Gl. Conf. c. 86. Jonas dagegen nennt den Heiligen ,Sigonus', wie Fredegar die Sequana, Sigona', ,Segona', ,Secona، schreibt. Wenn aber anch in Ados Martyrologium (Surius VII, 1192) steht: ,13. Kal. Oct. in territorio Lingonicae civitatis sancti Sigonis presbyteri', so darf man annehmen, dass der Verf. die Schrift des Jonas benutzt hat.

2) Mabillon, Saec. I, p. 264 .

3) Paris 5337 saec. XIII. und 5353 saec. XIV. 
Wenn es soweit war, befahl er daher den Fremden, zuuächst abzutreten und vor der Kirche zu warten. Ein gewisser Agrestius nahm diese Zurücksetzung sehr übel auf und kehrte grollenden Herzens heim. Durch eine nächtliche Vision aber zur Einkehr bewogen, suchte er den Johannes am Morgen wieder auf und bat ihn um Verzeihung.

Das Kloster war ein Asyl für Bedrückte und die letate Hoffnung für schwer Erkrankte. Ein Sclave, der einen Fehltritt begangen hatte, nahm die Vermittlung des Johannes in Anspruch, um ron seinem Herrn Verzeihung zu erlangen. Der Heilige setzte auch einen Brief an letzteren auf, aber seine Fürbitte wurde nur verächtlich aufgenommen. Heftige Schmerzen im Schlunde straften den Uebelthäter für sein unangemessenes Verhalten gegen Johannes. - Vornehmlich waren es Kranke, welche dem Kloster zusprachen. Hatten sie dann durch den Heiligen ihre Gesundheit wiedererlangt, so blieben sie wohl auch aus Dankbarkeit gegen ihren Retter im Kloster.

Einer von diesen Geheilten war der Sclave des Nicasius, ,qui eo tempore curam rei publicae administrabatt. Der Ausdruck, cura rei publicae' scheint einen römischen Beamten zu bezeichnen, aber schon der Ueberarbeiter der Schrift des Jonas hat gesehen, dass der Comes Nicasius von Avallon, einer unweit rom Kloster gelegenen Stadt, gemeint ist, derselbe welchen Bischof Germanus von Paris um die Freilassung Gefangener angieng und später von den Folgen eines Sturzes heilte. Die Begeguung des Bischofs mit dem Grafen ist nach Fortunats V. Germani c. 30. 31. nach dem Tode König Childeherts 5508 erfolgt. Weun nun auch die Heilung des Sclaven des Nicasius durch Johannes früher geschehen sein muss, so darf man doch kaum über die dreissiger Jahre des 6. Jahrh. hinausgehen.

Hiermit erlangen wir festen historischen Boden. Von diesem Capitel (11) an bietet die V. Johannis einige sichere Anhaltspunkte zur Bestimmung der erzählten Ereignisse und sogar eine politische Nacbricht von Werth.

Jonas versetzt uns unter die Regierung Theudeberts, des Enkels Chlodovechs, als schon fast ganz Gallien den Franken gehorchte, und dieser hochstrebende, aber rücksichtslose Fürst nun den Plan fasste, unter geschickter Benutzung der Kämpfe zwischen 0stgothen und Byzantinern die fränkischen Waffen sogar nach Italien zu tragen.

Er überschritt die Alpen und beunruhigte Italien, kehrte aber schnell in die Heimath zurüek mit Zurücklassung der Herzoge Mummolenus und Buccelenus, denen er den Oberbefehl übertrug. Bei diesen Truppen befand sich ein Mann, der von heftigem Fieber geplagt wurde. Dessen Bruder eilte zu Johannes und erbat sich von ihm geweihte 
Esswaaren ("eulogiae"), ersuchte auch den Heiligen, den Kranken in sein Gebet einzuschliessen. Er erhielt 1 Brot und 5 Obstfrüchte, die man dem schon ungeduldig harrenden Kranken in drei Theilen, mit Wein befeuchtet, eingab. Die Wirkung dieser Arznei war eine überraschende: der Fieberkranke fühlte sich sogleich wieder ganz wohl.

Es kann keinem Zweifel unterliegen, dass der Heereszug Theudeberts nach Italien vom J. 539 gemeint ist. Mit Jonas stimmt der Hauptgewährsmann dieser Expedition, Procop, De bello Gothico II, 25, darin überein, dass er das Ueberschreiten der Alpen ausdrücklich er-

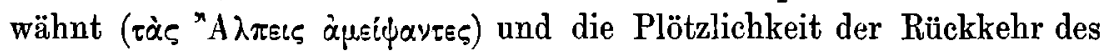

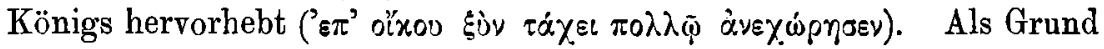
für dieselbe gibt Procop den Untergang eines Drittels des fränkischen Heeres in Folge schlechter Ernährung in der menschenleeren Gegend an. Dass grosse Verluste Theudebert zur Rückkehr gezwungen haben, bestätigen auch die andern Quellen. Nach Gregor, H. Fr. III, 32 wurde sie aber nicht durch Verdauungsstörungen, sondern durch Fieber herbeigeführt, und der von Jonas angeführte Specialfall steht mit dieser Ansicht im Einklang.

Dass ein Theil der fränkischen Truppen in Italien zurïckgeblieben sei, erzählt Procop nicht. Es ist dies aber an sich sehr wahrscheinlich, denn Theudebert folgte, wenn er das Hauptcorps zurückzog, mehr einem Gebote der Nothwendigkeit, als dass er seine Pläne auf Italien aufgegeben hätte. Schon bald darauf fand sich eine fränkische Gesandtschaft beim König Vitigis ein, die ihm die Bundesgenossenschaft unter der Bedingung antrug, dass die Franken zusammen mit ihm über Italien herrschen sollten ${ }^{1}$ ). Die Gesandten meinten damals, es hätten bereits 500.000 Franken die Alpen überschritten. Diese Verhandlungen fanden noch in demselben Jahre 539 statt. Wir wissen endlich, dass Theudebert bei seinem Tode (548) einige Orte Liguriens, die cottischen Alpen und den grössten Theil Venetiens in seinem Besitz hatte, der gegen die Gothen vertragsmässig gesichert war ${ }^{2}$ ).

Nun berichtet Paulus, Hist. Langob. II, 2, dass Theudebert bei seinem Rückzuge nach Gallien die Herzoge Buccelenus und Amingus in Italien zurückgelassen habe. Der langobardische Geschichtsschreiber hat eine jetzt verlorene Quelle, vielleicht das Geschichtswerk des Secundus von Trient, für die Darstellung dieser Ereignisse benutzt. Andrerseits nimmt Gregor eine zweite Sendung Buecelen's durch Theudebert an. Aber auch Dahn, Urgeschichte III, 93, ist in jüngster Zeit der

\footnotetext{
1) Procop., de bello Goth. II, 28.

2) Procop. 1. 1. p. IV, 24.
} 
Angabe des Paulus beigetreten, wenn er schreibt, dass Theudebert trotz des Rückzugs der Hauptmacht durch zurückgelassene Besatzungen unter etlichen Feldherrn zahlreiche Städte und Castelle festgehalten habe.

Diese Ansicht stützt unser Hagiograph. Er nennt die zurückgelassenen Herzoge Mummolenus und Buccelenus. Der letztere ist der bekannte Alamannen-Herzog, der später seine ganze Kraft für die gothische Sache in Italien einsetzte und mit ibr unterging. Aber auch des Mummolenus Existenz ist gesichert. Es ist der Mummolus Gregors ${ }^{1}$ ), der zu Theudeberts Zeiten als Gesandter an Kaiser Justinian nach Constantinopel geschickt wurde, in Patrae erkrankte und durch ein Wunder des $\mathbf{h}$. Andreas genas. Dieser ausser der gelegentlichen Erwähnung Gregors in einer seiner Wunderschriften sonst durchaus unbekannte Beamte König Theudeberts bietet meines Erachtens eine sichere Bürgschaft dafür, dass die Nachricht des Jonas gut ist.

An den letzten Kämpfen der Gothen hat allerdings Mummolenus keinen Antheil genommen. Daher sein Fehlen bei Paulus, der nur die zurückgelassenen Feldherrn nennt, welche später in den Schlussalkt der gothischen Herrsehaft eingegriffen haben. Wenn er auch den Amingus dazu zählt, so mag dies richtig sein. Wahrscheinlich gehörte noch ein vierter dazu, der Herzog Lanthacarius, der nach Marius 548 im römischen Kriege seinen Tod fand.

Der kranke Soldat Theudeberts, welcher seine Genesung vom $h$. Johannes erhoffte und von Italien aus seinen Bruder an diesen sulıdte, kann natürlich nur ein Burgunder gewesen sein. Es ist auch nichts wahrscheinlicher, als dass der König in erster Linie die Italien am nächsten gesessenen Völkerschaften, die Alamannen und Burgunder, für diesen Zug aufgeboten hat. Schon vor dieser Expedition hatte Theudebert 10000 Mann Burgunder dem König Vitigis zu Hilfe geschickt²).

Das letzte Wunder des Johannes fällt in die Zeit, als eine schwere Seuche ganz Gallien verheerte. Ein Mann wird auf der Heimreise von Paris von der Krankheit befallen, indem sich ein böses Geschwür bildet. Sobald er nach Hause zurückgekehrt ist, lässt er sich Wasser aus dem Brunnen holen, den der Heilige geweiht hatte. Ein Diener bringt ihm das Gewünschte mit dem Segen des Heiligen. Als er nun gläubig davou getrunken hatte, barst das Geschwür und er erlangte seine Gesundheit wieder.

Schon Roverius hat erkannt, dass Jonas nur die Seuche von 543 gemeint haben kann. Diese nahm ihren Anfang 542 in Aegypten

1) G1. Mart. c. 30. Eine Handschrift hatte zuerst "Mummolenus".

2) Procop., de bello Gothico II, 12. 
und verbreitete sich von hier ans über den ganzen Erdkreis. Zuerst trat sie regelmässig in den Küstenstrichen auf. In Constantinopel wïthete sie über ein halbes Jahr; in Gallien wurde die ,Arelatensis provincia am heftigsten mitgenommen. Die Kranken klagten über Anschwellung der Drüsen in den Weichtheilen, aber auch unter der Achsel und bisweilen hinter den Ohren. In den schlimmsten Fällen zeigten sich am ganzen Körper schwarze Pocken von der Grösse einer Linse, die fast unmittelbar zun Tode führten ${ }^{1}$ ). Der Schrecken, deu diese furchtbare Krankheit in Gallien verbreitete, spiegelt sich in den Schriften Gregors an zahlreichen Stellen wieder.

Johannes stand in grosser Verehrung bei den fränkischen Königen und beim Adel. In weltliche Geschäfte mischte er sich aber nicht. Er starb im Alter von etwa 120 Jahren am 28. Januar. Da sein letztes Wunder 543 erfolgt ist, kann sein Tod nicht vor 544 eingetreten sein, gewiss aber auch nicht viel später. Ist die Altersangabe des Jonas richtig, so wäre der Heilige etwa 424 geboren. Begraben wurde er nicht fern vom Kloster im Gebiete desselben an der Stelle, die er selbst bestimmt hatte.

Auf den Wunsch des Johannes wurde Silvester zu seinem Nachfolger gewählt. Jonas weiss von ihm weiter nichts, als dass er in Bezug auf Religiosität und Befolgung der Regel in die Fusstapfen seines Meisters trat und lange lebte. Er war Zeitgenosse des Bischofs Germanus von Paris (c. 555-576). Fortunat erzählt nämlich von einem Cleriker aus der nächsten Umgegend des Klosters, der sich an einem Sonntage Schuhe zurechtgemacht hatte und deshalb gelähmt worden war, dass ihm Silvester die Füsse heilte, während er den Gebrauch der Hände durch den h. Germanus zurückerlangte ${ }^{2}$ ). Nach dem dritten Texte starb dieser $A b t$ am 15. April und wurde in der Kirche des $h$. Johannes begraben. Auf denselben Tag legt auch das Martyrologium des Klosters seine Beisetzung ${ }^{3}$ ).

Der Name des dritten Abtes war bisher nur aus einem sehr späten Abtskataloge des Klosters bekannt, den Roverius, Reomaus S. 437 abgedruckt hatte ${ }^{4}$ ). Die Angabe findet jetzt durch Jonas ihre Bestä-

7) Procop., de bello Persico II, 22.

2) V. Germani c. 35 .

3) Cod. Semur 24, saec. XV : 17. Kl. Maj. Et in Reomau cenobio deposicio sancti Silvestri, discipuli sancti Johannis conf."; vergl. N. Archiv XVIII, S. 618 .

4) Der Katalog reicht bis in das 14. Jahrh. Die bezügliche Notiz lautet: ,Mummolus III, sancti S. Johannis discipulus, postea Lingonensis episcopus?. In der Hs. Semur N. 1. steht fälschlich, Nimmolus" statt ,Munmolus“. 
tigung. Mumulinus, wie er den neuen Abt nennt, übernahm auf Befehl des Silvester die Leitung des Klosters und setzte später, zum Bischof von Langres erwählt, mit Zustimmung der Mönche den Leubardinus an seine Stelle.

Die Nachfolger des Johannes sind also nach Jonas von ihren Amtsvorgängern zu der Abtswürde designirt worden, and dem Convent stand zuerst ein Einfluss auf die Besetzung der Stelle überhaupt nicht zu. Der Stifter des Klosters und der zweite Abt befahlen einfach vor ihrem Ableben den Mönchen, diese oder jene Person zum Nachfolger einzusetzen. Der dritte Abt Silvester schied durch Beförderung auf einen höhern Kirchenposten aus dem Klosterverbande aus. Er war also in der Lage nicht bloss zu designiren, sondern geradezu einen neuen Abt einzusetzen. Hierzu bedurfte er aber um so mehr der Zustimmung der Mönche, weil er der Diöcesanbischof des Klosters geworden war, und soust dieser Fall von dem Bischof von Langres leicht als Präcedenz dafür hätte hingestellt werdeu können, dass ihm die Eiusetzung des Abtes in dem Kloster zukomme. Der Bischof als solcher hatte aber überhaupt keinen Anspruch auf Mitwirkung bei derselben, weil das Eigenthumsrecht des Klosters dem Stifter Johannes zustand, von dew es auf die folgende Aebte übergegangen war.

In Langres war auf Bischof Gregor 539 oder 540, dessen Sohn Tetricus gefolgt. Als dieser in hohem Alter vou einem Schlaganfall getroffen wurde, wählte der Clerus mit Einwilligung des Königs den Monderich. Zunüchst sollte dieser das Archipresbyterat von Tonnerre verwalten, und erst nach dem Tode seines Vorgängers den Bischofsstuhl besteigen. Aber noch ehe es dazu kam, fiel er in Ungnade beim König und wurde verbannt. Nach dem Tode des Tetricus (572 $\mid 3)$ wurde nun einer seiner Verwandten zum Bischof erkoren; er starb aber, bevor er in Lyon die Weihe erhalten hatte. Nachdem die Versuche, die Stelle zu besetzen, zweimal fehlgeschlagen waren, erhielt endlich Pappolus, ein früherer Archidiaconus von Autun den Bischofsstuhl. Die schlimme Amtsverwaltung dieses Mannes liess die Diöcese auch jetzt noch nicht zur Ruhe kommen. Glücklicherweise danerte dieser Zustand nicht lange, denn Pappolus starb schon im 8. Jahre seiner Verwaltung auf einer Visitationsreise.

So lagen die Verhältnisse im Bisthum Langres, als 579/80 der Abt Mummolus, mit dem Beinamen der Gute, die Verwaltung desselben übernahm. Gregor ${ }^{1}$ ) bezeichnet zwar nicht das Kloster, dem dieser Mummolus vorgestanden hatte; man weiss aber längst, dass es Reo-

1) Vergl. Gregor, H. Fr. V, 5. 
maus war. Allerdings gebraucht Jonas die Diminutivform Mumulinus, und dieselbe Differenz zwischen ihm und Gregor findet sich, wie wir oben sahen, bei dem Herzog dieses Namens unter König Theudebert. In dem vorliegenden Falle lässt sich aber ganz sicher nachweisen, dass Jonas im Unrecht ist. Der neue Bischof von Langres wohnte nämlich bald nach seiner Einsetzung dem 1. Concile von Mâcon bei und unterzeichnete dasselbe mit den Worten ${ }^{1}$ ): ,Mummulus episcopus ecclesiae Lingonice subscripsi'. In dem ehrenvollen Beinamen, welchen er führt, sah Roverius ${ }^{2}$ ) die Unterscheidung von zwei hohen weltlichen Beamten dieses Namens, welche sich Schandthaten hatten zu Schulden kommen lassen; näher lag es aber offenbar den Pfarrkindern der Diöcese Langres, dabei an seine schlechten Vorgängern zu denken. Auch Gregor ist seines Lobes voll, während er den Pappolus nach Kräften herabsetzt. Mummolus war nach ihm keusch, nüchtern, maassvoll, gerecht, liebevoll, überhaupt das Muster von einem Menschen.

Unter dem Abte Leubardinus erfolgte die erste Translation der Gebeine des h. Johannes. Bei derselben geschah das übliche Wunder. Als das Grab aufgegraben war, liess sich der Sarkophag nicht von der Stelle bewegen. Ein dreitägiges Fasten sollte die Schwierigkeit beseitigen. Am dritten Tage, - es war der 22. September, das Fest des h. Mauricius, - als die Mönche nach der Frühmesse, von den Fasten erschöpft, sich wieder zur Ruhe begeben hatte, betrat ein Greis die Kirche und erblickte hier vor dem Grabe die h. Johannes und Silvester, wie sie einigen weissgekleideten Gestalten den Befehl gaben, den Sarg von der Stelle zu bewegen. Der unberufene Zuschauer wurde von dem Einen, den er für Johannes hielt, wegen seiner Kühnheit ausgescholten und angewiesen, schleunigst Leubardinus und die Mönche zu wecken, damit sie das begonnene Werk zu Ende führten. Nachdem so die Erlaubniss ertheilt worden war, ging die Translation prompt von Statten. An der neuen Ruhestätte des h. Johamnes erbaute man mit dem Rathe der Bischöfe einen Altar, an welchem Kranke Hilfe von ihren Leiden fanden und ein Jeglicher Erfüllung seiner Wünsche.

Leider hat es Jonas ganz unterlassen, anzugeben, wohin die Gebeine des h. Johannes übertragen wurden. Seine Ausdrucksweise: ,in loco in quo nunc est' oder, ubi nunc est' lässt nur darüber keinen Zweifel, dass sie sich zu jener Zeit noch an der Stelle befanden, wohin sie Leubardinus gebracht hatte.

1) Concilia ed. Maassen p. 161. Mummolus befand sich auch anf dem folgenden Concile von Mâcon.

2) Reomaus S. 543. 
Ursprünglich war der Heilige in geringer Entfernung vom Kloster im Gebiete desselben begraben. Den Ort hält man mit grosser Wahrscheinlichkeit für das heutige Corsaint, welches 3 Kilometer südlich von Moutiers Saint Jean gelegen ist. Der lateinische Name dieses Ortes Corpus sancti, der schon 950 bezeugt ist ${ }^{1}$ ), hat den Anlass zu dieser sehr plausiblen Combination gegeben. Zur Zeit des Abtes Leubardinus befand sich das Grab in einer Kirehe. Nun hat Corsaint noch heute eine Kirche des h. Mauricius ${ }^{2}$ ), deren Weihung das Martyrologium von Reomaus unter dem 28. Juni mit folgenden Worten erwähnt: ,In Reomau (,monasterio' ist getilgt) vico dedicatio ecclesie sancti Mauricii martyris, in qua sanctus Johannes confessor corpore quiescit' ${ }^{3}$ ). Diese Kirche scheint mir Jonas gemeint zu haben. Denn die Hervorhebung des Festes des h. Mauricius bei der Erscheinung des h. Johannes und Silvester steht gewiss damit im Zusammenhang, dass er der. Schutzpatron derselben war.

Wenn ich nun auch der Ansicht bin, dass las Grab des h. Johannes zuerst in Corsaint war, so kann ich doch Roverius darin nicht beistimmen, dass er die Translation durch Leubardinus in das Kloster selbst vornehmen lässt ${ }^{4}$ ). Denu die unbestimmte Angabe des Jonas, dass das Grab an den Ort gebracht worden sei, wo es jetzt ist, schliesst meines Erachtens aus, dass es in die Klostermauern transferirt worden sei. Weshalb soll es nun nicht an eine andere Stelle in Corsaint selbst verlegt worden sein? Erst zu Karls d. Gr. Zeit ist, wie wir unten sehen werden, der h. Johannes wieder in das Kloster zurückgeführt wordeu, das seinen Namen trägt.

Von schriftlichen Quellen hat Jonas nur Cassian benutzt. Die Laster, gegen welche der Heilige eiferte, sind dieselben, welche schon Cassian in seinen Institutiones gegeisselt hatte, und das Vorbild des Heiligen war nach Jonas der Abt Isaac in den Collationes des Cassian, dessen Lehre er sich so sehr zur Richtschnur genommen hatte, dass der Biograph für die Schilderung der Trigenden seines Helden nur den Cassian auszuschreiben brauchte. Stöbcr hat mit Unrecht diese Cassianbenutzung den Epigonen des Jonas in die Schuhe geschoben ${ }^{5}$ ). Die Schrift des Jonas (A) wurde in karolingischer Zeit einer

1) Vergl. Longnon, „Géographie de la Gaule au lI siécle", p. 214.

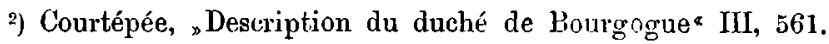

s) N. Archiv XVIII, S. 618.

${ }^{4)}$ Reomaus S. 523. Er ist aber seiner Sache nicht sicher. Ganz bestimmt nehmen dies erst die Bollandisten a. a. U. S. 863 an.

5) S. 67,68 . 
durchgreifenden Umarbeitung unterzogen $(B)^{1}$ ). Die holperige Sprache des 7. Jahrh. und die mangelhafte Composition machte den älteren 'Text einem verwöhnteren Geschlechte ganz ungeniessbar. Wurde am Jahrestage des Heiligen seine Legende im Kloster vorgelesen, dann verletzten die Soloecismen, und die oberflächliche Aneinanderreihung von Wunder an Wunder ermüdete und langweilte die Zuhörer, ohne sie zu erbauen. Daher goss man die alte Vita in eine neue Form um, die sich durch eine bessere Sprache und geläufigere Darstellung auszeichnete, aber nicht durch grössere Wahrhaftigkeit. Für die Aenderungen der Recension B war massgebend ihr Zweck, dass sie eine zum Vorlesen bestimmte Frbauungsschrift sein sollte, die den Lebenslauf des Heiligen in nöglichser Vollständigkeit und mit der scheinbar grössten Genauigkeit schilderte. Daher vereinfachte der Verfasser die zwar sehr speziellen, aber auch höchst schwerfälligen Ortsbestimnungen des Jonas und ergänzte, wo sich etwa in der Darstellang des Lebensganges des Heiligen bei diesem Lüicken zeigten. Ueber die Jugend des Johannes bis zum 20. Jahre hatte sich A ganz kurz gefasst; B rühmt die musterhafte Aufführung des Knaben, seine Fortschritte in der Schule, sein Verhalten gegen die Mitschüler. Möglichst suchte B unbestimmte Angaben von A zu präcisiren, um so das Ganze glanbhafter zu machen. Während Jonas den Heiligen mit Genossen (,cum sodalibus') an den Brunnen kommeu lässt, ohne vorher etwas von diesen erwähnt zu haben, sind in B zwei Burschen in dem Oratorium in der Heimath bei ihm und begleiten ihn auch in die Wüste, wo er sein Klosteı gründet. Der Bischof Gregor schickt in A Männer (,virus') mit Briefen ab, aber B weiss, dass es zwei Mönchsbrüder waren. Auch die Zeitangabe vom Consul Johannes, die ja in der That nichts bestimmt, genügte dem Ueberarbeiter nicht. Er schob daher vor derselben die Bemerkung ein, Johannes habe von der Zeit des Cäsars Valentinian (424 - 455) und des Kaisers Marcian (450-457) bis auf Justinian (527 -565), als die Franken unter Chlodovech Gallien einnahmen, und von da bis zur Regierung der Könige Theuderich $(511-534)$ und Theudebert (534-548) gelebt. Die Berechnung ist richtig, war aber auch nicht schwer zu finden, da A selbst durch Angabe der Regierung Theudeberts und des Lebensalters des Heiligen die nöthigen Daten geliefert hatte. B weiss, dass der Fremde den h. Johannes in Lerinum au Gesicht und Stinme erkannte, während Jonas es nicht für nöthig gehalten hatte, Merkmale anzugeben. Der Ueberarbeiter giebt sich wei-

1) Lis ist dies der von Mabillon veröffentlichte und von Stöber mit M bezeichnete 'Text. 
ter den Anstrich eines sehr kritischen Forschers, denn er versichert, nach den beiden Briefen des Bischofs Gregor gesucht zu haben, weil er sie gern seiner Schrift beigegeben hätte. Von den Wundern seiner Vorlage hat er nur drei aufgenommen. Mit dem einen von den gestohlenen Beilen will er beweisen, dass die Mönche des Johannes nach dem Beispiel der ägyptischen Väter die Handarbeit pflegten, die Geschichte vom Agrestius bezeugt ihm die Barmherzigkeit des Heiligen und das dritte Wunder von der Heilung des besessenen Sclaven des Nicasius, dass Johann bis an sein Lebensende der kräftigste Teufelsaustreiber gewesen sei. Die ausgewählten drei Fälle dienen ihm also nur zur Illustrierung allgemeinerer Sätze, die er sich selbst erst aus den Einzelfällen abstrahirt hatte. Es wäre eine sehr mühsame Arbeit gewesen, wenn er in dieser Weise sämmtlicheWunder des Jonas hätte verwerthen wollen. Daher zog er es vor, sich auf die angeführten Beispiele zu beschränkeu und die übrigen Wunder wegzulassen. Er selbst freilich begründet seine Kürze mit der üblichen Phrase, dass die grosse Menge der Wunder seine Kräfte übersteigen würde. Bemerkenswerth ist anch bei den ausgewählten Wundern das Bestreben von $B$ die Personen näher zu bestimmen. Den Agrestius macht der Umarbeiter zum Bürger von Mesmont (,Magnimontensiuın partium civis's), einem Dorfe, welches früher Hauptort des gleichnamigen Gaues gewesen ist, und beim Nicasius, welchen Jonas nur allgemein als Staatsbeamten characterisirt, giebt er die Stadt Avallon als seinen Verwaltungsbezirk an. Die erste Angabe hat $B$ erfunden, die andere aber Fortunats V. Germani entnommen, wo in der That der Graf von Avallon Nicasius heisst.

Damit Niemand an der Wahrheit zweifele, betheuert $B$ am Schlusse der Geschichte von Agrestius, er habe dieselbe aus dem Munde des Diaconus Agripinus, des Sohnes jenes Agrestius, erfahren. Damit macht sich der Ueberarbeiter zu einem ungefähren Zeitgenossen des h. Johannes; seine Vita würde folglich noch in das 6. Jahrh. gehören und die Quelle der Darstellung des Jonas sein. In der That ist sie bis vor wenigen Jahren dafür gehalten worden. Erst Stöbers Entdeckung des ursprünglichen 'Textes des Jonas hat zur Evidenz erwiesen, dass $B$ nur diesen umgearbeitet, also durch Einflechtung der obigen Bemerkung in ganz unverschämter Weise gelogen hat. Man sieht aber aus diesem Specialfalle, was von den Gleichzeitigkeitszeugnissen, welche sich die Hagiographen selbst ausstellen, zu halten ist.

B sehliesst mit den Wundern am Grabe des h. Johannes. Die Erzählung von den folgenden Aebten und die Translation des Heiligen hat der Ueberarbeiter fortgelassen, da sie ausserhalb der Grenzen 
seiner Aufgabe lagen. Er war wohl ein Angehöriger des Klosters 1) des h. Johannes, denu er nennt diesen ,summus sacerdos Dei und ,pater noster' und den Bischof Gregorius von Langres ,pontifex noster."

Schon Stöber S. 25 hatte die Verwandschaft der Recension B mit einem Capitel von Gregors Buch ,In gloria conf.' bemerkt, woraus er auf Benutzung desselben schloss. Es handelt sich nur um wenige Sätzchen, welche die Drachentödtung und das Ende des Heiligen behandeln. Wäre es nun schon an und für sich wenig wahrscheinlich, dass der gewandte Stilist B, der so ziemlich die ganze Vita des Jonas umschrieb, für diese paar Zeilen eine andere Quelle nachgeschlagen hätte, die ihm noch dazu nur ein Excerpt bot, so kommt noch hinzu, dass die Art der Darstellung durchaus die Manier von B verräth. Denn während A einfach angibt, dass der Heilige Kenntniss erhielt von den Brunnen mit dem Drachen und sich dorthin begab, sucht der Ueberarbeiter B nach dem Motive zur Aufsuchung des Brunnens und findet dieses in dem Wassermangel der Mönche: ,nimiam aquae penuriam patiebantur.' Wenn nun bei Gregor dieselbe Begründung er.scheint, so behaupte ich, dass dort $B$ benutzt ist und nicht umgekehrt. Die neue Gregorausgabe, welche Stöber noch nicht vorlag, bestätigt dies²). Das Johannes von Reomaus betreffende Capitel steht nämlich nur in einer Gregor-Hs. Bern n. 199 saec. IX; in der ebenfalls noch erhalteneu Vorlage dieser Hs. Paris 2204 saec. IX. fehlt aber das Einschiebsel. Der h. Johanues ist also erst im 9. Jahrh. durch eine Interpolation in den Gregortext gelangt. Damit ist der späteste 'l'ermin für die Entstehung der Recension B gegeben. Sie kann aber auch nicht viel vor diese Zeit gesetzt werden, und auf jeden Fall verbietet die glatte Sprache über das Ende des 8. Jahrh. hinauszugehen.

Der Recension B mangelte vor Allem die Vollständigkeit. Bei eiver Vergleichung mit A musste man bald finden, dass der Ueberarbeiter die meisten Wunder des Heiligen weggelassen hatte, und also der neue T'ext den altfränkischen keineswegs überflüssig machte. Um nun alles zusammen zu haben, verband man jetzt $B$ mit $A$ und schuf so eine neue Recension $C^{3}$ ), die nicht nur den gesammten luhalt von $B$ und A vereinigt, sondern auch noch einige neue Fabeln hinzufügt. Die Arbeit zerfällt in zwei Bücher. Das erste enthält im Allgemeinen die Recension B mit einigen Umänderungen und Zusätzen, - unter andern sind zwei der ausgelassenen Capitel aus $\mathrm{A}$ au der rechten

1) Stöber S. 34.

2) Vergl. SS, rer. Meroving. I, p. 803.

s) Dies ist der von Roverins und Bollandus publicirte Text, bei Stöber BR. 
Stelle ergänzt, - aber auch mit Abstrichen, denn die erbaulichen Betrachtungen von A wusste $B$ nicht zu würdigen. Das zweite Buch enthält die übrigen von B übergangenen Wunder, das Lob des Heiligen und sein Ende, sowie die Geschichte seines Nachfolgers Silvester. Dem Compilator mangelte das stilistische Geschick seines Vorgängers. Den B-Text hat er fast buchstäblich abgeschrieben und sogar den AText häufig wörtlich wiedergegeben, theilweise allerdings auch überarbeitet. Mit Vorreden ist $\mathrm{C}$ reichlich ausgestattet. Es enthält nicht allein die Vorbemerkung des Jonas über den Anlass zur Abfassung der Vita und dessen Vorrede mit dem aus B entlehnten Zusatze über die Lebenszeit des Heiligen, sondern auch eine eigene Vorrede des Compilators, worin er den Leser über seine Arbeit aufklärt oder vielmehr irre führt. Er entschuldigt hier zunächst seine ungrammatische Sprache mit denselben Worten, wie dies Sulpicius Severus in der Vorrede der V. Martini thut, und versichert, dass er die Arbeit nicht unternommen haben würde, wenn der Ruhm und die Wunder des Heiligen ohne sein Zuthun der Nachwelt hätte bekannt werden können. Damit leugnet er, dass er schon zwei Lebensbeschreibungen des Heiligen vorgefunden hatte. $\mathrm{Ja}$ er geht noch weiter. Wenn er sich brüstet, den merkwürdigen Mann nach der Erinnerung von Augenzengen zu verewigen, die noch leben (,vivorum ac praesentium'), so macht er sich eines ziemlich einfältigen Betruges schuldig, denn in der vorangestellten Vorbemerkung des Jonas war doch 659 als Abfassungsjahr genannt. Die Fiction, dass er Zeitgenosse des Heiligen sei und also directe Nachrichten von ihm habe, hält er auch sonst aufrecht. Er versetzt den Johannes nach Semur und lässt ihn hier mit einem lüderlichen Weibe zusamımentreffen, welches ihn in die Felder locken will; natürlich geht aber der heilige Maun aus diesem Kampte als Sieger hervor. Diese Geschichte, die nicht in $\mathrm{AB}$ steht, hat nach C Johannes selbst exzïhlt (,proprio sermone narravit'). Das darf uns nicht weiter wundern, denn das ganze zweite Buch will der Compilator nach mündlichen Mittheilungen des Diaconus Laetus, des Famulus des heiligen Mannes, zusammengeschrieben haben. Am Anfang desselben findet sich nämlich die folgende rührende Geschichte, zu der, wie bereits Stöber gesehen hat, die Dialoge des Sulpicius Severus das Vorbild gewesen sind. Während der Verfasser in dem ersten Buche der Lebenbeschreibung blättert, besucht ihn sein Freund Laetus. Nach einer überaus höflichen Begrüssung fragt ihn dieser, womit er in seiner Zelle beschäftigt sei. Der Verfasser zeigt ihm seine Arbeit, und Laetus entgegnet freudig: "Als ich dich einst vorlesen gehört hatte, fiel es mir nachher ein, ob du wohl meine Nachrichten über den Johannes in 
dem Buche hättest; aber weil sie dir vielleicht unbekannt sind, schreibe sie gefälligst nach meiner Erzählung auf."

Nun beginnt Laetus die bekannten Wunder des Johannes zu errählen, die $B$ ausgelassen hatte. Das erste Wunder allerdings erscheint uns fremd. Laetus kommt zu dem Patricius Secundinus mit einem Vorwortschreiben des h. Johannes für einen Armen. Die ungnädige Aufnahne des Patricius, der u. a. den Brief des Heiligen mit Füssen tritt, veranlasst den Diaconus, sich zurückzuziehen. Secundinus aber verfällt sofort in eine schwere Krankheit, schickt jetzt reuig Boten zu dem Heiligen und wird geheilt. Dieses neue Wunder des Laetus ist wenig originell, denn eine ganz ähnliche Geschichte hatte schon Jonas von Clarus ${ }^{1}$ ) erzählt, und diese hat der Compilator in sein erstes Buch aufgenommen. Den Secundinus aber kannte er aus Gregor, h. Fr. III, 33, als einen einflussreichen Rathgeber des Königs Theudebert.

Auch bei den zunächst folgenden Wundern hält der Compilator noch die Fiction aufrecht, dass er nach mündlichen Berichten des Zeitgenossen Laetus erzähle. Der, quidan vir des Jonas, der auf der Heimreise von Paris an der Seuche erkrankt und durch das Wasser aus dem Brunnen des $\mathrm{h}$. Johannes geheilt wird, ist in $\mathrm{C}$ unser Freund Laetus und der ebenfalls von Jonas nicht genannte Mann, der bei König Theudeberts Zeiten in Italien erkrankte, des Laetus Bruder Fidamiolus. Wenn dieser in A durch den Genuss von Victualien gesundete, die der Heilige geweiht hatte, so kann sich $\mathrm{C}$ nicht versagen, mit diesem Heilmittel noch weitere Wunderkuren auszuführen. Fidamiolus giebt einem Verwandten davon und erzielte denselben Erfolg, und solchen vom h. Johannes gereichten Gegenständen verdanken noch viele Kranke ihre Gesundheit.

Jetzt aber lässt der Compilator seinen Gewährsmann Laetus falleu. Die Umarbeitung des Jonastextes auf die Person seines Strohmannes hatte ihm doch zu viel Schwierigkeiten gemacht. Er vereinfacht sich nun seine Aufgabe, indem er im Folgenden A ungefähr wörtlich ausschreibt. Damit gewinnt seine Arbeit wenigstens einigen Werth für die Textkritik der Schrift des Jonas.

Mit B theilt der Compilator die Sucht, allgemeine Angaben zu präcisiren, um sich so den Schein der vollsten Sachkenntniss zu geben. Jonas hatte bei dem Sclaven des Clarus, der wegen eines Verbrechens zum Heiligen floh, dieses selbst nicht angegeben. Der Compilator aber kennt die Schuld des Sclaven sehr wohl; wenn er sie verschweigt, geschieht es nur: ,ne tragoediam magis quam historiam

1) Vergl. Stöber S. 65 . 
texere videamur'. Während Clarus bei Jonas lange 'Leit (,per multa spacia temporum') keine Nahrung $z$ u sich nehmen kounte, weiss $C$, dass dieser Zustand 9 Jahre anhielt. Ihm ist ferner bekannt, dass der den h. Johannes besuchende Sequanus aus der Gegend von Mesmont kam; das Kloster des letztereu (St. Seine) liegt nämlich in diesem Gau.

Wie gross die Verehrung war, deren sich der Heilige bei den Frankenkönigen und dem Adel erfreute, darauf geht Jonas nicht weiter ein („enarrare longum est"), aber der Compilator führt als Beweis dafür die Königsurkunden an, die noch zu seiner Zeit in dem Klosterarchive aufbewahrt wurden: „ambigit nemo, qui beneficia a praedictis regibus praestita per praecepta chartarum, quae usque nunc in publicis archivis praedicti condita sunt monasterii, relegere cupit". Es existiren in der That zwei gefälschte Diplome der Könige Chlodovech und Chlothar für Reomaus ${ }^{1}$ ), die Frage aber, ob sie dem Compilator vorgelegen haben oder erst auf Grund seiner Notiz fabricirt worden sind, mag ich nicht entscheiden. In dem aus Reomaus stammenden, jetzt in Semur befindlichen Codex N. 1, saec. X, stehen die beiden Urkunden hinter der Compilation C; sie sind aber erst von einer Hand saec. XI. nachgetragen worden. Die Urkunde Chlodovechs ist so plump gearbeitet, dass sie heute wohl Niemanden mehr zu täuschen vermag; das Formular der andern ist aber etwas besser, und in der That hat diese noch in Löning ${ }^{2}$ ) einen Vertheidiger gefunden. Unecht ist aber auch sie. Zunächst entspricht weder die Adresse, noch die Unterzeichnung des Königs: „Signum (Monogr:) incliti regis Chlotharii" mit einem Monogramm $^{3}$ ) dem Gebrauche der Merowingischen Königskanzlei. Einige Alterthümlichkeiten, wie ,emunitas", das sich jedoch bis in das 9. Jahrh. erhalten hat, und die Phrase "sperare ${ }^{4}$ ) videntur", die indessen falsch angewendet ist, werden aus einer ältern Vorlage stammen, wie auch die ganze Arenga aus dem Privileg Theuderichs IV. für Murbach abgeschrieben ist ${ }^{5}$ ). Den Hauptheweis gegen die Echtheit liefert aber die Datirung. Die Urkunde ist gegeben am 22. Febr. in 5. Jahre Chlothars I. Dieses würde, da Chlothar 511 König wurde, dem J. $515 \mid 6$ p. Chr. entsprechen. Aber dieses Jahr kann der Verf. der Urkunde nicht meinen, denn er lässt in ihr den Abt Silvester, den Nachfolger des Johannes, in den Königsschutz aufgenommen werden,

1) Gedruckt bei Pertz, Dipl. I, p. 113, 125, nur nach älteren Drucken.

2) Geschichte des deutschen Kirchenrechts II, 644 .

s) In den Ausgaben fehlt es.

4) So die Hs. Im Druck steht, spectare ${ }^{\star}$.

5) Vergl. Pertz, Dipl. I, p. 85. Das falsche , auditum* Pertz p. 125, 35 steht nicht in der Hs, von Semur und ist also zu tilgen. 
und es wusste doch jeder, dass Johannes König 'Theudeberts Regierung (534-548) erlebt hat, und Reomaus 515/6 nach nicht fränkisch war. Erst 534 theilten Childebert, Chlothar und Theudebert Burgund nach der Vertreibung Godomars. Rechnet man nun die Regierungsjahre Chlothars von dort aus, dann würde sein fünftes Jahr $=538 \mid 9$ sein. $\mathrm{Da}$, wie wir gleich sehen werden, in der That 539 für das Todesjahr des h. Johannes galt, würde die Urkunde vom 22. Febr. d. J. wenige Wochen nach dem Ableben des Gründers gegeben sein. Dazu stimmit auch ihr Inhalt. Das Prinzip aber, welches der Verfertiger der Urkunde bei der Berechnung der fränkischen Königsjahre befolgt, ist ein falsches. In allen echten Urkunden sind die Jahre der Könige von ilrrem ersten Regierungsantritte gezählt.

Die Recension C schliesst in den AA. SS. Jan. II, 862 ganz so wie B mit den Wunderı an Grabe des h. Johannes. Diesen Schluss ersetzt in der Ausgabe des Roverius eine, wie es scheint, sehr wichtige chronologische Angabe: ,anno Domini quingentesimo duodecimo, iuxta quod in cyclo beati Victuri episcopi numeratur". Darnach müsste der Heilige im J. $539^{1}$ ) gestorben scin. Stöber liält die Notiz für sehr werthvoll und vermuthet, dass sie aus dem ihm nicht bekannten Schlusse von A stamme. Wenn aber Jouas ein Lirlebniss des Heiligen aus der Zeit der italienischen Expedition 'Theudeberts 539 und im Verfolg noch ein späteres, wie ich mit Roverius meine, aus dcm J. 543 anführt, so kann die Berechnung des Roverins-'T'extes nicht zutreffend sein. Sie ist auch handschriftlich nieht genügenl beglaubigt. Die von mir benutzte Handschrift von C, Met $\%$ u. 195, saec. XI, schliesst ebenso wie Bollandus, und die Vorlage des Roverius war am Schlusse unvollständig, wie sie es heute ist 2). Die Vermuthung Stöher's hat der aufgefundene A-Text nicht bestätigt, welchem, ebenso wie B, das Todesjahr fehlt. Die beiden Quellen A B bestätigen vielmehr die Lesart Bollands und zeugen mit der Metyer Hs. von $\mathrm{C}$ gegen den Text des Roverius. Woher der Heruusgeber jenen Schluss genommen hat, bleibt also ungewiss, nur dies steht fest, dass er nicht zum Texte gehört.

Die Quelle der obigen Notiz scheint ein alter Computus des Klosters Reomaus gewesen zu sein. In einem Abtskataloge, der von

1) Vergl. N. Archiv IX, 125. Dagegen berechnet Stöber S. 77 das Jahr 540, weil er den Jahresanfang auf den 1. März legt. Die Jahre des Victorius beginnen aber mit dem 1. Januar, wie die Epacten zeigen.

2) Semur N. 1 saec. X. schliesst mit den Worten ${ }_{\star}$ sed portavit ${ }^{\circ}$ am Ende von II, 10 der Bollandisten-Ausgabe, indem nach Fol. 69 vier Blätter ausgeschuitten sind. Ebenda endigte auch die Hs. des Roverius. 
einer Hand saec. XIV. in die Hs. von Semur eingetragen ist, findet sich die folgende Randbemerkung 1): „qui locus seu cenobium fundatum fuit anno Domini 415, sicut in quodam libro antiquo reperitur, qui liber dicitur liber conpoti". Das Jahr 415 bezieht schon Roverius S. 475 richtig auf den Cyclus des Victorius, denn als Incarnationsjahr wäre es ganz unsinnig. Nun nennt Jonas den Heiligen vor der Gründung des Klosters ungefähr 20 jährig und bei seinem Tode soll er ungefähr $120 \mathrm{Jahre}$ gehabt haben. Die Victorischen Jahre 415 für die Klostergründung und 512 für den Tod passen also, wie man sieht, ganz gut zusammen; vorausgesetzt ist dabei, dass Johannes 23 Jahre alt war, als er Reomaus griindete. Der leider verlorene Computus des Klosters aber. muss vor der Mitte des 8. Jahrh. verfasst worden sein, dia um diese Zeit die Rechnung nach Victorius ansser Gebrauch kam.

Das 2. Buch der Recension C schliesst mit dem Leben des Abtes Silvester, wofür ausser A Fortunats V. Germani c 35. benutyt ist. Aus dieser entnahm der Compilator das einzige Wunder des Abtes, nannte aber gewissenhaft seine Quelle: "Scriptum in gestis habetur praefati beati Germani". Auch für die folgenden Trauslationen war zunächst noch A massgebend, woraus der Compilator die Uebertragung durch Teubardinus entlehnte; dann aber wird seine Darstellung selbstständig, die sich mit den Worten: „Post annos aliquot" zunächst der Uebertragung durch den Bischof Betto von Langres zuwendet. Aber gleich den Abstand zwischen den beiden 'Translationen hat der Compilator zu gering angeschlagen; es waren nicht, wie er meint, einige Jahre, sondern, wie schon Roverius S. 524 bemerkt hat, mindestens zwei Jahrhunderte von Leubardinus bis auf Betto verflossen, der um die Wende des 8. Jahrh. lebte ${ }^{2}$ ). Damals muss der Heilige nach Reomaus übergeführt worden sein, denn bei den nach der Translation erzählten Wundern wird vorausgesetzt, dass das Grab im Kloster war ${ }^{3}$ ).

Mit der Schilderung der Wunder nach der zweiten Uebertragung schliesst C. Eine Fortsetzung der Translationen und Wunder beginnt mit einer nenen Vorrede, ans der hervorgeht, dass jetzt ein anderer Schreiber einsetzt. Sie schildert die Flïchtung des heiligen Leibes nach Semur vor den einfallenden Normanen 888, zur Zeit des Bisehofs Adelgerius von Autun ( $†$ 893), und am Schlusse eine neue Ueberführung nach Semur ebenfalls zum Schutze vor eindringenden Fein-

1) Ged. bei Roverius S. 437.

2) Gall. christ. IV, 529.

3) Man vergl. AA. SS, Jan. II, p. 864, § 4. 7. 
den. Der Fortsetzer war ebensowenig ehrlich, wie sein Vorgänger. Er schrieb nämlich eine Geschichte von einem Brudermörder aus der Berner Gregorhandschrift saec. IX, von der oben die Rede war, ab, ${ }^{1}$ ), setzte aber hinzu, er habe den Mörder selbst gesehen: „Quendam etiam fratricidam vidimus". Während jener Mörder an das Grab des h. Johannes flüchtete, als es noch in Corsaint war, also vor Betto's Uebertragung am Ausgang des 8. Jahrh. oder Beginn des 9. Jahrh., schrieb der Fortsetzer wahrscheinlich im Anfange des 10., sicher aber nicht vor dem Ende des 9. Jahrh. Für die Compilation C ergibt sich aus der Fortsetzung, dass sie vor dem Normanneneinfalle im J. 888 verfasst sein muss.

Von den drei Biographen des $h$. Johannes ist Jonas die sympathischste Erscheinung. Mit offenem Visir tritt er vor uns, nennt seinen Namen, das Jahr, in dem er schrieb, seine Quellen, erläutert die Veranlassung, gibt kurz selbst alle Aufschlüsse, die wir sonst erst mühsam mit Hilfe der Kritik gewinnen können. Wie kläglich nehmen sich neben ihm seine beiden Paraphrasten aus! Beide behaupten Zeitgenossen zu sein. Der Eine hat am. Schlusse des 8. Jahrh. den Jonas-Text umgeschrieben, der Andere noch im 9. Jahrh. aus den beiden älteren Schriften unter Zuthat etlicher selbst erfundener Geschichten eine dritte gebildet. Diese drei Phasen haben aber die verbreiteteren fränkischen Heiligenleben fast alle durchgemacht, und die V. Johannis verkörpert in dieser Beziehung nur einen Typus. Die Urform (A), in Karolingischer Zeit ele anter stilisirt (B), wurde später mit ihrer Ableitung zu einem neuen Text (C) verbunden, der dann durch seine Vollständigkeit die grösste Verbreitung fand und die alte Merovingische Fassung ganz in den Hintergrund drängte. Ist aber diese wiederaufgefunden, dann vereinfacht sich die vordem höchst verwickelte Quellenfrage, die beiden Ableitungen verlieren allen ihren Werth und erwecken höchstens noch ein literarisches Interesse; die Kritik aber kann jetzt zu dem Urquell hinabsteigen, um an ihm reinere Wahrheit zu schöpfen. Von diesem Standpunkte aus betrachtet, darf auch das neuaufgefundene Leben des $h$. Johannes von Jonas einige Beachtung beanspruchen.

Für die folgende Editio princeps der V. S. Johannis von Jonas sind die folgenden Hilfsmittel benutzt worden:

$\mathrm{A} 1=$ Paris. lat. 11748 , saec. X.

1) Vergl. AA. SS. 1. 1. p. 865, cap. 3, mit Script. rer. Merov. I, S. 805. 
A $2=$ Paris. lat. 5306, saec. XIV.

B = Text Mabillon's, AA. SS. ord. S. Benedicti, Saec. I, p. $633-636$.

$\mathrm{C}=$ Text der Bollandisten, AA. SS. Jan. II., p. 856--863 (ich habe ihn verbessert aus der Metzer Hs. N. 195 saec. XI).

Die V. Treverii (AA. SS. Jan. II, 33), deren Uebereinstiminung mit der V. Johaunis Stöber S. 66 nicht zu erklïren wusste, ist zum grossen Theile ein Plagiat und für die Textkritik nicht unwichtig.

Soweit A 1 vorhanden war, ist natürlich diese Hs. zu Grunde gelegt, die aber nicht fehlerlos und daher aus A 2, B, C bisweilen zu bessern war. Durch [ ] sind kenntlich gemacht die in A 1 unlesbaren Stellen der Vorrede und des Kapitelverzeichnisses, welche beide in A 2 fehlen, durch $\langle>$ die in den nur durch je eine Hs. beglanbigten Theilen irrthümlich von A 1 oder A 2 ausgelassenen Stellen. Die Foliozahlen am Rande sind die der Hs. A 1.

*INCIPIT ${ }^{a}$ ) VITA SANCTI IOHANNES ${ }^{\prime)}$ MONACHI ET *f. 151 . ABBATIS $^{c}$ ).

Anno centesimo post explicionem numeri sancti Victori episcopi, ciclum recapitulantem, anno tercio regni domni Clotharii regis indolis, ex iusso ipsius principes vel genetricę suae praecęlse domne Baltilde regine cum ad orbem d) (abalonnensem ${ }^{\theta}$ ) noni mensis se- 659 Nov secunda ebdomada Ionas abbas per Riomao sancti Iohannis monasterio preteriens, paucis diebus inibi pro labore itineris quievit. Cumque victus precibus fratrum ipsius coenubii, ut qui per discipulus memorati confessoris Christi vel posteris eorum veraciter conperta erant de actuale vita hac spiritale contemplatione, articulo dicendi convertit, praedictus Ionas Hunnane abbati inquid.

PRAEFATIO VITAE BEATI IOANNES PRESBYTERT ET ABBATIS.

Pre[cel]lentissime sanctorum prosequentes exempla, que luce clarius urbem tam in sermone docendum quam exemplum monstrando inluminavere, prorsus declarare adque 〈omnibus ${ }^{f}$ ) patefacere〉 om.e studio *homneque conato, cum conperta fuerint, debemus, ut *f. 151: scilicet [tam men]tis [homi]num cael[esti desi]derii innexas, quam

a) prologum et laterculum capitulorum om. A2.

c) QUOD EST (spatio relicto) add. A 1.

c) mitteretur add. cod. Sinemur. textus $C$ m. s. $X V$.

b) $\mathrm{IO} \overline{\mathrm{H}}: \mathrm{E} A 1$.

d) pr. m. corr. urbem $A 1$.

f) ita $C$; o. p. om. A 1 . 
[etiam sim]plicium animos honinibus $\mathrm{p}[\mathrm{rofani}] \mathrm{s}^{\mathrm{a}}$ ) [ad vita]m pro[vocenus aeternam], [ut ${ }^{b}$ ) dum] prae[cede]ntium p[rae]s[ulum, monachorum $\left.\left.{ }^{c}\right)\right]$ adque patrum [labores atque studia cont]ricio[num mortificationu]m[que exem]pl[a] [trucina]nd[o mentis intentione pensamus, in eorum imitationem tam nostra corda quam aliorum mentes erigimus], qu[atinus et doctrinae solamina] et [laborum supplimenta, Christo] f「avente, studeamus subire. Nec inmerito eorum virtutes ac gesta religiosa christiana laude fulciunt]ur, [qui uno spiritu diversitate virtutum florentes, diversis quoque donorum] mu[n]e[ri]b[us adornantur Job 68,8 iuxta i]llu[d] Isa[iae dictum: Qui sunt isti, qu7i ut nubes vo[lant et quasi columbae a]d fenest/ra/s s[ua7s? $\mathrm{N}$ [nlli quippe dubiu]m [est], iuxta quod [va]s [electionis sup]plimentum dono[rum] sp[iritaliu]m, S[piritus] sancti tu]ba canente [ac de]monstr[an]te formam, p[ate]fecit, $\left.\mathrm{et}^{\mathrm{d}}\right), \mathrm{d}$ [um silnguli in singulis ex [conditor]is [la]rgicione pro mer[it]is dona capi[endo] famul[a]tum $\operatorname{div}[\mathrm{i}] \mathrm{ni}$ n[om]inis exer[ce]nt, [cu]mulum post recipiant meritorum. EXPLICIT.

\section{[INC]IPI[UNT CAP]ITULA.}

1. De orto et conversione ${ }^{\circ}$ [e]ius.

2. De in[tro]itu he[re]mi et coenubii sit[u] ${ }^{f}$ ) ac serpentem mortua.

3. De [concur]so fra[tr]urn religiosorum et progresso itiueris, ad* cul. 2. que processum *ad $\mathrm{s}$ [uum] p[erferebat c]oe[n]ubium.

4. Qualiter sub [dici]one abbatis Lerine[n]si[um] s[e]s[e] oboedi[en]do [co]utulit adque pat[riam a $] g[$ nitu]s [iubetur] rep[edire].

5. De re[gres]su $\mathrm{g}$ ) [eius et Filoneris soda]lis su[ffragio].

6. $\mathrm{D}[\mathrm{e}$ visita]tione matris et conte[m]ptu [oblectationis ma $]$ terui desiderii.

7. D[e] f[urto] r[eperto] s[ecur]u[mi].

8. D[e pauperem seminu ]dum [in]ventum.

9. Dé cont[emptu] Agr[e]st[i et pe Jnitudine e[ius].

[10.] De [s]pretoh) [gerulo] ad Cla[rum] der[ec]to.

[11. Qua]l[iter famulus] d[em]one ....... et s[anitati ... $\ldots \ldots \ldots$. . . redit]ur.

[12.] De [restitutione] lingu[ae]') cuiusdam.

[13.] D[e faris munere a Deo mult]iplicato.

a) itc conieci; h. pr. om. C. b) ita $C$; evanuisse videtur $Q u$. . (quas vel quam) A 1. c) a. p. m. C. d) ita $A 1$; ut $C$ (Mett.); quin Boll. ') conversatione $C$. f) et constructione monasterii $C$. g) regressione $C . \quad$ h) litterarum add. C. i) suppleas obsidetur. k) suppleas per virum Dei. l) \& add. sed exp. (?) $A 1$. 
$\left.[14 . \mathrm{D}] \mathrm{e} \ldots \ldots \mathrm{e}^{\mathrm{a}}\right) \mathrm{S}[\mathrm{egoni}], \ldots \ldots \ldots$. . . b) clam $[\mathrm{ec}]-$ lesia $[\mathrm{m}$ introii $] \mathrm{t}, \mathbf{r} \ldots \ldots \ldots$. $)$.

$[15.] \mathrm{D}[\mathrm{e}] \ldots \ldots \ldots \ldots \ldots[\mathrm{e}] \mathrm{\ldots log}[\mathrm{iaru}] \mathrm{\ldots}[\mathrm{mun}] \operatorname{er}[\mathrm{e}] \ldots \ldots$ g . . . . . . . . . . . [Io]h[anni]s [sanato].

[16.] De C[la]udio [monach]o, qui [ce]lus ap[ertu]s vidi[t].

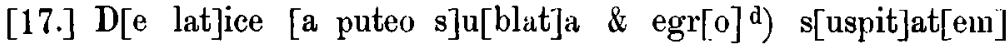
$r[$ edito].

18. $\mathrm{D}[\mathrm{e}$ visitatio $]$ ne $\mathrm{r}[\mathrm{egum}$ a]dque $[\mathrm{n}] \mathrm{ob}[\mathrm{i}] \mathrm{liu}[\mathrm{m}$ ad virum Domini] ve[nientiujm adque [ad moni]t[io]ne et [exho]r[ta]tion[e] sub[iector]um . . . . . . . . . . .

19. $\mathrm{D}[\mathrm{e}]$ sanctissi[mi viri obitu] ..... hac [de praelatione Silve $] \operatorname{str}[\mathrm{i}$ abb. $]$ ac $\mathrm{u} \ldots \ldots \ldots \ldots \ldots \ldots \ldots \ldots$ $\ldots \ldots$ tione . . . . ri . . . . . . . . latione.

\section{[E]XP[LIC]IUNT CAPITULA.}

\section{VITA SANCTI IOHANNIS MONACHI ET ABBATIS e).}

1. ') Igitur') venerandi viri cultuque religionis imitandi beati Iohannis monachi atquely) abbatis vitam memorie commendando i) stilo patefacere nitimur, quae ${ }^{k}$ ) et quanta sui laboris studuit subire certamina et nostris egregial) exempla monstrando'II) memoriam dimiserit seculis, ut non solum ille suis") laboris fructus ${ }^{0}$ ) reciperet, verum etiam quosque ${ }^{p}$ ) ad imitacionem sui certaminis in postmodum traheret, doceat q) post gloriosos triumphos ${ }^{r}$ ) et peccatorum medicinam et eternes) vite premia ${ }^{t}$ capere sublimenta. Ab ipso ${ }^{u}$ ) ergo primordio, quibus parentibus vel in quo loco exortus fuerat, sunt prosequenda v). Hortus w) venerandus cultus ${ }^{x}$ ) Iohaunes infra terminos Ternoderensis ${ }^{1}$ ) castri, qui locus in $\left.{ }^{y}\right)$ suburbano Lingonice urbis situs est, villa que vocatur Quartamiacum ${ }^{z}$ ) super fluvium Bridenam ${ }^{2}$ ). Parentibus non ignobiliz ${ }^{z}$ ) procreatus,

a) erat fortasse visitatione.

b) sippleas et qualiter.

c) suppleas revelatione. d) \&gro, expunct. $t$

(?) $A 1$.

e) QUOD EST ald. $A l$; maescr.: (ap. 32. Incipit vita sincti ac beatissimi Iohannis monachi atque abbatis, cuius transitus observatur $5^{\text {to }} \mathrm{Kl}$. Jebroarii praescr. A $2 . \quad$ ) numeri desunt $A \%$; ad laterculum supplevi. g) Igitur - ferre cepit (1. 416,1) om. $A 1$, follo exciso. $\quad$ b) ita $C$; abb. atque $A \& . \quad$ i) ita $A \&$ cum $V$. Trenerii; commendandaun $C . \quad$ k) scilicet add. $C . \quad$ l) per ald. $A 2$; om. $C$ et $V$. Trev. m) ita $C^{\prime}$; monstranda ac memoranda $A 2$; monstranda temporibus memoriam V. Trev. $\quad$ ") itu $A 2 . \quad$ ") fructum $C$ cum $V$. Trev. p) quousque $A \&$. q) ita V. Tren.; Docet ergo post $A \%$; qui iure eius gl. $C . \quad$ r) venerantes et imitantes ald. $C . \quad$ s) vitae aeternae (pr. om.) caperent $(. \quad$ t) praemii $V$. Trev. u) Ab ipsis e. primordiis $V$. Trev. v) ita $V$. Trev.; persequenda A 2. $\quad$ w) namque est add. $A$ \&.; igitur add. $\mathrm{V}$. Trev. $\quad x_{\text {) }}$ cultus (?) corr. cultu $A 2$; venerandi cultusque $V$. Trev. y) itu V. Them.; in suburbio $A 2$; sub teritorio $B$. $C$. x) itu A. 2 .

1) Hodie Tonnerre. $\quad$ 2) Sine dubio Brenne, affluens Armençon fl. 
patre Hilario $^{a}$ ), matre Quieta nomine, quorum animos cultus religionis cathenatos atque sub omui devocione christiani timoris innexos ${ }^{b}$ ) tenebat. Quique c) etiam inter ipsa primordie d) rudimenta tam in puericia quan in adolescentia sub christiani vigoris cultu atque religionis a parentibus alitus est atque uutritus.

2. Cumque circiter 20 esset annorum, cepit animo alciora atque solito artiora querere, ut, relicto natali solo, quo potissimum animi ostenderet affectum, et vitam ageret gloriosam ${ }^{e}$ ) et cultu religionis sub omni intentione mentem erudiret. Dedit tamen operam, ut eo in luco, ubit) ortus fuerat, perparvum oratorium fundaret, ut, dum anxia cordis vota, Christo annuente, pensando patraret, orationis solamina atque religionis, quomodo posset, occultum impleret. Sed, dum mens devota Deo nec a s) parentibus nec a familia quereret famulatum ${ }^{1}$ ) vel plebis non ferret pressuram, elegit, ut ereni, quo se locus dabat, secreta expeteret. Agebat enim hoc eo tempore, quo Gallias sub imperii iure Iohannes consul regebat. Itaque $\mathrm{i}$ ) cum quadam die ad basilicam, nisarum solempnia auditurus, pergeret, - erat enim beati Iohannis baptiste venerandak ${ }^{k}$ sollempnitas, - audita euvangelica lectione et deLue. 1,80. ducta serie, finem eius desiderii igne penetrans, quo ait: I'uer autem crescebat et confortabatur in spiritu et erat in deserto usque ad diem ostensionis sue ad Isruel, ac deinceps cum alia vice audisset, quod beatus cf. Mure. 1,20. Iohannes euvangelista reliquisset patren Zebedeum cum navi et absque ulla ambiguitate Christum secutus fuisset, intrepidus mentisque ardore et celesti desiderio accensus, relinquens patrem et matrem solumque natale, saltum, qui inter duos fluvios, id est inter Hornentionem ${ }^{1}$ ) et Sidenam situs est, qui a Sinemuro²) castro septem milibus abest, introiit. Repertoque loco, in quo tyro Christi habitaret, et celestis milicie fulgentem ensem baiulans, quo ostem adversarium bellando repelleret, ovans resedit]) ibi. Ubi etiam erat puteus, in quo serpens inter deserta positus habitabat. Quo comperto, cum sodalibus ad in) puteum venit, Deoque oratione peracta, puteum ") quo poterat modo de industria inquietavit ac deinceps serpentem nocivum mortuum repperit. Abiectoque eo procul a loco, ibique quantisper ${ }^{0}$ ) moratus, cenobii ${ }^{3}$ ) locum construxit et sanctorum patrum exemplo sub regule tenore,

a) Ylazio $A 2 . \quad$ b) ita $B$. $C$; innexas $A 2$. A2. $\quad$ ) gloriam $A 2$. f) 1 . mortus $A 2$. mulatum famulatum, expuncto altero fam. $A \mathcal{Z}$.

$A 2$, corr. l) recedit $A 2$. m) apud teum $A 2$. scripsi; aliquantisper commoratus $A 2$.

1) Armançon et Serain fl., Ormentio saec. $X$ et Sedena a. 867 vocati ; ef. Quantin, ,Dictionn. du dép. de l'Yonne' p. 4. 123. Utriusque hoc loco prima mentio fit.

2) Hodie Semur-en-Auxois (dép. Côte-d' Or).

s) Moutiers St. Jeau circa 7 milia a Semur castro abest. 
quam custodiendo proficerent, subiectam plebem constituit et, ut precedencium monachorum studia imitando prosequerentur et celestis antidoti pocula prebendo, quo peccatorum sanies pelleretur, omni nisu adortatus est.

3. Et cum iam passim viri Dei fama cresceret ${ }^{1}$ ), cepit undique plebs concurrere atque eum suis famulatibus honorare. Crescente ergo ibi monachorum caterva, cepit anxio cordis stimulo pensare, quid melius foret quidqne salubrius mercedis cumulo obveniret, si plebi dominando preesset aut subiectus aliis obediendo sub obtentu ${ }^{a}$ ) religionis proficeret. Fuit tandem consilii ${ }^{b}$ ), melius esse sub vinculo mortificationis se c) subdere, quam aliis imperando dominari ${ }^{d}$ ). Et cum presertim ipse, infra monasteriorum septa positus, regularis macherie ${ }^{e}$ ) normam atque precedencium patrum disciplinam sub obediencie rigore nequaquam didicerit, sed tantummodo quod lectio vel fama religionis vel cordi inseruerit vel auri advexerit f), postposita percunctatione $s$ ) atque omni ambiguitate, cepit querere arma, quibus possit subiecta membra tueri: clipeum, quo diabolicam artem vitaret, galea, qua fidei caput inlesum ef. Eph. 6, servaret, muchronem h), quo mundiales errores coerceret, impinget ${ }^{\mathrm{i}}$ ).

4. Tandem religiosorum mores perquirens, ad Lirinense monasterium pervenit, ubi tunc venerabilis Honorati religionis forma plures instruebat et regularis discipline normam tenere eos commonebatk). Cum ergo duorum tantummodo sodalium comitatione ibi pervenisset, submotu omnis honoris et cultui, humilitati ${ }^{1}$ ) atque obediencie subiectus, ultimum se omnibus obediencie iugum ferendo adaptavit ${ }^{m}$ ). Et cum iam per circulum anni ${ }^{n}$ ) sexque menses sub omni humilitatis cultu ultimus obediencie rigorem ferret, venit quidam ad prefatum ${ }^{\circ}$ ) Lirinense cenobium. Cumque singulos monachorum in operis necessarii usus cerneret laborare, vidit $p$ ) inter ceteros venerabilem virum Iohannem. Quem diu contenplatus ac de industria nomen eius inquirens, cognoscit, quis esset, omnibusque patefaciens, ad eius vestigia prostratus, inquid: ,Noune hic est venerabilis Iohanues monachus, qui praelationem q) honorum fugiens, ad hoc ${ }^{\mathrm{r}}$ ) loca pervenit? Cumque qui aderant inquirerent, quid dicere vellet, ille omnia ex ordines) depromit, quali $r$ se rei veritas habeat. Sicque agnitus, tam a senioribus quam a fratrum cetu debite venerationi est habitus. Quo com-

a) ita B. C.: cultu A 2: sub obtentu relegionis etiam infra c. 12. b) ita B. C.; consilium ut melius esset se sub $A 2 . \quad$ c) ita $B$. C.; m. subcedere $A 2 . \quad$ d) dñi'ari $A 2 . \quad$ e) $i . e$ materiae. f) avexerit $A 2$. g) percuctatione $A 2 . \quad$ h) nuchronem $A 2 . \quad$ i) ita $A 2 . \quad$ k) commanebat $A 2 . \quad$ 1) humilitatis $A 2 . \quad$ m) adoptavit $A 2 . \quad$ n) inni $A 2 . \quad$ o) prefactum $A 2$, corr. $\quad$ p) venit $A 2 . \quad$ 9) ita $B . C$; sublimitatem $A 2$. r) ita $A 2 . \quad$ s) exordinet $A 2$.

1) V. Columbani c. 18: croverat iam passim fana sancti viri. 
${ }^{*}$ f. 1 2. perto, Lingonice a) urbis Gregorius pontifex egre ${ }^{a}$ ) ferre cepit, *utb) subiecta sibic) plebi solamina ${ }^{d}$ ) perderite), direxitque absque dilatione ) $e^{g}$ ) eius coenubii septa virus cum epistularum ${ }^{h}$ ) subplimentum : unam ad eum qui praeerat adque ${ }^{i}$ ) subiecta sibi plebe ${ }^{k}$ ), eius redito contrarii ne ${ }^{1}$ ) essent, nam ${ }^{n}$ ) damno ${ }^{n}$ ) communi particeps forent; aliam propriae ${ }^{0}$ ) ad virum venerabilem Iohannem, reditum postulans. Quod si, opposita dilatione, facere neclexitp), iudicium omnipotentis Dei de damno omisse q) hac derelicta plebes ${ }^{r}$ ) recipere metuerit. Quam causam utrique, tam qui praeerat ob boni sodalis s) amisione, quam etiam venerandus Iohannis ob iudicii inlati penam ${ }^{t}$ ), anxio cordis stimulo ${ }^{t *}$ ) trucinare ceperunt, sed omnium consultu ${ }^{\mathrm{a}}$ ) victus, ad patriam redire iubetur, et ${ }^{v}$ ) neclectam ${ }^{w}$ ) plebis curam aa) denuo ${ }^{\mathrm{bb}}$ ) caelestia ${ }^{\mathrm{cc}}$ ) preconia administrare, ne iudicium damuationis de omisione tantarum animarum adquireretdd), qui propriam perpotire ${ }^{\mathrm{ee}}$ ) cupiebat salutem.

5. fl) Regressus ergo ad praefatum locum, studuit denuo salubria poculagg) sub ${ }^{\text {hh }}$ ) regulare tenore, quam ${ }^{\text {ii) }}$ beatus Macharius ${ }^{\mathrm{kk}}$ ) indedit ${ }^{\mathrm{ll}}$ ), monachis ministrare adque aeducatam in melius plebem ad caelestia gaudia provocare, adnitente ${ }^{m m}$ ) sibi monacho Filomere nonine, omni sanctitate et relegione deditum ${ }^{\mathrm{nn}}$, cuius fultus ${ }^{00}$ ) auxilio, caelestempp) praeconium tam monachis (quan populo aunuensqq), absque delatione conferebat.

6. ${ }^{\mathrm{rr}}$ ) Tum mater experiens desiderabilem adventum venerabilis filii, ad eum venire properatss), ut tam diu aspectum eius a se segregatum tandem ovans cerneret suisque votis aditum aperiret. Areptott)

* :ol. 2. itinere, "ad eum eo in loco, quo vir Dei positus erat, advenit hac ministrorum deposcit uu) affectum, ut agerent, qualiter desideratam diu

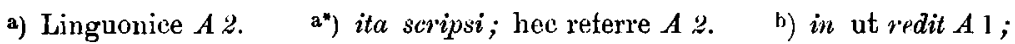
quod $A 2 . \quad$ c) sibi om. $A 1$; subiecte silbi urbis plebs $A \%$ d) magna add. $A 2$. e) perdiderat $A Z$. f) ita $A \&$; dilatacione $A 1$. g) ita $A 1$; ad $A \&$. l) epistolaribus exortationibus u. $A 2 . \quad$ i) pr. nocebio (sic pro cenobio) quod subiecte s. plebi A 2. $\quad$ k) in add. $A 2 . \quad$ l) ita scripsi; inessent $A 1$; essent $A 2 . \quad \mathrm{m}$ ) ne $A 1$; nam et $A 2 . \quad$ n) domno e. $A 1$; dampni communis $A 2 . \quad$ ") propriam $A 2 . \quad$ ) negligerit $A 2 . \quad$ q) admisso $A 2 . \quad$ r) plebe $A z$ s) sodolis $A 1$. t) itu $A 2$; om. A. $1 . \quad \mathrm{t}^{*}$ ) stimu $A . t . \quad$ u) consulti $A .1 . \quad$ v) ut - amministraret $A 2 . \quad$ w) necglecte $A 2 . \quad$ aa) periit $A 1$; recipiens ald. $A 2 . \quad$ bb) de uno $A 2 . \quad$ (c) caelestian pr. $A 1$; celestis patrie prec. $A 2 . \quad$ dd) adqui periit $A 1 . \quad$ (e) ita $A 1$; percipere $A 2 . \quad$ fi) R. V. $A 1$; haec. om. $A 2$. $\mathrm{gg})$ ita $A$ 1.2; $\operatorname{dogmata} B . C . \quad$ lih) ita $A . B$; iuxta regulam q. $A .2 . \quad$ ii) ita $A$ 2. B. $C ; \mathrm{Q} \overline{\mathrm{n}} \mathrm{i} A$. $\mathrm{k \textrm {k }}$ ) Marcharius $A 1$. $\quad$ ll) ita $B$. $C$; (in periit) dedit $A .1$; illis dedit $A \& . \quad \mathrm{mm})$ ita $A$ 1. B. $C$; Annuente $A 2 . \quad \mathrm{nm}$ ita $A$ 1; dedito $B . C$; perdito $A 2 . \quad 0^{\circ}$ ) vix add. sed eras. $A 1 . \quad$ py) celeste $A .2$. 4q) ita $A$ 1. B. C; om. $A 2 . \quad$ rr) om. A 1.2. ss) perperet $A 1 . \quad$ tt) itaque add. A 2. C. $\quad$ uu) depossit $A 1$. 
prolem suis obtutibus a) contemplare ${ }^{b}$ ) meruisset. Hoc $^{c}$ ) ille auditu abnuit, matrisque affectum ut faverit ${ }^{d}$ ), recusavit, reminiscens illud: Qui non reliquerit ${ }^{\mathrm{e}}$ ) patrem aut matrem $\mathrm{f}$ ), non est me dignus. Sed tamen, cf. Matth. ne fidem matris, quamg) in Christi amorem ${ }^{\mathrm{h}}$ ) et timorem inditam noverat, temere ${ }^{\mathrm{i}}$ ) contemnendo violaret, transsiens ${ }^{\mathrm{k}}$ ) antel) aeam, parumper obtutibus eius apparuit, ut et desiderium matris saciaret et vigorem relegionis ob matris blandimenta non molliret. Poposcit'm) per ministros, sese ${ }^{n}$ ) incolumen habendo ad caelestia desideria ${ }^{\circ}$ ) cor locaret hac deinceps numquam sep) visurum in praesentemq) vitam sciret.

7. $\left.{ }^{r}\right)$ Eodem namques) tempore fratrum convenientiat) ad rura purganda ${ }^{u}$, sentiun frutecumque ${ }^{v}$ ) densitate ${ }^{w}$ ) amputanda processerat, $q^{2} 0^{\text {aa }}$ ) ager cultui redditus uberius ${ }^{b b}$ ) deferret fructus. Quocc) cum operis labore ${ }^{c c^{*}}$ ) incumberent, mox a seniore ${ }^{\mathrm{dd}}$ ) vocati, relictis oboediendo in opere securibus, ad coenobium remeantee); peractid ${ }^{f^{\prime}}$ ) oboediencia $\left.g \mathrm{~g}\right)$, modo ad agrum curahh) laborandi redire procurant. Ablatis ii) furto securibus reperiunt atque ${ }^{\mathrm{k}}$ ) neglegentiae damnum patri nuntiandall) properant ${ }^{\mathrm{mm}}$ ). Cumque ille eorum neglegentiam ${ }^{\mathrm{nu}}$ ) aegre ferens, fratribus imperaret ${ }^{\mathrm{oo}}$ ), nt oratione lectioneque incumberent, ipse oratione innexus, Dominum pulsando deposcit, qur huncpp) famulis suis patiatur damnum *inferri. ${ }^{*}$ f. 152 : Moxque; peracta oratione, ad agrum properat et propere quiuq) furti scelus patraverat venirerr) conspicit; festinoque conamivess) ad vestigia beati viri curruit, patrati sceleris reatum denuntiat ${ }^{t}$ ), reformandaque praedeuu) absque dilatione horam $^{v v}$ ) pollicetur. Tum $w^{w}$ ) ille et ${ }^{x}$ ) veniam postulanti et eologias ${ }^{y}$ ) non abnuit tribuere confitenti.

a) obtucibus $A 1 . \quad$ b) contemplari $A \% . \quad$ c) ita $A$ 1. $C$; Quod i. auditus $A 2 . \quad$ d) ita $A 1$; affectui favere rec. $C$; ut agerent qualiter desideratam sibi fari recusavit $A 2, \quad$ e) relinquerit $A 2 . \quad$ f) propter me add. $A 2$ (om. A 1.C). $\quad$ g) ita $A 2 . C . ; \operatorname{cum} A 1 . \quad$ h) honore et timore sibi i. $A 2$; amore et timore fixam $C . \quad$ i) timore, tum sibi inditam iterantur sed del. $A$ 2. $\quad$ k) ita $A$ 1. $C$; 'Iranseuntem $A 2 . \quad$ l) ita $A$ 1. $C$; antē ipsa p. $A 2$. m) dsserit tamen illi per $A 2$; Hortatur namque eam per $C . \quad$ n) se

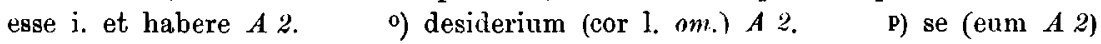
visuram $A 2, C . \quad$ 4) presenti vita se sciret $A \% . \quad$ r) om. $A 2 . \quad$ s) in add. $A 2 . \quad{ }^{\mathrm{t}}$ ) coniventia $A 1$; conveniencia fut ald $A z$ u) et add. $A 2$. v) frutumcumque $A z$ w) densitatem ad imputandam $A 2$. $\quad$ aa) ita $A \psi$; qu ..g...... redd. $A 1 . \quad$ bb) ita $A 2 ;$ uber.s d . ferr ..... us $A 1$. cc) Cumque operis $A 2 . \quad$ cc*) labori $A 2 .^{*} \quad$ dd) seni . . revocati $A 1 . \quad$ e) remaneant $A 2 . \quad$ tr) vero add. $A 2 . \quad$ gg) oboedien: : ciae, ras. di? $A 1$; obedientia predicto modo $A 2$. hh) corroborandum redire $A 2$. ii) Ablatas t. secures $A 2 . \quad \mathrm{kk}$ ) hacque $A 1 . \quad$ li) nunciare $A 2 . \quad$ mm) pperant $A$ 1. $\quad$ nn) negligencie hec referens $A 2 . \quad 00$ ) imperarent $A 2 . \quad$ pp) ac $A 2$. q9) fuisti $a d d$, sed. delet. $A 2 . \quad$ rr) consp. v. $A 2 . \quad$ ss) conamina $A 2 . \quad$ tt) denunciant $A 2 . \quad$ uu) predam $A 2 . \quad$ vv) hora $A 2 . \quad$ ww) 'Tum-confitenti pr. m. in inf. mg. suppl. A 2. $\quad$ x) om. $A 2 . \quad$ y) ologias $A 1$. 
8. ${ }^{a}$. Cumque ${ }^{b}$ ) solito per saltum ${ }^{c}$ ) more adletarum antiquorum oratione et ieiuniis evacaret ${ }^{d}$ ), repperit quondam ${ }^{\mathrm{e}}$ ) pauperem seminu$\operatorname{dum}^{\mathrm{f}}$ ) necessaria alimenta quereres) fructusque ${ }^{\mathrm{b}}$ ), quos saltus gignere solet $^{i}$ ), omni studio ${ }^{k}$ ) investigare, ut carnis famem ${ }^{l}$ ) potuisset ${ }^{m}$ ) cybum superare. Ille inquirens, quid quereret, inlate $n$ ) miseriae oris confessione depromito). At ille: ,Utinam te', inquit, 'sola carnis famis urguerit $p$ ), et non famis p) vel sitisq) anime, que omne sine daper) manet, cruciaret. Aut certe, si ea te pauperies, des) qua Dominus praeciMatth. ธ, 3. wens dixit: Beati pauperes spiritu, quoniam ipsorum est regnum cae-

ib. 6. lorum, et: Beati, que ${ }^{\text {t) }}$ aesuriunt et siciunt iusticiam, quoniam ipsi saturabuntur, possiderit, nulla dapum ${ }^{u}$ ) cupia indigeris. Sed dabo quocumque poterov) modo consilium, ut spem new) praecedas ${ }^{\mathrm{x}}$ ), - multi enim 1's. ${ }^{44,23 .}$ ex inspiratay) temporis ${ }^{z}$ ) usu egvaseruntaa): Pone in Dominob) spem r. $\mathbf{F}_{\mathrm{p}}^{\mathrm{b}}$ 4,28.tuam, et ipse te enutriet, - areptoque ${ }^{\mathrm{cc}}$ ) laboris studio iuxta apostolum ${ }^{\mathrm{dd}}$ ), quod bonum est, ut habias, undeeo) et tuo husuiff) et aegentumgs) prebeas necessaria'. Factoque in ${ }^{\text {lhh}}$ ) pectore eius erncisii) signum, ire ad propriau $^{k \mathrm{k}}$ ) imperat. Ille imperio viri Dei obtemperans ${ }^{11}$ ), tantan co*ool. 2. piam ${ }^{\mathrm{mm}}$ ) laboris suscepit, ut nequaquam deinceps, qui ${ }^{\mathrm{mu}}$ ) necessiria* eranton), defuissent.

9.pp) Quidam etenimqq) vir Agrestius nomine ad praefatum coenubium ad ${ }^{\mathrm{rr}}$ ) missarum solemnia audienda ${ }^{\text {ss}}$ ) desiderio ${ }^{\mathrm{tt}}$ ) actus venerat, et pavimento prostratus, uberis fundens praeces, communemuu) dominum oratione pulsabatrv). Taudem a pavimento elevatus, $\operatorname{ad}^{\mathrm{ww}}$ ) ore beati ${ }^{\mathrm{xx}}$ ) viri missarum solemnia audire cupiens expectabat. Cumque iam hora

a) om. $A 2$.

c) sactum $A 1$.

b) ita A 1. C; Cum autem per saltum m. solito $A 2$. d) ita $A 1$; vacaret $A 2$; exerceretur $C$.

e) quedam $A 2$. f) ita $C$; semi (nudum periit) $A 1$; seminandos ad necessaria $A 2 . \quad$ g) om. $C$. h) fructus quo $A 2 . \quad$ i) et $a d d . A 2 . \quad$ k) ita $A 1 . C$; vestigare studio ut $A 2 . \quad$ l) quo add. $A$ 1., m) postui sed cyloo $A 2 . \quad$ n) illatam (illatc $A$ 2) miseriam $A$ 2.C.

()) deprom ..A 1; deprompsit $A 2 . C$. p) $\operatorname{urg}$. - famis om. $A 2$. 4) non add. $A 2$.

r) ita $A 2 . C$; sineda $p$ manet $A 1$. $\begin{array}{llll}\text { s) periit } A 1 . & \text { t) qui } A 2 . C . & \text { u) dapnum } A 2 . & \text { v) ita } A 2 . C \text {; postero }\end{array}$ $A 1 . \quad$ w) non $A 2 . C . \quad$ x) precedat $A 2$; perdas $C . \quad$ y) insperato $A 2 . C$. z) ita $A$ 1. $C$; tempus usum $A 2$ at ita $A$ 1. $C$; habuerunt $A 2 . \quad$ bb) leo add. $A 1$; om. $A 2 . C . \quad$ cc) arrepto itaque $A 2 . \quad$ du) age add. $A 2$; om.

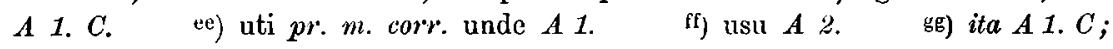
regencium $A 2 . \quad$ hh) (in om.) peccatore $A 1 . \quad$ ii) signo crucis $A 2$. kk) propria $A 2 . \quad$ ll) ita $A$ 1. $C$; obtemperando $A 2 . \quad \mathrm{mm}$ ita $C$; t. piam $A 1$; (t. om.) copiam $A 2 . \quad{ }^{2}$ nin que $A \% . \quad{ }^{\circ}$ ) ita $A 2 . C$; aderint $A 1$. py) om. $A 2 . \quad$ qq) etiam $A z . \quad$ rr) om. $A Z . \quad$ ss) audiendi $A 2$. tt) erio periit $A$ 1. $\quad$ uu) communi $A 2 . \quad$ vv) ita $A 2$; pulsa $A 1$. ww) ad. o. onl. $A 2 . \quad \mathrm{xx}) \mathrm{ti}$ viri perierunt $A 1$; beatus viri $A 2$. 
adesset $^{a}$ ), vir Dei imperat, ut foris eclesia ${ }^{b}$ ) egressi omnes, locum quieti tribuant, qualiter solita ${ }^{c}$ ) solemnia, ut eius mos erat ${ }^{d}$ ), suis consodalibus perageret atque hostias Deo absque populari tumultu offeret. At ille, mutu ${ }^{e}$ ) animo, forisf ${ }^{f}$ progreditur nec subsistere ante fores neque oblationumg) sacramenta patetur expectareh). Tumido cordis intimo ${ }^{i}$ ) domum repedat ${ }^{k}$ ), ibique intempesta ${ }^{l}$ ) nocte stratui ${ }^{m}$ ) obvolutus, vidit venerabilem virum $^{\mathrm{n}}$ ), dextera gemmam ${ }^{0}$ ) eucharistiae ferentem ${ }^{p}$ ), ante stratum adstare eique increpandoq) dicere ${ }^{r}$ ): ,Cerne', inquid, ,Agrestiae ${ }^{\mathrm{s}}$ ), quia, si t) die exsterna ${ }^{\mathrm{u}}$ ) blasphemare distulisses, quamquam corporis ore eocharistiev ) sacramento w) non accepisses, tibi spiritaliter largiretur; nunc vero, quia $\mathrm{x}$ ) blasphemare praesumistiy), spiritaliter tibi denegatur.' Ille ${ }^{z}$ a somno consurgens, noxae aa) suae maculas abluere parat, hac rediens ad virum Dei, veniam postulando ablui culpas inplorat.

10. $\left.{ }^{\mathrm{bb}}\right)$ Subsequente vero tempore quidam ${ }^{\mathrm{cc}}$ ) famulus cuiusdam viri, cuius ${ }^{\mathrm{dd}}$ ) vocabulum erat Clarus, ad beatum virum ob noxam scegleris confugit. Cumque ille studiose reati culpam requireret, repperit noxam rei comnisse, et ${ }^{e e}$ ) veniam petenti misericordiam denegaret $f^{f}$ ). Iubet cuidam, ut apicum seriaemgg) "susciperet, et pro reatum ${ }^{\mathrm{hh}}$ ) miseri $*_{\mathrm{f} .} 153$. homines ad Clarum pergens, et vitam et veniam impetraret. Cumque ii) ergo Clarus oblatam a gerolo epistolam suscepisset, causam rei exquiret $^{k \mathrm{k}}$ ), quid se textus epistole vel gerulus ${ }^{11}$ ) vellit $\mathrm{mm}$ ). llle ${ }^{\mathrm{nn}}$ ) rei causam depromit ${ }^{00}$ ). Cumque Clarus $\mathrm{pp}$ ) nomen audisset, in furore $\mathrm{qq}$ ) versus, beati viri epistolam salibo ${ }^{\mathrm{rr}}$ ) inlitam abiecit, et ferocia redens responsa, gerolum exprevit. Nec ${ }^{\mathrm{ss}}$ ) dilata divinatt) ultio! Orem ${ }^{\mathrm{uu}}$ ) Clari faucisque hitavv) vehemensww) perculit, ut per multa spacia

a) ora eadem esset $A 2 . \quad$ b) ecclesie $A 2 . \quad$ c) q. more solito missarum sollempnia $A 2 . \quad$ d) cum add. $A 2 . \quad$ e) ita $A 2 ; \mathrm{m} .$. tu $A 1 . \quad$ f) foras $A 2$. g) ablationum $A 1$; oblationis $A 2$. l) expectares sed tumida $A 2$. i) intentione $A 2 . \quad$ k) inpedat $p r . m . c o r r$. repedat. $A 1$; repetit $A 2 . \quad$ l) ita $A 2$; intempest...n...A1. m) n. in strata $A 2 . \quad$ n) in add. $A 2$; om. $A 1$. $B . C . \quad$ o) gemma $A 2 . \quad$ p) et add. $A 2 . \quad$ 4) ando periit $A 1 . \quad$ r) re periit $A 1 . \quad$ s) Agresti $A 2 . B . C . \quad$ t) ita $B . C$; quasi $A 1$; qui si $A 2$. u) Domini add. A 2; om. A 1. B. C. v) eocharastiie $A 1 . \quad$ w) ita $A 2$; o periit $A 1 . \quad$ x) ita $A 1 . B . C$; qui $A 2 . \quad$ y) ita $A 1$; praesumpsisti $A 2$. $\begin{array}{lllll}B . C . & \text { 2) vero add. } A 2 . & \text { aa) noxi } A 2 . & \text { bb) om. } A 2 . & \text { ec) in } A 2 .\end{array}$ dd) cui $A 2 . \quad$ ee) ne add. $A 2 . \quad$ if) post. deneg. fortasse \& eras. $A 1$. gg) ita $A 2$; miseriaem $A 1$ hb) reatu $A 2 . \quad$ ii que om. $A 2 . \quad$ kk) et add. $A 2 . \quad$ l) gerusol $A 1 . \quad \mathrm{mm}$ ) velit $A 2 . \quad$ nn) vero add. $A 2$.

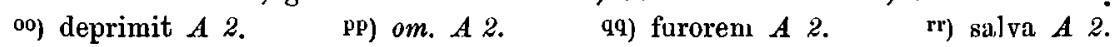
s) sprevit sed non d. $A 2 . \quad$ tt) ita $C$; divina uultio $A 2$; di ultio $A 1$. uu) $\overline{\text { or }}$ $A 1$; os $A 2 . \quad$ vv) om. $A 2 . \quad$ ww) vehementer $A 2$. 
temporum nee panis alimenta nec ${ }^{a}$ ) sacri corporis sacramenta capere possit.

$\left.11 .^{b}\right) \mathrm{Ac}^{\mathrm{c}}$ ) deinceps famulus cuiusdan, cui nomen erat Nicasius ${ }^{d}$ ), qui eo tenpore curam rei publicae administrabate), demones arte obsessus, diversis ${ }^{f}$ ) cruciatibus vellatus ${ }^{g}$ ), ut vix angi catenis crederetur, ad venerabilem virum Iohannem ${ }^{\mathrm{h}}$ ) adductus hac obtutibus ${ }^{\mathrm{i}}$ ) eius oblatus ${ }^{\mathrm{k}}$ ) est. Quem cum intuens vidisset, misertus ${ }^{1}$ ) cruciatui, sese in ${ }^{m}$ ) orationem dedit; pulsaque daemonis pesten), homo reditur sanitatae. Qui post incolomis multo tempore famulatui eius iunctus mansit.

12. ${ }^{\circ}$ Post haec cuiusdam filius astu demonis captus, usu $\mathrm{P}$ ) lingueq) sublatu, queque longeva labiorum vexaverantr) silentia, ad virum Dei deductus eique oblatus s) est. Quem intuens mestus, pro humani generis dispendio et iniqui hostis permisso oratione adque deprecatioue intentionem dedit. Nec dilata diu divine pietatis bonitas: et sui famuli libens praeces suscepit et usum lingue damnato restituit, qui post fratrum coetn t) insertus, sub obtentu relegionis eodem in loco usque ad u) finem permansit.

$*$ เol. 2 .

13. v) Quodam in tempore loca circummanentia "valida famis torrebat ita vehemens, ut nec ${ }^{w}$ ) spes vivendi plerumque ${ }^{x}$ ) foret. Cum$\left.q^{y}{ }^{y}\right)$ ergo ad virum Dei ob alimonia ${ }^{z}$ ) querenda properarent, ille aa) Is. 58,7 . aeuangelicae ${ }^{\mathrm{bb}}$ ) praeconji dictum ante oculos ferens, quo ait: Frange Luc. 6,30 esurienti panem tuum cc) et: Omni petenti tedd) tribue, quosqueee) advenire cerneret, necessariaff) ministrabat. Cumque iann undique egentum gs) plebs crebrius advenirethh), ille adsuetum opus inpendens, omnibus fenerabat. Tum unus e subditisii) ad patrem accedens, ait, sekk) tantis ${ }^{11}$ ) farris cupiem ${ }^{m m}$ ) non habere, quantum ${ }^{\mathrm{nn}}$ ) egentum ${ }^{\mathrm{gg}}$ ) poscebant quohortes. Ille gemens poposcit sibi vas, quem ${ }^{00}$ ) voluissent plenum segregari, unde egentum pr) alimenta preberentur.

a) ita $A 2$; nec ipsius quidem eucharistiae usquam potuit sanctificatio intromitti $C$; nec s. c. s. om. $A 1 . \quad$ b) om. $A 2 . \quad$ c) Item famulus $A 2$. d) Henchasius $A 2 . \quad$ e) ministrabat $A 2 . \quad$ f) que add. $A 2 . \quad$ g) vexaius $A 2$; fortasse recte. $\quad$ h) thom $A$ 1. i) ob ducibus $A 1 . \quad$ k) ablatus $A 1 . \quad$ l) $m$. eins cruciatus $A 2 . \quad$ m) (in om.) orationi $A \mathcal{2}$ n) po-

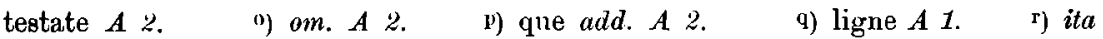

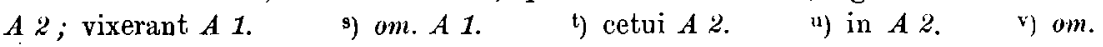
A 1. 2. w) etiam $a d d . A 2$; am. $A$ 1.C. $\quad$ x) plerisque $A 2 . C . \quad$ y) que om. $A$ 2. $C . \quad$ a) alimoniam querendam $A 2 . \quad$ aaj illi $A \&$ bb) euangelii $A 2 . \quad$ ec) om. $A 2 . \quad$ dd) ita $A$ 2. $C$; p. retribue $A 1 . \quad$ ee) quousque $A 2 ;$ quoscumque $C . \quad$ ff) eis add. $A 2 ;$ om. $A 1 . C . \quad$ gg) egencium $A 2 . \quad$ lh) ita $A$ 1. $C$; advenisset $A 2 . \quad$ ii) subditus $A 1 . \quad$ kk) si $A 2$. 11) tantam ferris $A$ 2.C. mm) ita $A$; copiam $A 2 . \quad{ }^{n n}$ ) quantam $A$ 2. $C$. ๑0) quod $A 2 . \quad$ pp) egenis $A 2$. 
Moxque ille obplebere ${ }^{a}$ ) vas, capientem ${ }^{b}$ ) plnsve $^{c}$ ) modia quinquies quina $^{\mathrm{d}}$ ); cetera, que ${ }^{\mathrm{e}}$ ) habuissent, usui fratrum proficerent. Cumque ${ }^{f}$ ) ergo turba aegentum ${ }^{g}$ ) pro alico ${ }^{h}$ ) temporibus spatium ex eo vase alerentur, evenit, ut quidam iuxta morem sibi dare necessaria poscerit. Ille mensuram consuetam dare ${ }^{\mathrm{i}}$ ) iubet egenti. Tum ${ }^{\mathrm{k}}$ ) minister: ,Nequaquam $^{4}$, inquid, , vell) perparvum in vase remansit, sed ${ }^{\mathrm{m}}$ ) totum ${ }^{\mathrm{n}}$ ) imperiis tuis ${ }^{\circ}$ ) pauperibus ${ }^{p}$ ) erogatum'. Quo audito, oculos ad caelum adtollitq), genuque ${ }^{r}$ ) flexo, Largitorem ${ }^{\mathrm{s}}$ ) omnium Dominum ${ }^{\mathrm{t}}$ ) inplorat. Peractaque oratione, ministro $\left.{ }^{u}\right)$ iubet: Vade $^{b}$, inquid, ,cum fidei adminiculo deffer $v$ ) alimenta aegenti $w$ ). Pergens ${ }^{x}$ ) minister, repperit vas plenum, sumptaque mensura, pauperibus tribuit. Deinde patri nuntianda credit, sed ille silendum esse imperat, ne elationis macula cumulum gratiae tollat.

14. ${ }^{y}$ ) Quadam etenim nocte ${ }^{z}$ ) inter densa aa) tenebrarum "ad- *f. 153: veniens vir ${ }^{\text {bb) }}$ renerabilis Segonus ${ }^{(c)}$ ) ad ${ }^{d d}$ ) cellula sua, basilicam ${ }^{\text {ee }}$ ) latenter introivitff), communem $\mathrm{gg}$ ) Dominum orationibus pulsabathh).

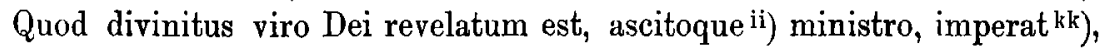
ut concito gradu pergat, tactoque signo, sodales excitet, quia frater $\left\langle\right.$ communis $\left.\left.^{\mathrm{Il}}\right)\right\rangle$ Segonus abditemm) fores ecclesie penetrando ${ }^{\mathrm{nn}}$ ) Dominum orationibus pulsat. Quod ita repertum est, atque de industria venerando ${ }^{\circ 0}$ ) fratri ospitalitatis munus est impletum.

15. pr) Cumque qq) iam Gallias Francorum regis sue dictione ${ }^{\mathrm{rr}}$ ), sublato imperii iure, gubernaculass) ponerent et, postposita rei publice dominatione, propria fruerentur ${ }^{\mathrm{tt}}$ ) potestate, evenit, ut Theudebertus "'iI)

a) implenere $A$ 2.

plus fere modios $C$.

$A$; ceterent que $A 2$.

quod temporis $A$ 2. $C$. b) capiens $A 2$.

d) quinos $C$; ut nos pro q. $A 2$.

f) que om. $A 2 . C$.

i) dari $A 2$.

k) Tunc $A 2$.

c) plus quam modios $A 2$;

m) ita $A$ 1. $C$; et $A 2$.

g) egencium $A 2$.

e) c\&kera que quia $A 2$.

p) est add. A 2. C.

1) ita $A$ 1. C;

o) ita $A$ 2. $C$; om. $A 1$.

) ita $A$ 2. $C$; ut aut pro t. $A 1$. r) ita $C$; genuque flexa (e corr flega) $A 2$; semu que (om. fl., spatio relicto) $A 1$. s) ita $A$ 1. $C$; genitorem $A 2 . \quad$ t) Deum $C$; om. $A 2 . \quad$ u) ita add. $A 2$; om. A 1.C. $\quad$ v) ita $A 2$; $\operatorname{def}$ per $A 1$.

A. 2. C. x vero add. A 2; om. A 1. C.

w) aegentum $A$ 1; egeno

\section{$A 2 . \quad$ aa) densas tenebras $A 2 . \quad$ b) periit $A 1$.}

$A 1$; Sequanus $C . \quad$ dd) a $A 2$.

ec) basilica $A 2$.

y) om. A 1.2.

z) noctem introivit corr. introiit $A 2 . \quad$ gg) ita $C$; Clom]u[ne]m $A$ 1, ubi inde textus periit, frustulis tantum litterarum relictis; et piis pro comm. $A 2 . \quad$ hh) pulsans $C . \quad$ ii) citoque $C . \quad$ kk) ita $C$; impatus ei ut $A 2 . \quad$ ll) ita $C$; om. $A$ 2. $\mathrm{mm}$ ) abscondite $C . \quad \mathrm{nn}$ ) penetrans $C . \quad{ }^{\text {on }}$ ) venerande ne frater $A 2$; venerando famulo Dei $C . \quad$ pp) om. $A 2 . \quad$ qq) ita $A$ 2 cum V. Trev.; p .. a quam (postquam ?) $A$ 1. $\quad$ rr) ita $A 1$; dicioni $A 2 . \quad$ ss) gubernacula $A 2$; | cula $A 1$. th) ita $A 2 \mathrm{cum} \mathrm{V}$. Trev.; dominabantur $C$. uu) ita V. Trev.; Theod. $A 2$. 
filius Teudericia), Clodovei condam filii, bellum Italie inferret $\left.{ }^{b}\right)$, trans539. actis Alpibus, Italiam inquietaret; celerque ${ }^{c}$ ) reversus, demissis ${ }^{\mathrm{d}}$ ) ducibus, quibus ${ }^{\mathrm{e}}$ ) summam bellorum commiseratf), Mumoleno et Bucceleno, ipse ad propriam repedavit. Eo itaque in tempore quidam vir cum quartano inquomodo eger teneretur et pene ultimum anelitum dimissurus expectaretur, germanus eius adg) virum Dei properat, festinans advenit donumque eulogiarum cum premessa ${ }^{b}$ ) ad Dominum oratione adi) egrik) solamina humilil) prece deposcit. Tum ille et orationem atque eulogiarum solemnial) dare non distulit, sed ${ }^{\mathrm{m}}$ ) enim cuivis cum fidei ardore petenti ${ }^{n}$ ) suffragium porrexit: inlatum ${ }^{\circ}$ ) unum paximaciop) cum quinque ponıorum numero egri deferri iussit. Receptum q) munus, celeriter ${ }^{\mathrm{r}}$ ) ad germanum venit; eum ${ }^{\mathrm{s}}$ ) procul positum, adveniente ${ }^{t}$ ) munus eger ${ }^{u}$ ) sensit, hac germanum requirens, dari v) sibi eologiarum munus deposcit. Cumque ille introiens, deportasset, factis tribus particulas w) vinoque infusis ${ }^{x}$ ), egro esurienti ${ }^{y}$ ) administravitit ${ }^{z}$. * col. 2. Cumque ovans cum fidei ardore aa) "eologiarum munus sumpsisset, statim pulsa tabe, sospitatem ${ }^{b b}$ ) recepit.

16. ${ }^{\mathrm{cc}}$ Q Quantaque sublimia mirabiliorum dd) Domini in sanctis ${ }^{\mathrm{ee}}$ ) suis redoleant exempla, sinibus eclesea $\mathrm{ff}$ ) in orbem terrarum diffusa $\mathrm{gg}$ ) personuithh), adque, elucubranti ${ }^{i i}$ ) luce veritatis, fldelibuskk) notum est. Cum eo in tempore ${ }^{I I}$ ) segetis, annuam $\mathrm{mm}$ ) maturitatem confecte, ad praecidendum in supradictum ${ }^{n n}$ ) coenubio fuissent paratae, concio fratrum ad segitem praecidendam catervatim ${ }^{00}$ ) properare studuit $\mathrm{pp}$ ), opusque per totius diei meta qq) peractum ${ }^{\mathrm{rr}}$ ) adventus tetrae noctis ${ }^{\mathrm{ss}}$ ) proi-

a) Teude | $A$ 1; Theoderici $A 2 . \quad$ b) ac ipse add. A 2; om. V. Trev. c) ita $V$. Trev.; i. cumque celeriter inde reversus $A 2 . \quad$ d) demi restat $A$ 1; dimissis d. V. Trev.; dimisso duce $C$; (dem. om.) ducibus $A 2 . \quad$ e) ita $V$. Trev.; cui summam $C$; (q. om.) curam b. A 2. $\quad$ f) ita $C$ cum V. Trev.; comississet $A 2 . \quad$ g) a $A 2 . \quad$ b) ...e essa $A 1$; premissa $A 2 . \quad$ i) . d $A 1$; ob $A 2 . \quad$ k) $\cdot$ gri $A 1$; egris $A 2 . \quad$ l) humili - solemnia om. $A 1$ (habet $A$ 2). m) sed enim $\overline{\mathrm{q}}$ vis [c]um $A$, inde melius conservatus ; et omni nisu cum' $A 2 . \quad$ n) potenti (?) $A$ 1. ${ }^{\circ}$ ) illatoque paxmacio $A 2$.

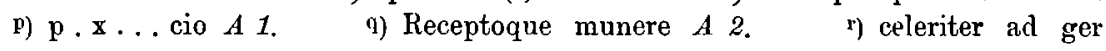
perierunt $A 1 . \quad$ s) eum (eo $A$ 2) procul perierunt $A 1 . \quad$ t) advenietis $A 2$. u) eger sensit perierunt $A 1 . \quad$ v) d. s. perierunt $A 1 . \quad$ w) particulis $A 2$. x) ita $A 2$; fusis $A 1$; vini infusione $C . \quad$ y) ita $A 2$; esuram $A 1$. nistrabat $A 2 . \quad$ aa) om. $A 1 . \quad$ bb) s...itatem $A 1 . \quad$ cc) om. $A$ 1. 2. dd) miraculorum $A 2 . \quad$ ee) ita $A$ 1. $C$; sancto suo $A 2 . \quad$ ff) ecclesie $A 2$. gg) $\mathrm{d}$. fus . $A 1$; diffuse $A 2 . \quad$ hh) periit $A 1 . \quad$ ii) ti luce perierunt $A 1$; lucubranti 1. $A 2$; elucubrata 1. C. $\quad$ kk) ita $C ; \ldots \ldots$ b. A 1 ; f. om. $A 2$. 1) ita $C$; periit $A 1$; t. quo segetis $A 2 . \quad \mathrm{mm}$ ) ita $C$; annu periit $A 1$; messium maturitate confecta $A 2 . \quad{ }^{n}$ ) supradicto cenobio $A 2 . C . \quad$ oo) cathervancium $A 2 . \quad$ pp) ita $A 2$; properare stu ...A 1 ; properavit $C . \quad$ qq) $\mathrm{me}^{-}$ tam $A 2$; metab $C . \quad$ rr) esse add. $A 2$; om. $A$ 1. C. ${ }^{\text {ss }}$ ) $\mid$ ctus $A 1$. 
buit. Cumque omnesa) ad coenobium remeassent, imperio seniorum unus $\mathrm{e}^{\mathrm{b}}$ ) fratibus Claudius nomine ad frugem custodiendam remansit. Quic) cum somno caperet, hac intempestad) nocte evigilans, mentis ardorem ad caelum tolleret iuxta illud: Ego enim ${ }^{\mathrm{e}}$ ) dormio, (ant. 5, ? et cor meum vigilat, coepit cogitare, ne, fessus f) artus, sodalium $\mathrm{g}$ ) membra nimio occubuissent sopore, neglectuque orationis usu, in aurore adventum iustum tramitis usum ${ }^{\mathrm{h}}$ ) deferrent ${ }^{\mathrm{i}}$ ). Cumque hec $^{\mathrm{k}}$ ) anxio cordis animo trucinaret, vidit subito caelos apertos et micantem globum totam ${ }^{1}$ ) lustrare mundum. Moxque, dum mirandi ${ }^{m}$ ) facta mens pavefacta pulsaret ${ }^{n}$ ), alifer gallus solitam ${ }^{0}$ ) vocem adtollens, mundo venturam lucem nuntiavit, signoque tacto, omnis concio") fratrum ad orationem cantosque peragendos ecleseam penetravit. Ovans ille, postquam lux dedeta mundo fuit, patri de industria, quidq) viderit, nuntiavit. Ille, ner) stimulo elacionis corruptus s), mentem pollueret, increpans ait: ,Nequaquam talia tet) vel corde tumido ${ }^{\mathrm{u}}$ ) vidisse praesumas narrare! Quid enim fas ${ }^{\nabla}$ ) est, ut homo subw) fragilitate positus et $\left.{ }^{x}\right)$ contagione" peccatorum $y$ ) maculatus, mereatur caelestia contem- * ${ }^{\text {f. }}$ lă. plare $\left.^{x}\right)$ ?

17.aa) Quidam enimbb) vir cum de Parius ${ }^{c c}$ ) properaedd) ad patriam remearet, percussus ${ }^{e e}$ ) ulcerae pessimo, quod ${ }^{\mathrm{ff}}$ ) passimg ${ }^{\mathrm{gg}}$ ) per Galiae ${ }^{\mathrm{hh}}$ ) finibus dilatatu ${ }^{\mathrm{ii}}$ ), locakk) plurima pollulabat ${ }^{11}$ ), veniensque ad pro- 543. priam, petiit, ut sibi $\mathrm{mm}$ ) de puteo, quem vir ${ }^{\mathrm{nn}}$ ) Dei benedixerat, et inter ${ }^{00}$ ) septa caenubii sui situs $\mathrm{P}$ ) erat, limpa deferretur: moxque ${ }^{q 1}$ ) se fidem haberae ${ }^{\mathrm{rr}}$ ) sospitatem ${ }^{\mathrm{ss}}$ ) recepturum. Dericto ${ }^{\text {tt) }}$ ministro,

a) ita $C$; nobis $A 2$; periit $A 1 . \quad$ b) ex $A 2 . \quad$ c) Qui cum som perierunt $A$ 1; Qui cum somnum $C$; Quem cum sompnus $A 2 . \quad$ d) ita $C$; i. n. perierunt $A 1$; ac per intempestam noctem $A 2 . \quad$ e) om. $A 2$; habet A 1. C. f) f. ssus (artus periit) $A 1$; fessis artibus $A 1$; fessi artus $C$. g) ita $A$ 2. $C$; sadolum $A 1 . \quad$ b) ita $A 2 ; \ldots \operatorname{sum} A 1 . \quad$ i) diff. $A 2 . C$. k) ita $A$ 1. $C$; hanc $A$ 2. $\quad$ 1) totum $A$ 2. C. $\quad$ m) ita.A 1; mirando facto $A 2$; mixandi facti $C . \quad$ n) pulsaretur $A$ 2.C. $\quad$ o) siletiam $A 1 . \quad$ p) conscio $A 2$; periit $A 1 . \quad$ q) ita $C ; \ldots \ldots$ quid viderit $A 1$; quod viderat $A 2$. r) ine stimulus $A 2 . \quad$ s) ita $A$ 1. $C$; corruptam $A 2 . \quad$ t) cernere add. $A 2$; om. A 1.C. $\quad$ u) stumido, exp. s $A 1 . \quad$ v) enim nefas $A 2$; enim num fas $C . \quad$ w) suffrag. $A 2 . \quad$ x) ita $A$ 1. $C$; aut $A 2 . \quad$ y) inde altera manus atramento nigriore $A 1 . \quad$ z) corr. contemplari $A$, et sic $A 2$. a) om. A 1.2. $\quad$ bb) autem $A 2 . \quad$ cc) ita $A 1$; Parisius $A 2 . \quad$ dd) prope $A 2 . \quad$ ee) est add. A $2 . \quad$ ff) Quid $A 2 . \quad$ gg) ita $A 2$; passi simper G. $A$ 1. hb) Gallie fines quid per dilatata $A 2 . \quad$ ii) ita $A 1 . \quad$ kk) atque add. $A 2 . \quad$ li) ita scripsi; poculabat $A 1$; passus fuit. V. $A 2 . \quad$ num et intra cepta cenobii add. $A 2$ (habet ea etiam suo loco). nn) viri $A 2, \quad$ oo) intra cepta utroque loco $A 2 . \quad$ pp) : : tus $A 1 . \quad$ qq) ita $A 2$; Vox quae se $A 1$. r) redixit add. $A 2 . \quad$ ss) se add. $A 2 . \quad$ ti) itaque add. $A 2$. 
laticem cum benedictionem ${ }^{a}$ ) deportat $\left.^{b}\right)$; austaque ${ }^{c}$ ) eger $^{d}$ ), vie) dolorisf) incendii vulnus craebuit, adque suspitatem reditus, vitam post incolomis cum ${ }^{8}$ ) superis ggit.

18.h) Quanto iam onorae hac veneratione regum Francorum adque nobilium fulceretur, enarrare ${ }^{i}$ ) longum est. Inerrat ${ }^{k}$ ) in eum ${ }^{l}$ ), ut opidom) iurae dicam ${ }^{n}$, omnium virtutum flagrantia ${ }^{0}$ ). Corporis castigatio ieiuniis et orationibus aequep) ut iuveniliq) aetate tulerat, eodem ${ }^{r}$ ) modo et senile portabat, exhemplum subditus edocens, ut custrimargiae, id est gule, cenodoxiae, id est aelationes), arogantiae, id est superbiae, viciat) maxime "), per que conpereratv) Adam in paradiso deceptuw ${ }^{w}$, omnimodis ${ }^{\mathrm{x}}$ ) plebem subditam cavere ${ }^{\mathrm{y}}$ ) suadebat, $\mathbf{n e}^{\mathrm{z}}$ ) simili modo, sicut Adam his tribus vitiis delapsusaa) adque adbb) gaudia paradisi segraegatus et deiectus est, simili modo immitatores eius, dum ventris ingluviae gule obediendocc) subcumbunt, dum elationis ${ }^{\mathrm{dd}}$ ) stimolo $0^{\mathrm{ee}}$ ) inbecillitatis animi perturbantur, dum superbiae malum anime Deo decataeff) vulneranturgg), a consorcio ${ }^{\text {hh }}$ ) iustorum abscisi ii) et omni * col. 2. gaudio perpetuae lucis private, eternae ${ }^{\mathrm{kk}}$ ) cruciato damnerentur ${ }^{l l}$ ). "Ipse vero ieiuniis et vigiliis vacans, omnibus inlecebris aelisismm), pullulantibus virtutibus, animi vigore corporis voluptateme prohibuit, ut igniLnc. 12, 49. tum illum ${ }^{\circ 0}$ ) animi desiderium, de quo igne Dominus ait: Ignem veni mittere in terram, quampr) volo, ut ardeat, ut omnium virtutum fructus 9I) adtraheret, hocrr) verbum semper corde et ore proferrens: Ys. 118,20. Concupinit animass) mea desiderare iustificationes tuas in omni tempore,

a) benedictione $A 2 . \quad$ b) et add. $A 2 . \quad$ c) iuxta quod $A z$ d) diserat add. $A 2 . \quad \%$ in $A 1 ; \operatorname{vim} A z . \quad$ d. nec incendia ulceris deinceps non censit, sed sospitati redditus $A 2 . \quad g$ ) inc. suam usque ad finem peregit $A 2$. b) om. A 1.2. i) inar(re $p r . m$. corr. enar|re $A 1 . \quad$ k) enim add. $A 2$; om. A 1. B. $: \quad$ l) eo $A 2 . \quad$ m) ita $A$ 1; opinor $C$; ut o. i.d. am.

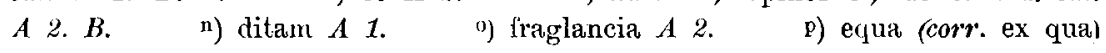
ita ut $A 2 . \quad$ q) ita $A$ 1. B. $C$; in veneralem etatem tolleret $A 2 . \quad$ r) eo m. et s. $B . C$; te eo m. s. $A 2 . \quad$ s) elacionis $A 2 . B . C . \quad$ t) vicie $A 2$. u) maxima $A$ 2.B.C. v) ita A 1.B.C.; perierat $A 2 . \quad$ w) deceptus $A 2$. x) omnibus modis fugerent et plebi sibi subdite $A 2 . \quad$ y) eam add. $A 2$. x) ita $A$ 2. $C$; Me $A 1 . \quad$ aa) dil. $A 2 . \quad$ bb) pr. m. supersce. $A 1$; ad corr. a $C$ (Mett); a gandiis $A 2 . \quad$ cc) obediende $p r . m$. corr. obediendo $A 1$. dd) eletionis $A 1$ ec) stimulatio (corr. stimulo) et inbecillilate $A 2$; stimulo imbecillilate $(: \quad$ if corr. dic. $A 1 . \quad \mathrm{gg})$ et add. $12 . \quad$ hh) ita $A 2 . C$; consorcia $A 1 . \quad$ ii) abscisae et $0 . C$; abscisis omni $A 2 . \quad$ kkj eterno $A 2 . C$. 11) ita $A$ 1; damnentur $A 2$; dampnarentur $C$. $\mathrm{mm}$ ) elicis et p. $A 2$ (non $C$ ). nn) voluntate $A 1$; voluptatem $A 2$; voluptates $C . \quad$ ignitum, illo igne a. $A 2$; ignitus illius ignis amore $C . \quad$ pr) quem $A 2 . \quad$ qq) sibi add. $A$ 2 (om. A 1.C). rr) ita $C$; hoc $A$ 1; hec verba $A 2 . \quad{ }^{\text {sq) }}$ sequitur V. Eugeniae (inde a verbis et iussit eam), versu non interrupto $A 1$. 
et item: Ideo dilexi mandata tua super auro et topazion. Fratresa) ib. 127. cohortans, vultu hilarisb) et letus facie monebatc), dicens: Venite, ${ }^{\text {Ps. 94, 1.2. }}$ exultemus Dominod), iubilemus Deo salutari nostro. Preoccupemus faciem eius in confessione et in psalmis iubilemus ei. Venite, adoremus et procidamus ante Dominum $\left\langle{ }^{\ominus}{ }^{\ominus}\right)$ ploremus ante Deum〉, qui fecit nos, ib. 7 . quia ipse est Dominus Deusf) noster. Operi piissimo corde et corpore vacans, memorabate) sanctum Paulum dixisse, si 〈quisb)〉 non laborasset, panem sine periculo non potuisset sumere. Et requirens instituta sanctorum patrum, inter multas collationes precipue sancti Ysaac abbatisi) doctrinam meditans, pro Christi dilectione se coartavit et crucem domini nostri Iesu Christi non erubuit ${ }^{\mathrm{k}}$ ), sed portavit. Semperl) habens profunde humilitatis inconcussa fundamiua, ab omni Cass. ('oll. lubrice impulsationis ${ }^{m}$ ) incursu animum inhibuit et ita paulatim ex contemplatione divina ac spiritali iutuitu meruit sublimari. Sollicitudin $e^{\mathrm{n}}$ ) rerum carnalium preter certas necessitatis ${ }^{0}$ ) generaliter abscidit et nullius $\mathrm{P}$ ) negocii causaeve $\mathrm{q}$ ) non solum curam, sed nec ${ }^{\mathrm{r}}$ ) memoriam quidems) penitus admisit. Detractionem, vaniloquia seu multiloquia, scurilitatis") pariter amputavit, sciens illud, quod sibi quomodum religionis ordo convexerat, hoc aliis utile fore impleri, quicquid scilicet ipse a pubertinis ${ }^{t}$ ) ad senilem etatem perduxerat. Nec prorsus, quamvis fesis ${ }^{u}$ ) artibus, paciebatur finiriv) psallentium quod cunctis in communew), vocis tuba civitate canente atque salutifera Domini precepta personante, proficeret in augmentum.

19. ${ }^{x}$ ) Obiit ergo ${ }^{y}$ ) circiter 120 annos $\left.^{z}\right)$, 5. Kalendas Febroarias, plenus etate corporis et decore religionis. $\mathrm{Nec}$ aa) oculis caligavit necai) dencium ${ }^{\mathrm{bb}}$ ) dampna sensit, memoriecc) vigorem teuacitatem retinens, etdl), ut in plerisque fieri assoletee), nequaquam etas decrepita, obmisso lar-

a) vero add. A 2; om. C. b) ylaris $A 2 . \quad$ c) ita $C$; manebat eos d. $A 2 . \quad$ d) ex. in dnio $A 2 . \quad$ e) et pl. a. D. om. $A$ 2; habent $C$ it $L X X$. f) deu $A 2 . \quad$ g) memor erat s. P. precepisse $C . \quad$ h) ita $C$; om. $A 2 . \quad$ i) Scithae add. $C . \quad$ k) ita $C$; eribuit $A 2 . \quad$ l) que add. $B . C . \quad$ m) inpul-

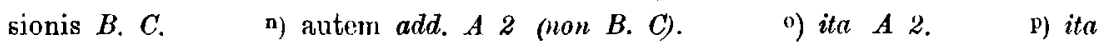
B. C cum Cass.; ullins $A 2 . \quad$ q) ita $B . C$ cum Cass.; n. secularis se non A 2. $\quad$ r) ita $B . C$; ne Cass.; etiam $A 2 . \quad$ s) ita $B . C$ cum Cass.; quid

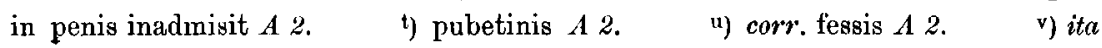
scripsi; fieri. silencium $A 2 . \quad$ w) coe m. al. corr.cōe $A 2 . \quad$ x) om. $A 2$. y) beatus lohannes abbas habens add. $A$ 2; om. $C . \quad$ z) annorum $B . C$. aa) non B. C. bb) damna dentium B. C. $\quad$ cc) ita $C$ (Mett.); memoriam nativitatis ret. $A 2 . \quad$ dd) om. $A 2 . \quad$ ce) solet $B . C$. 
gitatis usu, avaricie umquam subcumbuit, sed omnia a) bona, quibus etas iuvenilis succubuerat ${ }^{b}$ ), eque et senectus pollebat $c$ ). Sepultusque est aut procul a cenobio infra terminos monasterii, loco quem ipse predixerat. Suffectusque est in loco eius abbas Silvester nomine, quem $^{d}$ ) ipse antea vivens fratrum cetui ${ }^{\circ}$ ) preesse preciperat, qui et religionis formam $f$ ) et regule tenoremg) per vestigia magistri gradiens, longevo floruit tempore. Post quem in supradicto cenobio Mumuliuus ex iussu venerabilis viri Silvestri curam regiminis suscepit. Qui ${ }_{579 \mid 80 .}$ post Lingonice ecclesie pontifex electus, in loco suo Leubardinum cum consensu fratrum abbatem prefecit, qui sepulerum, ubi reliquie sancti corporis beati Iohannis condite erant, in loco in quo nunc est mutavit.

20. ${ }^{\text {h) }}$ Nec absurdum videtur huic operi inserere, que tunc in ea sunt acta commutatione. Nam cum sepulcrum illud a loco. in quo positum erat, avellere ac comutare voluissent, $\left\langle\right.$ et ${ }^{\mathrm{i}}$ ) sublata humo undique, nequaquam tamen sarcofagum movere possent $\rangle$, triduani ieiunii subire laborem consilium fuit. $\mathrm{Cum}^{\mathrm{k}}$ ) iam tercial) dies $\mathrm{a}^{\mathrm{m}}$ ) ieiunio Sept. 22. illuxit, - erat enim 10. Kals. ${ }^{n}$ ) Octobris, in quo die veneranda festivitas beati Mauricii martiris cum sociis suis mundo clara nitescito), - et fessa iam ieiunio membra post matutinosp) cantus rursum in sopore quiescerent $q$ ), quidain senex ecclesiam (introiens ${ }^{r}$ ), cernit beatos senes $>$, sibiques) videbatur Iohannem et Silvestrum ante sepulcrum adstare ${ }^{t}$ ) atque his qui cum eis inerantu), albis vestitiv) stolis, imperare, ut sepulcrum noverentw) ac in locum, ubi nunc est situm, promoveriut. Cumque ille audaci animo cerneret, quid ageretur, a Iohanne, ut ipse arbitrabatur, increpatus est: ,Cur', inquid, , ausus ${ }^{\mathrm{x}}$ ) ecclesiam introistis)? Sedz) quia simplici corde tuum cognovi introitum, vade;, inquid, ,et concito gradu, tam Leubardinoaa) quam sodalibus excitatis, ceptum opus cito peragant'. Festinus ille $a^{\mathrm{bb}}$ ) Leubardinum abbatem cucurrit ac rei geste causam depromitcc). Ille cum suis ovans

a) omnibus rebus bonis $B . C$.

b) ita B. C; cumbere solet $A 2$.

c) $i t a$

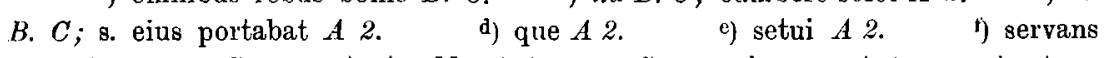
ald. $A 2 ;$ om. $C$.

g) et add. $42 ;$; $\mathrm{m} . C$.

h) om. $A 2$.

i) et jossent om. A 2; ex $C$ inserui. k) Cum enim iam $A 2$; Cumque iam $C$. 1) tercius $C . \quad$ m) d. ieiunii illuxisset $C . \quad$ ") Decembris add., sed delet.

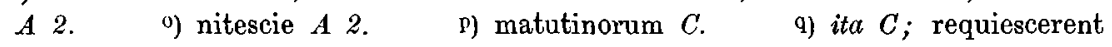
$A 2 . \quad$ r) ita $C$; introiens - senes om. $A 2 . \quad$ s) ut sibi $C . \quad$ t) qui ei in regimine loci successerat $a d d . C . \quad$ u) erant $C . \quad$ v) vestitis $C$ (Mett.). w) moventes in locum perducerent destinatum $C . \quad$ x) es add. $C . \quad$ y) introire $C . \quad$ a) $p r . m$. superscr. $A 2$. aa) Leopardinum quam sodales excitato, ut c. C. $\quad$ bb) ita $A 2 . \quad$ cc) deprompsit $C$. 
surrexit, ac ${ }^{a}$ ) agnitab) voluntate ${ }^{c}$ ) atque permissione ${ }^{d}$ ) proprie devocionis, surgentes atque ${ }^{e}$ ) sepulcrum amoventes, $\mathrm{eo}^{\mathfrak{f}}$ ) in loco, ubi nunc est, comutarunt, ubis) et sanctum altarium cum consilio episcoporum struxerunt $^{\text {h), quoi) (hristi hostiae litantur, atque orationum }}{ }^{\mathrm{k}}$ ) officia persolvuntur, ubi etl) remedia egris, cuiusque ${ }^{\mathrm{m}}$ ) votis solamina beneficiorum adcomodantur $^{\mathrm{n}}$ ), cui est honor et gloria in seculorum secula. Amen.

\section{Die ältere V. Vedastis u. die Taufe Chlodovechs.}

Ein Hauptmerkmal für die Beurtheilung der fränkischen Heiligenleben bildet die Sprache. Im Allgemeinen pflegt man heute aus barbarischem Latein auf höheres Alter zu schliessen und besseres als ein Zeichen späterer Fntstehung anzusehen. Es ist aber dies natürlich nur eine sehr oberflächliche Unterscheidung, denn wie man in der merowingischen Periode auch gebildetes Latein geschrieben hat, so in der karolingischen auch rohes. Die höhere Stilgattung, die hauptsächlich auf dem Gebiete der Epistolographie zur Anwendung kam, ging im 6. Jahrh. mit der alten Cultur unter. Die niedere aber hat sich, nachdem sie in der Zeit vom 6. bis zur Mitte des 8. Jahrh. die mannigfachsten Entwickelungen durchgemauht hatte, besonders in den romanischen Landestheilen bis tief in die Regierungszeit Karls d. Gr. hineingeschleppt. Es ist indessen ein gewaltiger Untersehied zwischen der Barbarei des 6. u. 7. und derjenigen des 8. Jahrh. Die Fehler Gregors und Fredegars sind sprachgeschichtlich begründet; beider Schriften repräsentiren nur verschiedene Stadien einer stetigen Weiterbildung der niederen gallischen Schriftsprache. Die natürliche Degenerirung findet etwa um die Mitte des 7. Jahrh. ihren Abschluss. Seit dieser Zeit entwickelt sich unter dem Einfluss der irischen Klöster und besonders der Schriften des Jonas aus der älteren Schriftsprache ein künstliches Product, das allmälich jede Fühlung mit der gesprochenen Sprache verlor. In grammatischer Beziehung hebt sich zwar die Schriftsprache etwas, es treten aber neben noch nicht abgethanenen alten Fehlern jetzt neue auf in Folge oberfächlicher Einprägung des Gedächtnissstoffes der todten Sprache. Die Schriften aus der Mitte des 8. Jahrh. sind

a) et $C . \quad$ b) agni eius v. $A$ 2. c) sancti viri $a d d . C . \quad$ d) permissu $C . \quad$ e) et $C . \quad$ f) in locum destinatu millud comm. $C . \quad$ g) ita $C$; et ad s. $A 2 . \quad$ h) ita $C$; est (Christum $a d d$., sed delet.) situm $A 2 . \quad$ i) ita $C$; ubi christicole letantur $A 2 . \quad$ k) ita $C$; orationis officio funguntur $A 2$. l) ita $C$; etiam $A 2 . \quad$ m) quorumque $C$; cecisque vota solempnia $A 2$. n) attribuuntur $C$. 
sprachlich fehlerhaft, wie die Gregors von Tours, und doch in ihrer Barbarei himmelweit von ihm verschieden.

Auch bei der kleinen Schrift über das Leben des h. Vedastes sind Uubeholfenheit und Fehlerhaftigkeit der Sprache, verbunden mit einer gewissen Natürlichkeit der Erzählung, für Kriterien eines sehr hohen Alters angesehen worden. Die richtige Beurtheilung dieser Quelle ist für die Geschichtsforschung nicht ohne Bedeutung. Sie enthält nämlich über Chlodovechs Feldzug gegen die Alamannen einen ausführlichen Bericht, der die neueren Darstellungen nicht unwesentlich beeinflusst hat. ZuJetzt hat die Vita kritisch untersucht, auch eiven Abdruck der alten Hs. in Montpellier veranstaltet v. Schubert1). Er glaubte, sie sei etwa 580 von einem Cleriker der Diöcese Arras verfasst worden. Eine neuere Spezialarbeit Arbellot's ${ }^{2}$ ) beschäftigt sich hauptsächlich mit der Streitfrage ïber den Geburtsort des Heiligen; die Ausgabe der Vita, welche dieser Schrift angehängt ist, ist ganz unkritisch und werthlos.

In der Darstellung der Alamannenschlacht stimmt die Vita im Allgemeinen mit Gregor überein. Chlodovech sieht die gänzliche Aufreibung (,ad internicione') seines Heeres und betet mit zum Himmel gerichteten Augen (,oculusque ad caelum elevatus') zu dem Gott, den seine Gemahlin Chlothilde (,quem Chlodchildis') bekennt, dass er ihm den Sieg über die Feinde verleihe; er wolle dann selbst an ihn glauben und ihn anbeten. Nach diesem Gebete fliehen (,terga vertere') die Feinde und überlassen Chlodovech den Sieg. Der Sieger nimmt die Alamannen mit ihrem Könige (,cum rege) in seine Botmässigkeit (,dicio') auf und kehrt in sein Vaterland zurück.

In beiden Quellen ist nicht bloss der Gedankengang ganz derselbe, die'Vita hat auch zum Ueberfluss noch alle die Ausdrïcke mit Gregor gemein, die ich in Klammern beigefügt habe. In einem Punct differirt sie aber von Gregor. Nach ihm fällt nämlich der Alamannenkönig, während er sich nach der Vita dem Chlodovech unterwirft:

$$
\text { Greg. h. Er. II } 30 .
$$

,Cumque regem summ cernirent interemptum, Chlodovechi se ditiobus subdunts.

\section{Vedastis}

,Victor deinde Alamannos cum rege in dicionem coepits.

1) Die Unterwerfung der Alamannen unter die K'ranken. Strassburg 1884 (Dissert.) S. 152-169 und 203-222.

2) „Dissertation sur le lieu de naissance de Saint Vaast suivie de l' ancienne vie du saint. * Paris 1886. 
Hier hat aber offenbar der Biograph durch flüchtige Benutzung geirrt und, indem er bei Gregor die Worte ,cernirent interemptum, übersah, nun ,cum' für die Präposition gehalten.

v. Schubert gibt für die Uebereinstimmung der beiden Schriften eine unbefriedigende Erklärung ${ }^{1}$ ). Die Annahme gemeinschaftlicher Benutzung einer Lokaltradition der Vedasteskirche zu Rilly an der Aisne durch die Vita und durch eine poetische Vorlage Gregors beruht auf zwei hypothetischen Factoren, erklärt nicht die wörtlichen Uebereinstimmungen und ist auch an sich ganz unwahrscheinlich, denn des Frankenkönigs Anrede an den Christengott, welche die Vita ebenfalls reproducirt, ist das eigenste Product Gregors, von ihm selbst erdacht und stilisirt, wie die meisten andern Reden in seinen Schriften, und natïrlich auch von gauz demselben Werthe, wie diese.

Dass man das richtige Verhältniss zwischen den beiden Quellen verkannt hat, daran trägt ein selbständiger Zusatz des Biographen Schuld, dem man grösseren Glauben beigemessen hat, als er verdiente. Nachdem in der Vita erzählt ist, dass Chlodovech einstmals gegen die Alamannen in den Krieg gezogen sei, heisst es weiter: ,Als die Schlachtlinien von beiden Seiten dorthin ${ }^{2}$ ) gelangt waren, hätte gern eine jede den Rheinstrom überschritten, wenn sie nicht den Feind gegenüber gehabt hätte. Als so die feindlichen Heere dastanden, und Franken wie Alamannen vor Kampfbegierde brannten, bemächtigte sich nach Beginn der Schlacht ein so gewaltiger Schrecken Chlodovechs, dass er in furchtbarer Angst das Ende des Wüthens erwog". Hierauf folgt die aus Gregor entlehnte Stelle, welche bereits oben analysirt ist.

Der Sehlachtenmaler hat sich hier verzeichnet. Wenn die Schlachtreihen der beiden Gegner am Rhein stehen, und keine wegen des auf der andern Seite befindlichen Feindes über den Fluss zu setzten wagt, so konnte ebensowenig der Blutdurst der Franken wie der der Alamannen befriedigt werden, und die oben erzählte Schlacht hätte der dazwischenliegende Fluss zur Unmöglichkeit gemacht. Statt durch die Einflechtung des Rheines den logischen Gedankengang zu stören, hätte der Biograph klüger gethan, von selbstäudiger Ausschmiückung des Gregorberichtes ganz Abstand zu nehmen. Besondere Kenntnisse waren aber für diese Erweiterung nicht erforderlich, als dass man wusste, dass die Alamannen am Rheine sassen, und diese Thatsache allein darf man aus der Stelle folgern, die ich daher auch nicht für besonders wichtig ${ }^{3}$ ), wohl aber für unlogisch halte.

i) S. 168 .

2) Der Ort ist aber nicht genannt. $\quad$ 3) So von Schubert S. 159. 
Nach der Unterwerfung der Alamannen begab sich Chlodovech zunächst nach Toul. Er nahm sich hier den h. Vedastes zum Reisegefährten in dem Wunsche, schnell zur Taufe zu gelangen, und setzte nun gemeinsam mit ihm seine Wanderung weiter fort. In Gau von Voncq, in Grandepons bei der Villa Rilly-aux-Oies am Aisne, heilte Vedastes einen Blinden, und fromme Leute bauten dort eine Kirche, bei welcher zur Ehre des Heiligen viele Wunder geschehen. Dann führte dieser den König nach Reims zum Bischof Remigius. Chlodovech empfieng hier nach einigem Aufenthalt die Taufe und kehrte alsbald in seine Heimath zurück. Den Vedastes aber empfahl er dem Bischof Remigius. Jener hielt sich von nun an in Reims auf, wo sich auf sein Gebet ein leeres Weinfass füllte, so dass er einen vornehmen Besuche einen Becher in seiner Celle credenzen konnte.

Mit dieser Darstellung hat der Biograph seinen Gregor verlassen, dessen folgende Schilderung er picht gebrauchen konnte. Denn da dieser die weitere Förderung der Taufangelegenheit nach der Heimkehr Chlodovechs von Chlothilde ausgehen lässt, die deu Remigius ruft, damit er den König vorbereite ${ }^{1}$ ), so war in diesem Zusammenhang für deu h. Vedastes kein Raum. Wenn man aber den König nach der Niederwerfung der Alamannen sofort von dem sehnlichsten Wunsche beseelt seiu liess, möglichst schnell ein Christ zu werden, so konnte gleich seine Rückkehr aus dem Felde für die Geschichte des h. Vedastes nutzbar gemacht werden. Selbstverständlich durfte aber Chlodovech nur solche Oertlichkeiten berühren, zu denen der Heilige Beziehungen hatte: Toul, den ersten Aufenthalt desselben, Rilly mit der ihm geweihten Kirche und Reims, den Sitz des Metropoliten des zukünftigen Bischofs von Arras. Dass Vedastes an diesen Orten geweilt hat, will ich nicht bestreiten; dass sie aber Chlodovech besucht hat, darf man wenigstens aus unserer Quelle nicht folgern, denn ihr Zweck ist gar zu durchsichtig. Der Gesichtskreis des Erzählers war aber ein ungemein beschränkter. Wenn er dem Chlodovech in Toul den Vedastes zum Reisegefährten giebt und dann beide weiterpilgern lässt (,Dum pariter pergerent'), wie etwa zwei terminirende Mönche, so scheint er ganz zu vergessen, dass in Chlodovech ein triumphirender König an der Spitze eines siegreichen Heeres zurückkehrte.

Remigius schätzte den $h$. Vedastes und wünschte ihn zu befördern. Nach reiflicher Ueberlegung machte er ihn zum Bischof von Arras, danit er das Frankenvolk allmälich zum Christenthum bekehre. Bei seinem Einzuge in Arras begegneten dem neuen Bischof Vedastes

1) H. Fx. II., 31. 
ein Blinder und ein Lahmer, die er beide heilte. Als er die Kirche betrat, bot sich ihm ein wenig erfreulicher Anblick. Dieselbe war durch die Nachlässigkeit der heidnischen Bürger gänzlich verwildert, mit Dornenhecken dicht bewachsen und mit Koth besudelt, eine Znfluchtsstätte der wilden Thiere. Ueberdies war die Stadt nach der Zerstörung durch Attila von Menschen ganz verlassen. Einen Bären, der sein Heim dort aufgeschlagen hatte, warf Vedastes vom Walle herab und verbot ihm, den vorbeifliessenden Crinchonfluss je zu überschreiten.

Nach der Vita wäre also Vedastes vom Metropoliten zum Bischof gemacht worden. Es ist aber bekannt, dass in früukischer Zeit der Metropolit nicht das Recht hatte, in den Civitates seiner Provinz einseitig Bischöfe zu setzen. Nicht durch den Entschluss des Bischofs Remigius, sondern durch die Wahl von Clerus und Volk und die Bestätigung des Königs konnte Vedastes Bischof von Arras werden; dem Remigius stand nur die Consecration zu. So war es unter Chlodovechs Nachfolgern gebräuchlich ${ }^{1}$ ), aber auch dieser selbst hat einen entscheidenden Einfluss auf die Besetzung der Bischofsstühle ausgeübt. Wir ersehen dies aus dem Briefe des Remigius an die Bischöfe Heraclius, Leo und Theodosius, die ihm wegen Beyünstigung eines verbrecherischen Priesters Claudius heftige Vorwürfe gemacht hatten. Remigius vertheidigt sich dagegen; nicht durch Geld bestochen, sondern auf das Zeugniss des Königs Chlodovech habe er den Claudius zum Priester gemacht. Auf ihren Finwand, dass nicht canonisch gewesen sei, was der König geboten habe, erinnert er sie an ihre eigene Ernennung: ,Summo fungamini sacerdotio; regionum praesul, custus patriae, gentium triumphator iniunxit'. Darnach scheint Chlodovech die vacanten Bischofssitze ganz selbständig ${ }^{2}$ ) besetzt und auch hinsichtlich der Priesterordinationen bisweilen Wüusche geäussert zu haben; Remigius war aber nicht bloss völlig einverstanden damit, sondern hat auch selbst, soweit es in seiner Macht stand, zur Ausführung der Vorschläge des Königs beigetragen.

Eine Mitwirkung von Clerus und Volk bei der Bischofsbestellung wäre allerdings im vorliegenden Falle kaum möglich gewesen, wenn die Schilderung der Vita von dem desolaten Zustande der Stadt Arras zutreffend ist, dass seit der Hunnenzeit die Stadt ganz unbewohnt von Menschen gewesen sei, und nur ein Bär daselbst gehaust habe. Der ganzen Darstellung der Verhältnisse, in denen Vedastes die Stadt fand, liegt aber eine so kindliche Anschauung zu Grunde, dass es kaum der Mühe lohut, ernstliche Einwände dagegen zu erheben.

1) Vergl. N. Archiv XVI, S. 230, die Erhebung Gaugerichs.

2) Vergl. Iöning, Gesch. des deutschen Kichenrechts II, 175. 
Ich will nur auf die Unwahrscheinlichkeit hinweisen, dass die Bürger von Arras die zerstörte Stadt ein halbes Jahrhundert leer stehen lassen, und auf die Unglaublichkeit, dass dann die Neubesiedlung mit dem Einzuge eines Bischofs beginnt.

Ueber die Zerstörung von Arras durch Attila ist sonst nichts bekannt, und es ist schon sehr zweifelhaft, ob die Hunnen überhaupt so weit nach Norden vorgedrungen sind. Dagegen erwähnt Hieronymus in dem bekannten Briefe an Ageruchia, dass unter andern Städten auch Arras von germanischen Völkern eingenonmen worden sei. Obwohl der alte Kirchenvater schon 420 gestorben ist, also Attilas Verheerungszug nicht erlebt hat, ist doch schon im 11. Jahrh. in St. Vaast die Hieronymus-Stelle auf diesen bezogen worden ${ }^{1}$ ); v. Schubert aber hätte in in diesen Fehler nicht verfallen sollen $\left.{ }^{2}\right)$. Nachdem Chlojo das Land der Atrebaten erobert ${ }^{3}$ ) hatte, hat Arras in der fränkischen Geschichte nie mehr eine Rolle gespielt. Die merovingischen Geschichtsschreiber erwähnen die Stadt ïberhaupt nicht.

Der h. Vedastes war bei Hofe sehr beliebt. Die Bekehrung der heidnischen Franken wollte ihm aber nur langsam gelingen, obschon er es an freundlichem Zuredeu nicht fehlen liess. Nach Chlodovechs 'Tode lud einmal ein gewisser Hocinus König Chlothachar zum Frühstück ein mit einigen Hofleuten und dem h. Vedastes. Als dieser das Haus des Gastgebers betrat, sah er mitten in demselben Bierfässer stehen. Einige von ihnen waren für die Christen bestinımt, andere für die Heideu, und diese waren nach heidnischem Brauche geopfert. Als nun der Bischof sämmtliche Fässer bekreuzigte und weihte, zersprangen die dem Götzendienste dienenden und ergossen ihren Inhalt auf den Boden.

Dies ist Alles, was der Biograph iiber den 40jähr. Episcopat des h. Vedastes zn berichten weiss; wie man ihn aber bei solcher Armseligkeit für trefflich unterrichtet und die Legende für eine der besten ihrer Art halten kann ${ }^{4}$ ), verstehe ich nicht.

Der h. Vedastes starb am 6. Februar. Bei seinem Begräbniss ereignete sich das häufige Wunder, dass sich die Bahre nicht von der Stelle bringen liess, weil man bei der Wahl der letzten Rubestätte den Wünschen des Todten nicht Rechnung getragen hatte. Der Archipresbyter Scubilio erinnerte daran, dass der Heilige verboten habe, Todte innerhalb der Stadtmauern zu begraben, und für seine
1) SS. XIII, 682.
2) a. a. O. S. 158 .
3) Sidon. carm. V., 212.
4) So v. Schubert S. 154. 155. 
Person die Beisetzung in einem hölzernen Oratorium am Crinchon gewünscht habe. Er bat aber den todten Bischof, in Anbetracht der hereinbrechenden Nacht ein Einsehen zu machen. Alsbald liess sich der Heilige erweichen, die Träger spürten keine Schwierigkeit mehr, und die Beerdigung in der Kirche der Stadt an der rechten Seite des Altars ging ohne weitere Hindernisse von Statten. Als später einmal das Sterbehaus des h. Vedastes theilweise in Flammen aufging, b]ieb doch die Celle mit seinem Bette unversehrt. Eine treue Dienerin Habita wollte den Heiligen gesehen haben, wie er selbst das Feuer von seiner Celle abwehrte. Mit dieser dürftigen Schilderung der Wunderthätigkeit des Heiligen endigt die Vita.

Das Schriftchen trägt die unverkennbaren Spuren einer gewissen Eilfertigkeit an sich. Der Biograph hatte in der Einleitung versprochen, der Nachwelt zu überliefern, woher der Heilige stammte, was er erlebt und welches Ende er genommen habe: ,ratum ducimus, ut unde originem duxerit vel sane vitae cursum peregerit quamque finem habuerit, prosequi studiamus verbis'. Den Geburtsort aber hat er direct wenigstens nicht angegeben, denn er erzählt nur, dass bei der Ankunft Chlodovechs in T'oul Vedastes daselbst ein religiöses Leben führte. Daher sind schon seit alten Zeiten verschiedene Vermuthungen über die Heimath des Heiligen aufgestellt worden, und noch heute ist man sich iiber diese Frage nicht einig.

Schon im 8. Jahrh. ist durch eine Interpolation am Schlusse die Lücke des Originals ergänzt worden. In diesem Zusatze wird ausdrücklich gemeldet, dass der Heilige in Toul geboren und in Arras gestorben und begraben sei; sein Grab sei mit Lampen, Gold, Silber und allerhand Edelsteinen geschmückt. Der Interpolator knüpfte an die oben citirten Worte der Vorrede an, die er aber gar nicht verstand; denn weun er seine Erweiterung beginnt: ,Nam sicut superius memoravimus, ut unde originem duxerit, ratum ducimus, Tullinse ortum genere oriundus fuit, so bleibt es ohne Zuhilfenahme des Originals unverständlich, was er eigentlich meint. Die Unklarheit im Ausdruck macht es unmöglich, diesen Text dem Biographen selbst zuzuschreiben und ihn etwa für eine spätere Bearbeitıng der ursprünglichen Vita zu erklären. Die handschriftliche Ueberlieferung der interpolirten Gestalt reicht aber ebenso wie die des ersten Textes bis in das 8. oder den Anfang des 9. Jahrh. hinauf ${ }^{1}$ ).

1) Die älteste His. des ersten Textes ist Paris 12598, saec. VIII, die des zweiten Montpellier H 55, saec. VIII.|IX. Letztere Hs. hat v. Schubert S. $210 \mathrm{ff}$. abgedruckt, obwohl bereits Archiv XI, 254, auf den reineren Text hingewiesen war. 
Dagegen stammte nach einer Tradition des Klosters St. Vaast der Heilige nicht aus Toul, sondern aus dem Périgord, und noch im 11. Jahrh. soll nach dem Zeugniss der Mönche von St. Vuast das Grab der Eltern des Vedastes dort vorhanden gewesen sein ${ }^{1}$ ). Diese Ansicht ist weiter entwickelt in einigen interpolirten Vedastiner $\mathrm{Hss}$. der V. Vedastis, die der Ausgabe Henschens ${ }^{2}$ ) zu Grunde liegen. Der Interpolator hat den Widerspruch seiner Vorlage, einer Hs. des zweiten Textes der Vita, und der Tradition durch Annahme einer Verwechselung gewisser Leuci im Grenzgebiet zwischen dem Périgord und Limousin mit den Leuci von Toul zu erklären gesucht. Zu bedauern bleibt dabei nur, dass seine neuen Leuci sonst nirgends bezeugt sind ${ }^{3}$ ). Seine unbestimmte Angabe hat aber Anlass zu einer literarischen Fehde zwischen den Gelehrten des Limousin und des Périgord gegeben. Denn während man bis vor Kurzen den Grenzort ziemlich allgemein als Courbefy in der Diöcese Limoges deutete, hat sich ein patriotischer Bürger des Périgord neulich vermessen, den h. Vedastes für seinen Landsmann zu erklären. Dafür ist ihm eine derbe Zurechtweisung von dem Canoniker Arbellot von Limoges ertheilt worden. Trotzdem hatte er Recht: in der älteren 'Iradition von St. Vaast ist nur von dem Périgord die Rede. In dieser Gegend besass die Kirche von Cambrai liegende Güter. Am Ende des 6. oder Aufang des 7. Jahrh. unternahm Bischof Gaugerich von Cambrai eine Inspectionsreise in den Périgord wegen der dort gelegenen, curtes' seiner Kirche ${ }^{4}$ ). Wenn die Mönche von St. Vaast die Heimath ihres Patrons gerade in den Périgord versetzten, so leiteten sie dabei vielleicht weniger religiöse als selbstsüchtige Motive, denn, nachdem durch die Verlegung nach Cambrai das Bisthum Arras cessirte, konnte allerdings das Kloster des h. Vedlastes eine nühere Anwartschaft anf jene Güter begrünlen, wenn es nachwies, dass sie Erbe des Heiligen gewesen seien.

Den Namen des Heiligen schreibt die älteste Hs. im Non, und Gen. ,Vedastis', im Acc. ,Vedastem'; doch dringen auch hier bereits die Endungen der zweiten Declination (,Vedastus' oder ,Vedasti, ,Vedasto*) ein, die später die allein herrschenden geworden sind. ,Vidastis' oder, Vedastis' nennt Gregor H. Fr. VII, 3 einen Verbrecher, der seine Schandthaten in der Touraine und im Poitou verübte. Vedastes

1) SS. XIII, p. 683 .

2) AA. SS. Febr. I, 794 .

s) Vergl. Longnon, Atlas historique. Texte ${ }^{\star}$. I, p. 5.

4) Vergl. Anal. Boll. TII, 394, N. Archiv XVI, S. 232. 
ist, wie mir Alfred Holder freundlichst mittheilt, der deutsche Name ,Widogaste' im 2. Prologe der Lex Salica. Weist vielleicht die starke Contraction auf eine westgallische Herkunft des Heiligen hin? Gregor nennt allerdings auch einen Trierer Presbyter ,Arboastis' statt ,Arbogastes' (Gl. conf. 91), aber das Geschichtchen von ihm verdankt er offenbar seinem Freunde Aridius von Limoges, der lïngere Zeit in Trier gelebt hatte. Sonst begegnen bei ihm Personen mit Eigennamen auf ,astis' besonders häufig in der Gegend von Tours: Leubastes ist ein Abt (H. Fr. IV, 11), Leudastes ein Graf von Tours (ib. V, 14) und Vinastes (Mart. II, 23) ein Bresthafter, der in Tours Heilung sucht. Der Name Vedastes scheint also der Ansicht nicht günstig zu sein, dass der Heilige aus Toul stammte.

Ueber seine Quellen schweigt der Biograph des h. Vedastes. Schriftliche Quellen hat er auch ansser Gregor kaum benütyt. Die Vita spiegelt vielmehr die Lokal-Tradition von Arras wieder und fixirt somit, was man sich zur Zeit des Verf. über den Heiligen daselbst erzählte. Nach der Kümmerlichkeit dieser Nachrichten zu urtheilen, ist aber die Anfzeichnung lange nach dem Tode des Heiligen erfolgt.

v. Schubert allerdings nimmt die allergünstigsteı Verhältnisse für die Entstehung der Vita an. Denn war es, wie er meint, ein Cleriker von Arras, der das Leben des Heiligen um 580, also etwa 40 Jahre nach dem jetzt gangbaren 'T'odesjahre desselben, niederschrieb, so hatte der Verf. allerdings die schönste Gelegenheit, sich durch Augenzeugen und schriftliche Quellen trefflich zu instruiren. Dass die Analyse seiner Nachrichten solehe Illusionen nicht aufkommen lässt, haben wir gesehen. Jch habe aber noch einen ganz untrüglichen Beweis dafïr, dass die Schrift nicht in 6, sondern erst im 7. Jahrh. aufgezeichnet wurde.

Die V. Vedastis ist nämlich nicht in der alten Merowingischen Schriftsprache, sondern in jenem geküustelten Latein geschrieben, welches durch Jonas von Susa in Gallieu eingeführt worden ist. Trotz aller grammatischen Mangelhaftigkeit füllt doch sofort eine reinere Wiedergabe der Vocale und die nicht selten grewählte und geradezu phrasenhafte Ansdrucksweise auf. Der Verfasser rerräth Bekauntschaft mit den Classikern, besonders den Dichtern; sein Streben geht aber auf das Absonderliche und so wählt er auch schlechte Vocabeln oder gibt gut lateinischen einen Sinn, den sie nicht haben. Diese höchst charakteristische, aus allerhand Brocken zusammengeflickte Sprache, welche sich sogleich wiedererkemnen lässt, wemn man auf ihre Eigenthünlichkeiten einmal aufmerksam gemacht worden ist, ist die des bedeutendsten Hagiographen des 7. Jahrh., des Jonas, der seine Bildung 
in Bobbio erhalten hatte, wo damals auch klassische Studien noch getrieben wurden. In seiner V. Columbani prunkt er mit Citaten nicht bloss aus Vergil und Juvencus ${ }^{1}$ ), sondern auch aus Livius ${ }^{2}$ ). Unter seinen Zeitgenossen möchte es kaum einen zweiten geben, der einer gleichen Belesenheit sich hätte rühmen können.

Wir finden in der V. Vedastis (V) sämmtliche Lieblingsausdrücke des Jonas, die dieser in den Vitis Columbaui (C), Eustasii (E), Attalae (A), Bertulfi (Be), Burgundofarae (Bu) wiederholentlich gebraucht. Durch die folgende Gegenüberstellung kann sich jeder von der Richtigkeit unserer Behauptung ïberzeugen ${ }^{3}$ ).

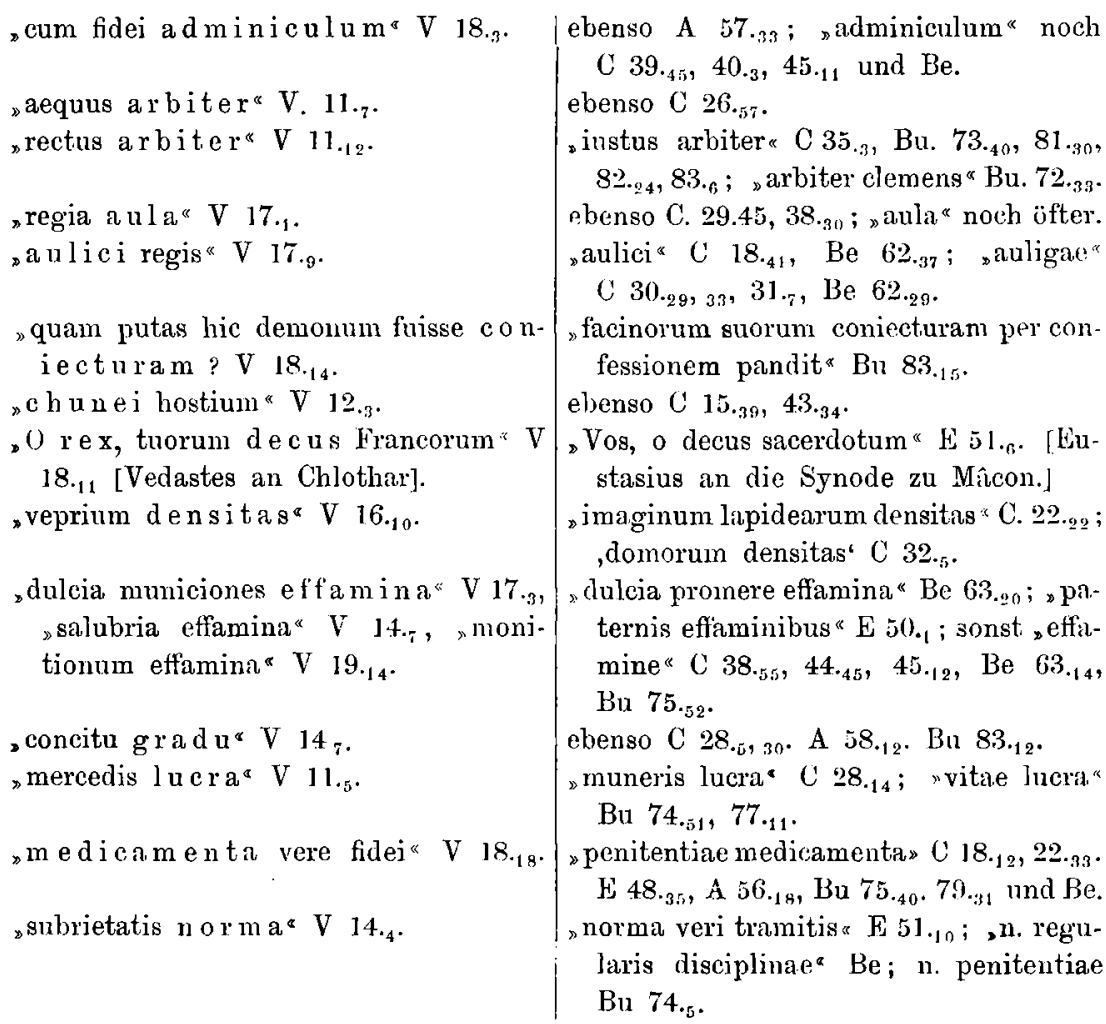

1) Praef. und c. 22. ed. Mabillon.

?) ib. c. 7 .

3) Es werden citirt V. nach v. Schuberts Abdruck der Hs. von Montpellier a. a. O. S. 211--222, die übrigen Leben nach Migne, Patrologia lat. LXXXVII, S. 1011-1084, doch sind bei den Seitenangaben nur die Zehner notirt (inlso V 11 für V 211 und C 11 für C 1011). Die Texte, welche mir vorliegen, sind bereits nach den Hss, berichtigt. Bei v. Schubert fehlen die folgenden Stellen: S. 14.7 , ministro iubet, ut concitu gradu post salubria efamina " und $15_{.4}$ " sed quoadusque inter superis vitam degereta. 
„in propatulo narrare $\mathrm{V} 18.0$.

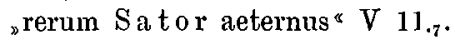
„rerum Sator $V$ 22.1. (Vergl. „rerum Auctor" V 12,14).

„litterarum seriae ${ }^{*} \mathrm{~V} 11_{.9}$. „solamina ad augendam relegionis copiam tribuit ${ }^{*} \mathrm{~V}$ 11.8. [„solamina “ für s subsidium"].

¿quadusque inter superis vitam degeret V. $15 \cdot 4$.

„s upplime ntum perficiendipraebere $\mathrm{V} 11.9$, subplimento auri argentique honerari V 15.14 [„ supplementum " hat die Bedeutung von semolumentum *, wie 2. Cor. $8 \cdot \cdot_{14}$.]

„ignis columna e caelo diffusa super cellole tegumenta capud tenuit " V 19.11 [ tegumenta " tür tectum "]. in propatulo $\mathrm{C} 19_{\cdot 47}, \mathrm{Bu} 71_{.37}, 78 ._{.31}$. ebenso C 13.51, Bu 75.21. ebenso $\mathrm{Bu} \mathrm{71.4}, 73_{.31}, 78_{.42}$.

"Scripturarum serie $\mathrm{E} 51_{12}$. "solamina " C 19.28, 29.24, Bu 80.51 u. s. w.

„si tunc vitam cum superis feras" C. $34_{.23}$; »superi " sonst C $12_{.25}, 19_{.43}, 22_{.52}$. E. $466_{5}, 54.33, \mathrm{Bu} \mathrm{72.54}, 75_{.35}, 78_{.28,46}$. "supplimentum * C 14.15, ${ }_{45}, 17.19,19.34$, $30.47,39_{.45}, 44 ._{35},{ }_{45}$, Be $62_{.28}, 63.3$. Bu $75_{.10}, 78_{.15},{ }_{20}$.

"audiunt fragorem supra cellulam et tegumenta personantia $\mathrm{Ba} 80.9$; „monasterii tegumenta* A 59.7

Am auffallendsten ist und schon von Mabillon wurde bemerkt, dass Jonas mit "superi “ die lebenden Menschen bezeichnet, während gewöhnlich die Götter darunter verstanden werden. In der dem Jonas geläufigen Bedeutung findet sich das Wort $u$. a. bei Valerius Flaceus ${ }^{1}$ ) dessen Lectüre auch die Anrede „o decus " verräth. Die Verbindung , concito gradu" gebraucht Phaedrus III, 2 :

"Et in cubile concito properat gradu"

und die Bezeichnung "rerum sator" für den Schöpfer ist Eigenthum des Silius Italicus IV, 432. Der späteren Dichtersprache gehört "effamina" an, aber „cunei" und, ,in propatulo" stammen aus der guten lateinischen Prosa. Von den Worten, die Jonas in ungewölnnlichem Sinne gebraucht, ist an merkwürdigsten ,coniectura", was an den beiden Stellen nur Haufen, Menge (,acervi facinorum" Cic.) bedeuten kanu.

Der Sprachschatz der V. Vedastis ist der gleiche, wie in den Heiligenleben des Jonas. Auch der Gebrauch gewisser Zeitwörter bestätigt dies. Die Verben "denuntiare" in der Bedeutung von ,indi-

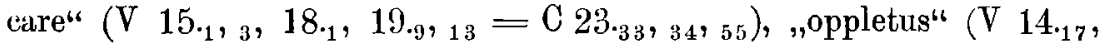
$16_{10}=\mathrm{C} 12_{\cdot_{22}}, \quad 13_{\cdot 31}$ und öfter), "pensare" überlegen (V 11.12

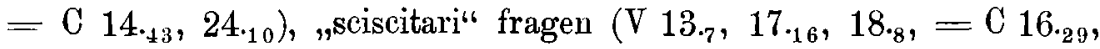
$19_{50}, 29_{40}, 35_{r_{19}},{ }_{28}$, sehr häufig) dürfte sich Jonas bei der Liviuslectüre angeeignet haben, wie auch "ratum ducere" (V 11.15 $=\mathrm{C} 13 ._{21}$, $45_{.9}, \mathrm{E} 51_{.20_{0}}$, Be $65_{.3}, \mathrm{Bu} 80_{._{23}}$ ), dessen richtige Bedeutung er aber

1) Die Belege findet nan bei Forcellini. 
nicht kennt 1). "Ovans" steht einmal bei dem siegreichen (hloduvech (V 12.16), ein anderes Mal aber in übertragener Bedeutung einfach für "laetus", wie es Jonas nach dem Beispicle der Dichter häufig anwendet $\left(\mathrm{V} 16_{._{7}}=\mathrm{C} 23 ._{8}, 35_{._{24}}, 38_{._{23}}, 45_{._{13}}, \mathrm{E} 48 ._{7}, \mathrm{Bu} \mathrm{72.{ } _ { 6 }}\right.$ und öfter). Dichterisch ist auch die Anwendung von „pulsare" in der Bedeutung von "urgere" (V 12.14, $15_{15}=\mathrm{C} \mathrm{22..7 \%}$ ), und die Phrasen ,colla submittere und subdere alicui aliquid“:

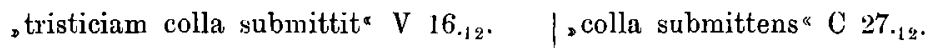

"religionis colla submiserunt " $\mathrm{V} 1 \mathbf{1 9}_{4}$, habenis“ oder „disciplinae colli submittere A $55_{.20}, \mathrm{Bu} 8 \mathbf{2}_{16}$.

,merore corda subdit. $\mathrm{V} 16_{\cdot 11}$.

„se relegioni subdebant" $\mathrm{V} 17_{.3}$. „merori corda subdas ${ }^{a}$ A 57.9, , ,animum merori subderat a $\mathrm{C} \mathbf{2 5} \mathbf{5}_{43}$. , ut sacre subderetur religioni * $\mathrm{C}_{42_{44}}$. sind Nachbildung von ,fortunae subdere colla" bei Silius X, 216. Erwähnenswerth sind noch "compilare" in der ungewöhnlichen Be-

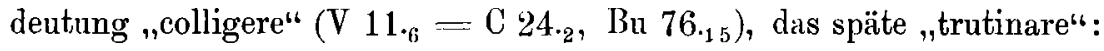
„horrenda anxietate trucinaret ${ }^{\circ} \mathrm{V}$ 12. ${ }_{16}$. , anxio animo trutinare ${ }^{\alpha}$ A 55.20; vergl. "horrendo desiderio" C $15_{.30}$.

und das transitiv gebrauchte "deviare":

${ }_{\text {} n e c}$ valebat Francorum viris a profanis ${ }_{\text {, ut }}$ se a supradictae matris monitis erroribus deviare $\mathrm{V} 17_{.2}$. nullatenus deviaret Bu $78_{.28}$.

Da Jonas sich in seiner ans den verschiedensten Autoren mühsam zusammgestoppelten Sprache nicht frei bewegen konute, hat er häufig dieselben Gedanken mit fast ganz denselben Worten wiederholt. Auch in der V. Vedastis findet man ganze Sätze, die wörtlich oder fast wörtlich in den andern Schriften wiederkehren:

„divino fultus auxilio $\mathrm{V} \mathrm{12.18.}$ „quo quantisper moratus" $\mathrm{V} 13.15$. und ebenso (1 20.4(1).

und ebenso $\mathrm{E} 45_{\cdot 10}$; ibi quantisper moratus C $36 ._{57}$; "quantisper morari " oder scommorari « sehr hïufig,

wobei zu bemerken ist, dass Jonas „quantisper" stets in Sivue vou „aliquantisper" gebraucht,

„et exemplo monstraret et verbis stude- , ut uberius exemplo monstraret, quid

bat edocere ${ }^{*} 14 ._{5}$.

„quid gestae rei causa fuerit $V$ 18.s. „solum desiderium viventibus reliquid“ $\mathrm{V} 19_{16}$. „firit tandem consilii, ut V $15_{.7}$.

aliis inplenda fore docuisset " $C$ 16.54. „rei gestae catsas auch $\mathrm{C}-0_{-33}, 300_{.1 \mathrm{n}}$. "solum desiderium superis dimisit" E 54. 53 . "fuit tandem consilium, ut" $\mathrm{C} 20_{.23}$.

1) Jonas gebraucht den Ausdruck in der Bedeutung „constituere“, „velle, während es den Sinn von „confirmare hat. 
Die Vorrede der V. Vedastis ist zun Theil in denselben Ausdrücken abgefasst, wie die der V. Columbani:

\author{
V. Vedastis \\ V. Columb.
}

Dum sanctorum presolum gloria sanctorum praesulum atque mo. potissimo semper iure ac solerti in- nachorum patrum solertia nobilium dagatione vel imitando exemplo condidit vitam doctorum, scilicet ut po. vel litterarum seriae memorias est steris alma redolerent priscorum exempla. commendando - eritque aequus Egit hoc a saeculis rerum Sator arbiter rerum Sator acternus.

a e t e $\mathrm{r}$ u $\mathrm{s}$, ut suorum famulorum famam commendaret perennem, utquae praeterita gesta linquerent futuris exempla, et de praecedentium meritis vel i mitando exemplo vel memoriae commen. dando ventura sobolis gloriaretur.

Endlich gleicht das Erlebniss des Vedastes in Hause des Hocinus (V. Ved. cap. 7) auch in der Form einem Abentener Columbans bei deu heidnischen Schwaben (V. Col. n. 53). Nach beiden Erzählungen gehen die nach heidnischem Brauche geopferten Bierfässer durch Einwirkung des Heiligen aus den Bänderu, und es läuft die Flüssigkeit aus, durch welche der T'eufel die Seelen der Heiligen verführen wollte. In Folge dieses Wunders lassen sich dann viele taufen. Man vergleiche:

\title{
V. Vedastis
}

V. Columbani

vasa plenacervisae - in medio "repperit vas magnum cervisa pledomus posita ${ }^{1}$-- - gentile ritu sacri- $\mathrm{num}$ in medio positum - - vasque ficata - moxsoluta legamini- rapide cum licore cervisae prorumpit bus cunctum cervisae ligorem - - - (diabolus), qui per prophanum - in pavimentum deiccerunt - - (con- liquorem caperet animas sacrifiiectura daemonum), quae per hunc li- cantium - (Columbanus), qui sic gor e m cervisae corda infidelium aeterne possit $d$ is s olvere vas liga minibus mortis subdere studerent. - - Nam munitum. - - Multique eorum tunc multi ex hoc ad gratiam baptismi per beati viri sunsum vel doctrinan ad confugerunt.

Christi fidem conversi, baptis $\mathrm{mm}$ sunt consecuti.

Doch dürfen wir hier abbrechen. Der Stil der V. Vedastis ist der des Jonas von Susa oder eine Nachahmung desselben. Zunächst wird man der letzteren Eventualität zuueigen, da nicht abzusehen ist, wie der Italieuer Jonas dazu gekommen sein sollte, das Leben eines Bischofs von Arras zu beschreiben. Es lässt sich indessen nachweisen, dass er in der That in jener Gegend sich aufgehalten hat.

Noch vor dem T'ode des Abtes Bertulf hatte Jonas das Kloster Bobbio verlassen und sich nach Gallien begeben. Er schloss sich hier dem $\mathrm{H}$. Amandus an, der in der sumpfigen Niederung des Elno, im

1) , in medio domi positum* auch V 20.5. 
äussersten Norden des Landes, sich angesiedelt hatte. Hier hatte er schon drei Jahre rüstig dem Heiligen bei der Bekehrung der heidnischen Franken geholfen, als er endlich dazu kam, sein den Bobbienser Freunden gegebenes Versprechen einzulösen und das Leben des h. Columban zu beschreiben. In dem an die Aebte von Luxeuil und Bobbio gerichteten Widmungshriefe beschreibt er in ziemlich schwülstiger Sprache seine Missionsreisen zur Ausrottung des Heidenthums: ,Quamquam me et per triennium Oceani per ora vehit et Scarbea ${ }^{1}$ ) lintris abacta ascoque Scaldeos molles secando vias madefacit saepe et lenta palus Elnonis plantas ob venerabilis Amandi pontificis ferendum suffragium'. Die Missionäre wählten also für ihre Excursionen den Wasserweg auf der Scarpe (,Scarbea ${ }^{\circ}$ ) und Schelde, ja sie fuhren sogar an der Seeküste entlang. Nun liegt Arras am Zusammenflusse der Scarpe und des Crinchon. Auf einer seiner Fahrten kann also Jonas mit seinem Kahne bis in diese Stadt gelangt sein.

Es steht mithin nichts im Wege, die V. Vedastis für eine Schrift des Jonas zu erklären. Sie ist dann in ganz ähnlicher Weise entstanden, wie die V. Johaunis Reom. Bei einem gelegentlichen Aufenthalte in Arras hat man den berühmten Hagiographen gebeten, das Leben des Lokalheiligen aufzuzeichnen, und der federfertige Mann wird seine Aufgabe in kürzester Frist gelöst haben, wie er ja anch für die etwas längere $\mathrm{V}$. Johannis nur wenige Tage gebraucht hat.

Die V. Vedastis zeigt in Ausdruck die meiste Verwandtschaft mit der V. Columbani, mit der sie ungefähr gleichzeitig entstanden sein mag. Wenn diese bereits in dem Fredegar von 642 benutat, also spätestens 641 geschrieben ist, so darf man ungefähr denselben Zeitpunkt für die Abfassung der V. Vedastis annehmen.

Diese ist etwa 100 Jahre nach dem Tode des Heiligen von einem Fremdling auf Bestellung verfasst worden, also fast unter denselben ungünstigen Umständen entstanden, wic die V. Johannis Reom. Sie leidet daher auch an ganz denselben Gebrechen wie diese; beide sind flüchtig hingeworfen und dürftig im Inhalt. Den kümmerlichen Stoff hat sich Jonas dadurch etwas erweitert, dass er Gregors Erzählung von Chlodovechs Alamannenkrieg in das Leben verflocht und im Auschluss daran einige Combinationen wagte. Für die Geschichte des h. Vedastes wird man aus Mangel an älteren und besseren Quellen auf seine Schrift stets zurückkommen müssen; für die politische Geschichte aber darf die Vita nicht mehr verwerthet werden, denn originalen Werth hat sie hier nicht.

1) Mabillon hat hier einen ganz verdorbenen 'Text. 
Beeinflusst aber hat sie bisher die Darstellung nicht bloss des Alamannenkrieges, sondern auch der Taufe Chlodovechs. Gregors 1) Bericht über diese ist durchaus sagenhaft. Nach ihm redet Chlotilde dem heidnischen Könige zu, den wahren Glanben anzunehmen und deu Götzendienst aufzugeben, ohne etwas auszurichten. Da geräth in der Schlacht gegen die Alamannen sein Heer in harte Bedrängniss. Er bittet jetzt in einer wohlgesetzten Rede Christus um den Sieg, mit dem Versprechen, sich dann zu dem Glauben der Chlothilde zu bekennen und sich taufen zu lassen. Wie diese nach seiner Heimkehr hört, dass er durch die Anrufung Christi gesiegt habe, lässt sie heimlich den Bischof Renigius von Reims holen, damit er das Bekehrungswerk vollende. Jener predigt dem Könige den wahren Gott und die Aufgabe des Heidenthums. Dieser erklärt sich zwar bereit, weist aber auf den Widerstand hin, den der Schritt bei seinem heidnischen Volke finden würde. Er versammelt dasselbe, um es von seiner Absicht zu unterrichten, aber noch ehe er beginnen kann, erklärt es sich einverstanden mit dem Uebertritte zu dem Glauben des Remigius. Höchst erfreut über diese Botschaft trifft letzterer die Vorbereitung zu der Taufe, die er selbst mit allem Gepränge zuerst an Chlodovech vollzieht. Nach Gregor ist est es also lediglich der katholische Glaube, der durch die Personen der Chlothilde und des Remigius auf den heidnischen König einwirkt. In welche Zeit er die Taufe setzt, kann nicht zweifelhaft sein. Wenn man auch die directe Angabe des 15. Regierungsjahres des Königs (496), welche nur in einer Hss.-Klasse steht, als Interpolation verwirft, so erzählt er doch diese Geschichte vor dem burgundischen Kriege von 500. Den Ort aber, wo sich der weltgeschichtliche Vorgang abgespielt hat, giebt er nicht an, obwohl er zweimal Gelegenheit hatte, eine solche Angabe zu machen. Sowoll] bei der Heimkehr des Königs (,regressus') als bei der Citirung des Remigius (,arcessire clam') nennt er den Bestimmungsort nicht.

In dieser Hinsicht brachte nun die V. Vedastis die gewïnschte Ergänzung. „Dass die Taufe in Reims geschah, gieht eine Quelle gauz bestimmt an ", sagt Junghans *) unter Berufung auf die Vita. Allerdings hätte er auch Fredegar III, 21 für seine Ansicht anführen können, aber er scheute sich wohl, aus dieser späten und sagenhaften Quelle zu schöpfen. Jetzt ist nun erwiesen, dass die V. Vedastis dem Fredegar gleichzeitig ist und keinen besseren Glauben verdient als dieser. Die Ansicht, dass die Taufe Chlodovechs in Reims erfolgt sei,

1) H. Fr. II, 30. 31.

2) Gesch. der fränkischen Könige Childerich und Chlodovech S. 57. 
ist also ein für allemal aufzugeben. Beide Gewährsmänner haben offenbar aus der Rolle, welche Gregor dem Bischof Remigius von Reims bei der Taufhandlung zutheilt, auf diese Stadt geschlossen, aber diesen Schluss verbietet schon Gregors, arcessire'. Für die spätere Geschichte Frankreichs ist der Irrthum bekainntlich von der grössten Bedeutung gewesen, und Reims hat Grund, den Urhebern desselben höchst dankbar zu sein.

Den Taufort nennt eine ältere Quelle als Gregor. Der Bischof Nicetius, der seit 525 den Trierer Stuhl innehatte und folglich die Regierung Chlodovechs noch selbst erlebt hat, ein rïhriger Vorkämpfer für den katholischen Glauben, hat in einem Schreiben ${ }^{1}$ ) die Langobarden-Königin Chlodoswinde, die Enkelin Chlodovechs, ermuntert, die Bekehrung ihres arianischen Gemahls Alboin zu bewirken, und ihr zugleich angegeben, wie das am besten zu machen sei. Am Schlusse stellt er die katholische Kirche der arianischen gegenüber, die Wunderthätigkeit der berühmten katholischen Heiligen, wie des h. Martin an seinem Feste am 11. Nov., dem Unvermögen der Ketzer, aber freilich Teufel körnten in ihren Kirchen nicht ausgetrieben werden, denn der Teufel exorcizire den Teufel nicht. Fr weist dann die Königin auf das Beispiel ihrer Grossmutter Chlothilde hin, wie diese nach Franken gekommen sei und Chlodovech zum katholischen Glauben bekehrt habe; doch der schlaue Mensch habe sich nicht überreden lassen, bevor er die Wahrheit erkannt hätte. Als er aber die eben angeführten Beweise sah, fiel er demüthig in der Kirche des h. Martin nieder und liess sich unverzüglich taufen; was er getauft gegen die Ketzer Alarich und Gundobad ausgerichtet habe, sei bekannt.

Diese ältere Darstellung der Taufe Chlodovechs weicht nicht unwesentlich von Gregors Berichte ab. Nach beiden Quellen geht der erste Anlass von der katholischen Chlothilde aus. Während aber bei Gregor hernach der König sich durch das Gelübde in der Alamannenschlacht zum Uebertritte zur katholischen Kirche verpflichtet und überhaupt nur zwischen Katholicismus und Heidenthum schwankt, will er bei Nicetius sich vor seiner freien Entscheidung zunächst vou der Richtigkeit des katholisehen Glaubens überzeugen, will sich selbst die Beweise verschaffen, ob wahr sei, ,quae super dixi', d. h. ob die katholischen Heiligen wirklich Wunder wirken, und die Arianer dazu nicht vermögend sind. Auch bei Nicetius ist Chlodovech nach der Predigt der Chlothilde uuentschlossen, aber nur, weil er nicht weiss, ob er sich dem Katholicismus oder Arianismus zuwenden soll; durch kein

2) M. G. Epistolae III, 122. 
Gelübde gebunden, eutscheidet er sich für den ersteren und lässt sich in der Martinskirche taufen, also in Tours.

Der Brief des Nicetius, welcher nach Chlothars Tode (561) geschrieben ist, hat schon von jeher die Aufmerksamkeit der fränkischen Geschichtsschreiber auf sich gezogen. Valesius, der das Gewicht dieses Zeugnisses wohl zu würdigen verstand, aber doch Reims nicht aufgeben wollte, hat beide Nachrichten in der Weise combinirt, dass er die Taufe in Reims, aber nicht in der Cathedrale S. Mariae, sondern in der Martinskirche daselbst vor sich gehen lässt ${ }^{1}$ ). Wie aber ,S. Petri limina nur die Peterskirche in Rom bezeichnet, so ist unter ,domni Martini limina' nur die erste und berühmteste Martinskirche in Tours und nicht irgend ein beliebiges Kirchlein zu verstehen, welches den Namen des Heiligen trägt. Weit schneller als Valesius findet sich Junghans mit diesem Zeugnisse ab. Ihm scheint die Nachricht „in der'That nur auf einem Versehen zu beruhen".

Wenn sich Chlodovech, wie Nicetius schreibt, in Tours taufen liess, so kann dies nicht vor dem Jahre 507 geschehen sein. Denn Tours gehörte 496 den Westgothen, und noch am 11. September 506 nahm ein Abgesandter des Bischofs Verus von Tours an dem westgothischen Concile zu Agde Theil. Erst durch den westgothischen Krieg von 507 ist die Stadt fränkisch geworden. Mit dieser Datirung setzt sich Nicetius selbst in Widerspruch durch den Zusatz, dass der König nach der T'aufe die Ketzer Alarich und Gundobad besiegt habe, denn damit führt er uns wieder in die Zeit vor dem burgundischen Kriege von 500. Man hat also bei ihm die Wahl, die Taufe entweder nach T'ours und frübestens in las Jahr 507 zu setzen, oder die Ortsangabe aufuugeben und nun das Ereigniss vor dem J. 500, also, wie es Gregor gethan hat, einzureihen.

Unmittelbar nach der Taufe hat der Bischof Avitus von Vienue ein Glückwunschschreiben an den Frankenkönig gerichtet ${ }^{2}$ ). Dieser unter dem Eindrucke der Ereignisse geschriehene Brief hat natürlich einen grossen Werth für die richtige Erkenutniss des Zusammenhanges, obwohl es der Bischof trefflich verstanden hat, seine Gedanken im Phrasenschwall zu verhüllen.

Nach Avitus war der König von schismatischen Irrlehrern umlagert, die ihm für ihr unwahres christliches Dogma zu gewimnen sucht. Lr trifft in freier Wabl seine Entscheidung zu Gunsten des Katholicismus, und jubelnd ruft Avitus aus: „Euer Glaube ist unser Sieg. Griechenland erfreut sich jetzt nicht mehr allein eines katho-

1) Res Francicae I, 263.

2) Auct. antiqu. VI, 2, p. 75 . 
lischen Regenten ${ }^{1}$ ". Die Taufe hatte zu Weihnachten stattgefunden. Eine zahlreiche Schaar Bischöfe war zusammengeströmt, um in heiligem Wettstreit die königlichen Glieder mit dem lebendigen Wasser zu netzen, und vor den Dienern des Herrn beugte sich das den Völkern furchtbare Haupt. Avitus war leider verhindert, persönlich an der Feierlichkeit Theil zu nehmen. Besorgt erwartete er die kommenden Ereignisse. Da langte noch vor der Taufe ein Bote des Königs im Burgunderlande ${ }^{2}$ ) an und brachte ihm die Meldung, dass sich der Frankenkönig sein Urtheil gebildet habe ${ }^{3}$ ).

Da unter den ,scismatum sectatores' bei Avitus nur die Arianer verstanden werden können, so bestätigt sich der Bericht des Nicetius. Nicht das Heidenthum hielt den König von dem entscheidenden Schritte ab, sondern der Zwiespalt in der christlichen Kirche selbst. Von Arianern und Katholiken umworben, reicht er endlich den letztereu den Apfel zur grössten Freude des katholischen Clerus. Die gegentheilige Schilderuug des Sachverhalts bei Gregor gehört mithin in das Bereich der Fabel. Chlodovech fühlte sich weder zu seinen Götzen hingezogen, noch band ihn ein Gelübde an den Glauben der Chlothilde. Es existirt folglich kein Zusammenhang zwischen der T'aufe und der Alamannenschlacht, auch kann Remigius nicht so in deu Vordergrund getreten sein, wie es nach Gregor scheint, denn er war besten Falls nur einer von den vieleu Bischöfen, die bei jenem Acte mitwirkten.

Ein chronologisches Merkmal hat bisher der Brief des Avitus nicht geliefert. Im Folgenden wird des Königs Mitleid gerühmt, welches ein erst neulich von ihm aus der Gefangenschaft befreites Volk freudig der Welt preise. Man bezieht diese Stelle jetzt auf die unterworfenen Alamannen ${ }^{4}$ ), auf die sie gewiss nicht passt. Ihre grausame Behandlung durch den Frankenkönig rief bekanntlich die Intervention Theoderichs des (ir. hervor ${ }^{5}$ ). Ebensowenig kann der Krieg gegen die Burgunder 500 als die Befreiung eines gefangenen Volkes aufgefasst werden, wolıl aber der gegen die Westgothen 507, denu die katholischen Gallo-Romanen schmachteten unter Unduldsamkeit ihrer arianischen

1) Die $\amalg_{s}$. L. hat , principem legisse nostrum ", und so licst Peiper. His ist a.ber nach der von Sirmond benutaten Hs. „prineipe legis nostrae" zu lesen, denn anch p. 40.15 wird, legis nostrac c im Hinblick auf' den Katholicismus gebraucht.

2) Bei Peiper steht „regionibus vestris“, es ist aber naturlich mit Sirmond „nostris zu lesen.

3) „qua competentem vos profitebamini".

4) Junghans S. 47 ; v. Schubert S. 171.

5) Cass. Variae II, 41 . 
Herrscher und sehnten sich schon längst nach dem fränkischen Regimente: ,Multi iam tune ex Galliis habere Francos dominos summo desiderio cupiebant' schreibt Gregor, H. Fr. II, 35, vor dem Westgothenkriege.

Avitus characterisirt dann die Aufgabe, welche dem katholischen Könige Chlodovech bevorsteht, mit den folgenden Worten: ,ut, quia Deus gentem vestram per nos ex toto suam faciet, ulterioribus quoque gentibus, quas in naturali adhue ignorantia constitutas nulla pravorum dogmatum germina corruperunt, de bono thesauro vestri cordis fidei semina porrigatis‘. Er soll also zunïchst sein eigenes Volk und dann die entfernteren Völker, welche noch nicht durch den Arianismus verdorben sind, der allgemeinen Kirche zuführen. Diese Stelle scheint mir für die Zeitbestimmung von ungeheuerer Wichtigkeit zu sein. Schrieb Avitus diesen Brief vor dem J. 500, so war unstreitig nach der Christanisirung der eigenen Franken die vornehmste und nächstliegende Aufgabe des katholischen Chlodovech die Vertreibung der arianischen Westgothen aus Gallien, die Niederwerfung des benachbarten, durch die ,pravorum dogmatum germina' verdorbenen Volkes und die Erlösung der katholischen Gallo-Romanen von dem drïckenden Joche. Lei Gregor, der die Taufe vor 500 set\%t, ist dies anch der heilige $Z_{w e c k}$ des westgothischen Krieges, denn er legt dem Chlodovech die bekannten Worte in den Mund: Valde molestum fero, quod hi Arriani partem teneant Galliarum'. Aber Avitus schweigt von dieser Aufgabe. War sie bereits gelöst, und ist der Brief nach dem Siege Chlodovechs ïber Alarich, also frühestens 507 geschrieben?

Die Sache würe leicht zu entscheiden, wenn die Briefsammlung des Avitus chronologisch geordnet wäre. 'Das ist sie nun leider nicht, die Briefe sind aber auch nicht ganz bunt durcheinandergeworfen. Schon Binding 1) hat erkannt, dass einzelne aufeinander folgende Briefe zusammengehören und zu derselben Zeit geschrieben sind. So handeln gleich die auf unsern Brief folgende Nummern 47-49 über dasselbe Ereigniss, eine burgundische Gesandtschaft nach Constantinopel, und zu dieser Briefserie gehört anch der Schluss von Nr. 46, den Peiper richtig von dem Gratulationsschreiben abgetrennt hat. Binding setzt diese Briefe in das J. 515; zu der Taufe Chlodovechs stehen sie jedenfalls in keiner Beziehung. Aber vielleicht schliesst sich der Brief an Chlodovech den vorhergehendesı an. Im Briefe 45 wünscht Avitus dem ins Feld rückenden Sigismund, dass er gesund und als Sieger zurückkehre; er soll mit seinen Glauben dic Waffen beseelen.

1) Geschichte des Burgundisch-Romanischen Königreichs S. $290 \mathrm{ff}$. 
Es war also ein Krieg gegen Andersgläubige, und wie Binding richtig. erkannt hat, der gegen die Westgothen. Der vor dem Glückwunschschreiben an Chlodovech stehepde Brief des Avitus ist also 507 geschricben. Nr. 44 ist undatirbar, aber Nr. 43 setzt Binding ebenfalls in das Jahr 507.

Es scheinen sich also eine Anzahl Indicien dafür zu vereinigen, dass das aus Anlass der Taufe an Chlodovech gesandte Schreiben Nr. 46 des Avitus im Anschluss an den westgothischen Krieg von 507 geschrieben ist, und nicht 496. Ist dies richtig, dann muss von den beiden Alternativen, die sich aus dem Briefe des Nicetius ergaben, die erste gewählt und die 'T'aufe des Frankenkönigs wirklich nach Tours und frühestens in das J. 507 gesetzt werden.

Den Winter 507/8 brachte Chlodovech in Bordeaux ${ }^{1}$ ) \%. Auf der Rïckkehr aus dem Feldzuge besuchte er 508 Tours, wo er mit ganz besonderem Gepränge auftrat. Iir erhielt hier vom Kaiser Anastasius das Patent über die Verleihung des Consulats und setzte sich in der Kirche des h. Martin, angethan mit der purpurnen Tunica und der Clılamys, das Diadem anf das Haupt. Alsdann ritt er dureh die Strassen und streute Gold und Silber unter dis Volk; auch die Martinskirche erhielt bei dieser Gelegenheit reiche (Yeschenke ${ }^{2}$ ). Ist in ihr der König getauft worden, so könnte es nur damals geschehen sein.

Aber dann hätte doch wohl unter den zahlreich versammelten Bischöfen der von Tours das nïichste Aurecht gehabt, den Taufact zu vollziehen, und nicht der Bischof Remigius von Reims, wie Gregor will. Die Uebergehung des Bischofs Licinius lïsst sich indessen rechtfertigen. Er hatte erst kurz zuvor den Bischofsstuhl von Tours bestiegen, denn, wie wir sahen, fungirte 506 noch Verus. Remigius dagegen hatte damals schon ein hohes Dienstalter. In einem seiner Briefe $^{3}$ ), den (Gundlach in das J. 512 setzt, und der anch gewiss nicht lange nach Chlodovechs Tode geschrieben ist, erklärt er selbst, bereits 53 Jahre der Reimser Kirche vorzustehen. Unter den zur Taufe Chlodovechs versammelten Bischöfen war er zweifellos einer der ïltesten, wenn nicht der älteste.

Erheblicher erscheint ein anderer Einwurf. Wenn der König in Tours getauft wurde, wäre die Unkenntniss Gregors, des Bischofs vom Tours, schier unerklärlich. Es ist jedoch im höclısten Grade wahrscheinlich, dass Gregor wenigstens die Stelle des Nicetius iiber Chlodovechs T'aufe in Tours gekaunt, und also alsichtlich ron dieser An-

\footnotetext{
1) Greg. II. Fr. IL, 37.

$\left.{ }^{2}\right)$ Greg., H. lir. II, 38 .

s) M. G. Ep. III., 114 .
} 
sicht keine Notiz genommen hat, Die Briefsammlung nämlich, in welcher das Schreiben des Nicetius überliefert ist, hat ihm vorgelegen, und er hat selbst aus dem ersten Briefe derselben eine Stelle in seiner H. Fr. II, 31 citirt. Er hat aber den Widerspruch in der Darstellung des Nicetius bemerkt und gesehen, dass Tours unmöglich war, wenn der getaufte Frankenkönig die Ketzer Alarich und Gundobad besiegt hat. Er wählte die zweite Alternative, weil sie seinem clerikalen Gesichtskreise besser entsprach, und schilderte nun die Taufe unter sorgfältiger Vermeidung einer Ortsangabe. Wenn schon Nicetius die Königiu Chlodeswinde auf die Kriegsthaten des katholischen Chlodovech gegen die arianischen Könige hinwies, in der Absicht den Alboin zu einer Glanbensänderung zu bewegen, so schilder Gregor nur noch viel drastischer die rein religiösen Motive, welche den katholischen Frankenkönig veranlassten, den Krieg gegen die Westgothen zu eröffnen. Ueber den Anlass zu diesem sind wir aber durch einen Zeitgenossen besser unterrichtet. Es waren geringfügige Ursachen, es war ein kleiner Streit um Worte, der den Entscheidungskampf herbeiführte. Noch kurz vor dem Ausbruche machte sich Theoderich der Gr. Hoffnung, die Differenzen auf schiedsrichterlichen Wege beizulegen ').

In der alten V. Remigii, die bereits Gregor ${ }^{2}$ ) benutat hat, wird der Taufe Chlodovechs mit keinem Worte gedacht. Dieses Stillschweigen war so auffallend, dass Junghans ${ }^{3)}$ Giesebrecht das Recht bestritt, diese Vita für die von Gregor benutzte zu lhalten, und sich selbst in seiner Phantasie eine schöne $V$. Remigii construirte, in der natürlich die Tuufe des Fraukenkünigs als das wichtigste Ereigniss im Leben des Heiligen mit besonderer Vorliebe behandelt war. Jetzt erklärt sich die Unkenntniss des Reimser Biographen: erfolgte die I'aufe in Tours, so war der Schauplatz seiner Heimath so weit entrückt, dass sich hier keine Tradition an sie knüpfen konnte.

Ich beanspruche nicht, durch die obige Untersuchung den Knoten gelöst, sonderu nur ihn geschürzt zu haben. Sicher ist aber, dass Reims der Taufort nicht gewesen ist, und dass die Motivirung des Schrittes bei Gregor falsch ist. Seine Auffassung des ungetauften Chlodovech ist ein durch die kirchliche Sage entstelltes Zerrbild. Kirchen hat der Frankenkönig nicht verbrannt, wie ihn Gregor durch Remigius vorhalten lässt: ,Mitis depone colla Sigamber; adora quod incendisti,

1) Man vgl. die Briefe Theoderichs an Alarich. Gundobad und Chlodovech in Cass. Variae III, 1, 2, 4.

2) H. Fr. II, 31: ,Est enim nunc liber vitae eius, qui enm narrat mortuum suscitasse $e^{*}$ mit Beziehung auf V. Remigii c. 8 (Auct. antiqu. IV, 2, p. 66).

) a. a. O. S. 53. 
incende quod adorasti. In seinem Innern kämpft nicht das Heidenthum gegen das Christenthum, sondern der Arianismus gegen den Katholicismus. Dem Christenthum stand der König schon lange vor seiner Taufe freundlich gegenüber, wohl nicht allein aus religiösen Gründen, sondern weil er als ,homo astutissimus' die politische Macht desselben sehr wohl erkannt hatte. Eine feindliche Stellung gegen dasselbe hätten seine ganzen Pläne vereiteln könuen. Viel richtiger als Gregor beurtheilte den König Remigius selbst, als er ihn zu dem Siege über Syagrius 586 beglückwünschte 1). Er räth hier seinem neuen Herrn, wie er die Regierung im eroberten Lande am besten einrichten könne: der König soll sich rechtschaffene Räthe auswählen, auf die Bischöfe hören und ihre Rathschläge einholen. An den wilden Maun bei Gregor hätte Remigius gewiss ein solches Schreiben nicht zu richten gewagt. Avitus ${ }^{2}$ ) sagt es geradezu: „Du hast den Glauben schon vor deiner Vollkommenheit ohne Prediger gesehen und bist uns, den Bischöfen, schou längst (,iam dudum') in frommer Demuth begegnet, wozu du erst jetat verpflichtet bist." Er hat aber den entscheidenden Schritt möglichst lange hinausgeschoben, um weder Katholiken noch Arianer zu kränken. Durch einen beim Ausbruch des westgothischen Krieges erlassenen Tagesbefehl befriedete er alle Kirchen (,ecclesiarum omnium'), also die arianischen, so gut wie die katholischen ${ }^{3}$ ). Wenn er im Stillen mehr zur Lehre des Arius hinneigte, würde er damit nur dem allgemeinen Zuge der Germanen gefolgt sein. Hatte doch in seiner Familie der Arianismns bereits Wurzel gefasst. Seine Schwester Lantechildis war der Ketzerei ergeben und ist erst später, mugleich mit dem Könige, katholiseh geworden.

t) M. G. Ep. III, 113.

2) F.d. Peiper p. 76.

3) M. G. Cap. reg. Fr. I, p. 1. 